\title{
UVB- and plasma radiation-induced cellular responses of human keratinocytes
}

\author{
Ph.D. Thesis
}

\section{Barbara Fazekas}

Szeged

2015 


\title{
UVB- and plasma radiation-induced cellular responses of human keratinocytes
}

\author{
Ph.D. Thesis
}

\section{Barbara Fazekas}

\section{Supervisors:}

\author{
Dr. Éva Ádám
}

Dr. Márta Széll

\author{
Graduate School of Clinical Medicine \\ Department of Dermatology and Allergology \\ University of Szeged, Szeged, Hungary \\ Institute of Plant Biology
}

Biological Research Centre of the Hungarian Academy of Sciences, Szeged, Hungary 


\section{TABLE OF CONTENTS}

LIST OF PUBLICATIONS

LIST OF ABBREVIATONS

1. INTRODUCTION 5

1.1. UVB-induced processes in the skin and in keratinocytes 5

1.2. COP1, the Constitutive Photomorphogenic Protein $1 \quad 5$

1.2.1. COP1 in plants 5

1.2.2. Structural and functional analogy between AtCOP1 and MmCOP1 7

1.2.3. Functions of mammalian COP1 8

1.3. The role of COP1 in the UVB response of plant and human cells 9

1.3.1. COP1 in the UVB response of plants 9

1.3.2. The role of huCOP1 in the UVB response of keratinocytes and $\quad 10$ its mechanism

1.4. Gas discharge plasma, the therapeutical gas mixture 11

1.4.1. Low-temperature gas discharge plasma for medical application 11

1.4.2. Low-temperature gas discharge plasma for wound healing 12

$\begin{array}{ll}\text { 1.4.3. Gas discharge plasma needle } & 12\end{array}$

$\begin{array}{ll}\text { 2. AIMS } & 14\end{array}$

3. MATERIALS AND METHODS

3.1. Cell cultures 15

3.2. Cell viability measurements 15

$\begin{array}{ll}\text { 3.3. UVB irradiation } & 16\end{array}$

3.4. Western blot analysis 16

$\begin{array}{ll}\text { 3.5. Immunocytochemistry } & 17\end{array}$

3.6. Real-time RT-PCR array 18

$\begin{array}{ll}\text { 3.7. Validation of the real-time RT-PCR experiments } & 18\end{array}$ 
3.8. Pathway analysis 19

3.9. Gas discharge plasma treatment 20

3.10. Scratch assay for wound-healing model 21

3.11. Cocultivation of Propionibacterium acnes and keratinocytes 22

4. RESULTS 23

4.1. The role of human Constitutive Photomorphogenic Protein $1 \quad 23$ in the light response of human keratinocytes

4.1.1. Characterization of the siCOP1 keratinocyte cell lines 23

4.1.2. UVB irradiation decreased huCOP1 protein abundance 24 in transformed cell lines

4.1.3. Array analysis of selected genes differentially expressed 26 in early UVB response revealed a transcriptional regulatory role for huCOP1 in keratinocytes

4.1.4. A UVB regulatory network identified by pathway analysis was modified by huCOP1 silencing

4.2. The effect of the gas discharge plasma needle on the human keratinocytes related to the wound healing processes

4.2.1. Effect of gas discharge plasma treatment on cell viability 32

4.2.2. Effect of gas discharge plasma treatment on cell proliferation 35

4.2.3. Effect of gas discharge plasma treatment on wound-healing 37

4.2.4. Cell selectivity of the gas discharge plasma treatment 41

5. DISCUSSION

$\begin{array}{ll}\text { 6. SUMMARY } & 47\end{array}$

7. ACKNOWLEDGEMENTS 49

8. REFERENCES 


\section{LIST OF PUBLICATIONS}

\section{Publications directly related to the subject of the dissertation}

I. Barbara Fazekas, Hilda Polyánka, Attila Bebes, Gábor Tax, Kornélia Szabó, Katalin Farkas, Ágnes Kinyó, Ferenc Nagy, Lajos Kemény, Márta Széll, Éva Ádám: UVB-dependent changes in the expression of fast-responding early genes is modulated by huCOP1 in keratinocytes.

Journal of Photochemistry and Photobiology B-Biology 140: pp. 215-222. (2014) IF: $\mathbf{2 . 8 0 3}$

II. Ihor Korolov, Barbara Fazekas, Márta Széll, Lajos Kemény, Kinga Kutasi: The effect of the plasma needle on the human keratinocytes related to the wound healing process.

Journal of Physics D: Applied Physics (Accepted for publication) (2015)

IF: $\mathbf{2 . 7 2 1}$

\section{Publication not related to the subject of the dissertation}

1. Nikoletta Nagy, Katalin Farkas, Ágnes Kinyó, Barbara Fazekas, Kornélia Szabó, Edit Kollár, Balázs Sztano, Angéla Meszes, Dóra Beke, Lajos Kemény, László Rovó, Márta Széll: A synonimous polymorphism of APCDD1 affects translation efficacy and is associated with androgenic alopecia.

Journal of Life Sciences (Libertyville) 8:(2) pp. 106-114. (2014)

2. Hilda Polyánka, Kornélia Szabó, Vilmos Tubak, Erzsébet Kusz, Lilla Erdei, Gábor Tax, Beáta Szilvia Bolla, Barbara Fazekas, Zsuzsanna Ujfaludi, Róbert Katona, Imre Boros, Zsuzsanna Bata-Csörgő, Lajos Kemény, Márta Széll: A novel immortalized keratinocyte cell line (HPV-KER) is a suitable model for in vitro analysis of UV-B-induced processes of keratinocytes.

(Under review in Archives of Dermatological Research; IF: 1.902 2015) 


\section{LIST OF ABBREVIATIONS}

ACC: Acetyl-CoA carboxylase

AP-1: Jun proto-oncogene (Jun)

AtCOP1: Arabidopsis thaliana COP1

ATM: Ataxia telangiectasia mutated

BCC: Basal cell carcinoma

BSA: Bovine serum albumin

bZIP: Basic domain plus leucin zipper protein

cAMP: Cyclic adenosine 3',5'-monophosphate

CAP: Cold atmospheric plasma

CDD complex: DNA DAMAGE-BINDING PROTEIN 1 (DDB1)- DE-ETIOLATED (DET1) complex

CO: CONSTANS

COP1: Constitutive photomorphogenic protein 1

CREB: cAMP responsive element binding protein

Cry1-2: Cryptochromes

CSN: Constitutive photomorphogenesis 9 signalosome

DAPI: 4',6-diamidino-2-phenylindole

DDB1: DNA DAMAGE BINDING PROTEIN 1

DET: DE-ETIOLATED GENE FAMILY

DET1: DE-ETIOLATED HOMOLOG 1

EDTA: Etilén-diamin-tetraecetsav

ERK: Mitogen-activated protein kinase

ETV: ETS variant

ETV1: ETS variant 1

FUS: FUS RNA binding protein

GI: GIGANTEA (flowering- and circadian clock-associated protein)

HFR1: LONG HYPOCOTYL IN FAR RED

HuCOP1: Human constitutive photomorphogenic protein 1

HY5: ELONGATED HYPOCOTYL 5

HYH: HY5 HOMOLOG

HuCOP1: Human COP1

HPV-KER: HPV-immortalized human keratinocyte

JUN: Jun proto-oncogene (AP-1)

LAF1: LONG AFTER FAR-RED LIGHT 1

Mdm2: Murine double minute 2

MMC: Mitomycin C

MmCOP1: Mammalian COP1

MOI: Multiplicity of infection

MTA1: Metastasis-associated protein 1

NES: Nuclear export signals

NFkB: Nuclear factor of kappa beta

NLS: Nuclear localization signals

NuRD: nucleosome remodelling and histone deacetylation

PBS: Phosphate buffered saline

PI: Propidium iodide

RBX1: RING-BOX PROTEIN 1

ROS: Reactive oxygen species

RNS: Reactive nitrogen species

RWD2: Ring finger and WD repeat domain 2 (COP1)

SCC: Squamous cell carcinoma

SDS-PAGE: Sodium dodecylsulfate-polyacrylamide gel electrophoresis

siCOP1: Stably silenced COP1

SLM: Standard liters per minute

SPA: SUPRESSOR OF PHYA-105

Ub: Ubiquitin

UVR8: UV Resistance Locus 8 (UVB photoreceptor)

WD40: Trp-Asp repeats domain 


\section{INTRODUCTION}

\subsection{UVB-induced processes in the skin and in keratinocytes}

UVB light, with a wavelength range between 290 and $320 \mathrm{~nm}$, is one of the most important physical carcinogens in the environment, and the skin is the first and major barrier to protect the body from its harmful effects. The mechanisms by which the skin protects against UV damage have been investigated in detail. At the molecular level, UVB causes DNA damage, transcriptional changes and apoptosis. Although epidermal keratinocytes, the main site of environmental UVB damage, provide a useful model system to study UVB-induced cellular responses, information on the molecular pathways mediating these processes is currently limited. UVB irradiation changes the expression of several genes in keratinocytes, including the p53 nuclear phosphoprotein (1-3). This tumour suppressor functions as a transcription factor and has a central role in keratinocyte stress responses, including UV-induced responses (1-4). DNA arrays have been used to examine the UV-induced change in expression of 6800 genes in epidermal keratinocytes. Differential expression of 198 genes was detected in three waves occurring at 0.5-2 h, 4$8 \mathrm{~h}$, and 16-24 h after UV irradiation (1).

\subsection{COP1, the Constitutive Photomorphogenic Protein 1}

\subsubsection{COP1 in plants}

The ultimate energy source for virtually all life on earth is sunlight. Only plants and some bacteria are able to absorb sunlight directly and plants have developed sophisticated mechanisms to sense light conditions and adjust their developmental programs accordingly (5). Many components of the light signalling cascades have been revealed over the years, mostly by genetic approaches. Among them, COP1 (constitutive photomorphogenic protein 1) was one of the first cloned and is one of the most extensively studied. The COP1 protein was first identified as a central negative regulator of light-regulated development in Arabidopsis thaliana (6, 7). Arabidopsis thaliana COP1 (AtCOP1) contains three conserved structural domains: a RING finger at the amino terminus mediating ligase activity, a coiled-coil domain in the middle mediating dimerization and seven WD40 repeat domains at the carboxyl-terminal end of the protein 
implicated in the binding of target proteins $(5,8,9)$. AtCOP1 functions as an E3 ubiquitin ligase targeting several transcription factors for proteosomal degradation in plants (5). In the dark, COP1 is confined to the nucleus, where it directs ubiquitylation and proteasomal degradation of ELONGATED HYPOCOTYL5 (HY5), HY5-HOMOLOG (HYH), LONG AFTER FAR-RED LIGHT 1 (LAF1) and LONG HYPOCOTYL IN FAR RED (HFR1) transcription factors that turn on light-activated genes (10). In the light, however, COP1 resides in the cytoplasm, allowing the light-responsive transcription factors to activate their downstream targets (Fig. 1) (5). Among its substrates is the HY5 protein, a basic domain/leucine zipper (bZIP) transcription factor, which is one of the key regulators of photomorphogenesis under all light conditions, including UVB. COP1 have long been known to affect flowering time in response to photoperiod $(11,12)$. COP1 is responsible for the ubiquitination of the transcriptional regulator CONSTANS $(\mathrm{CO})$ which promotes flowering under long days (13). It has been shown that the ability of COP1 by regulating the abundance of a circadian clock associated protein, GIGANTEA (GI), COP1 may play also a role in the modulation of the circadian clock in plants $(7,14)$.

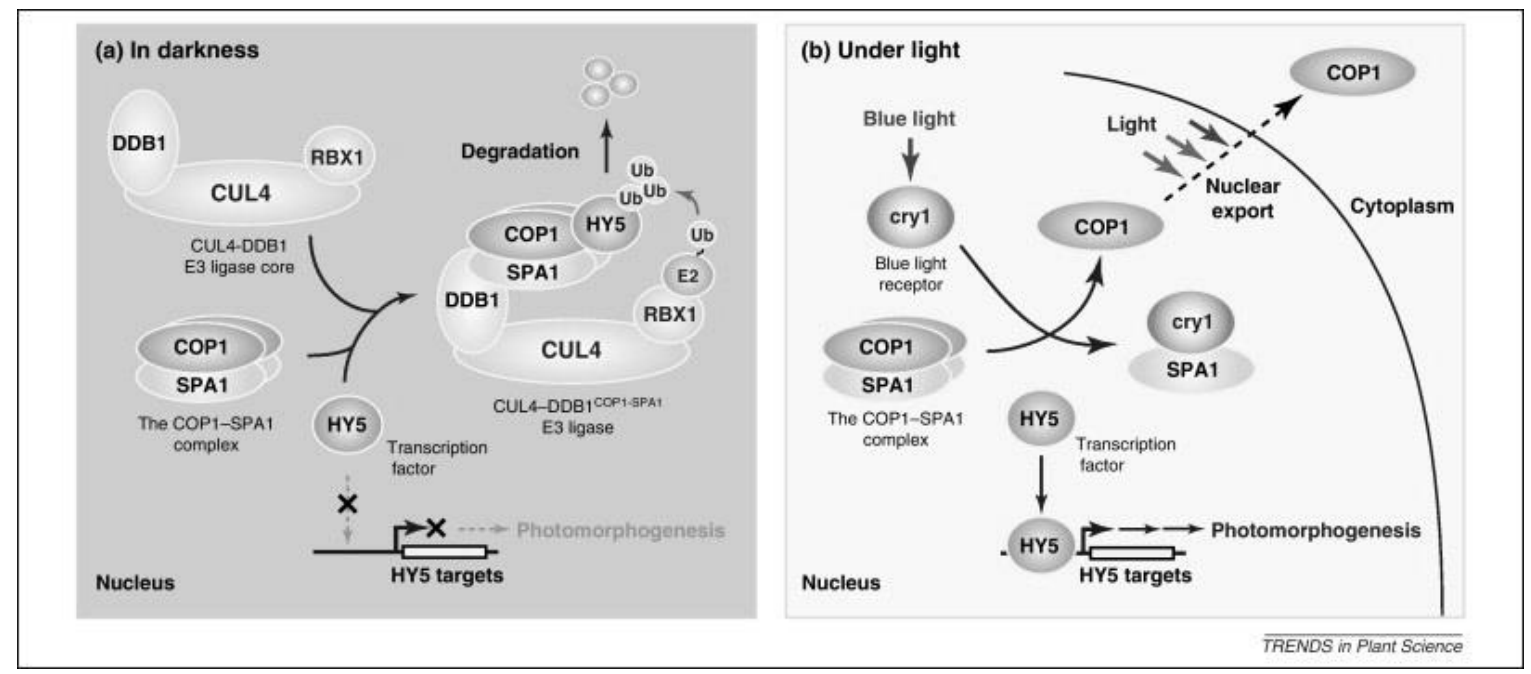

Figure 1. Mode of action of the CUL4-DDB1-COP1-SPA1 E3 ligase. (a) In darkness, COP1 is responsible for the proteasome-mediated degradation of transcription factors, such as HY5, that promote photomorphogenesis. COP1 forms a tetrameric complex with members of the SPA family (two COP1 s and two SPAs) and interacts with the substrate HY5. The WDXR motifs on either COP1 or SPA further mediate the interaction with the CUL4-DDB1 core, and the multimeric CUL4-DDB1-COP1-SPA1 E3 ligase is assembled. Activated E2s are recruited to the E3, resulting in the poly-ubiquitination of HY5 and its degradation. Photomorphogenesis is repressed. (b) Under light, COP1 is inhibited by the activated photoreceptors. In blue light, cry1 interacts with SPA1 and sequesters it from COP1, thereby probably disrupting the COP1-SPA1 complex that is important for E3 function. Visible light further promotes the nuclear export of COP1 for long-term suppression of COP1. As a result of reduced COP1 activity, HY5 accumulates, binds to its targets and promotes photomorphogenesis. CUL4, CULLIN4; DDB1, DAMAGED DNA BINDING PROTEIN 1; RBX1, RING-BOX 1; SPA1, SUPPRESSOR OF PHYA-105 1; Cry 1, Cryptochrome; Ub, ubiquitin (7). 


\subsubsection{Structural and functional analogy between AtCOP1 and mammalian COP1}

Sequence analysis of COP1 orthologs from the Arabidopsis, human and mouse genome indicated that the COP1 domain structure is highly conserved in higher plants and vertebrates (Fig. 2) (6, 15). The mouse (MmCOP1) and human COP1 (huCOP1) are located on chromosome 1 and the high degree of sequence conservation with AtCOP1 suggested functional conservation (16-18).

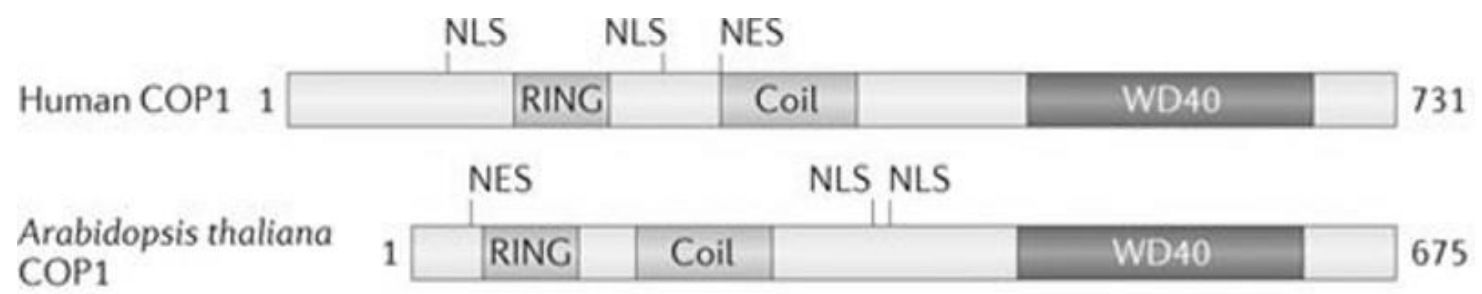

\section{Nature Reviews | Cancer}

Figure 2. Schematic representation of COP1 structural domains and the human COP1 locus. Although the human COP1 protein exhibits an amino-terminal extension, both mammalian and Arabidopsis thaliana COP1 share three common structural domains: an N-terminal RING finger domain, a coiled-coil domain and seven WD40 repeats at the carboxyl terminus. Nuclear localization signals (NLS) and nuclear export signals (NES) allow COP1 to shuttle between the nucleus and cytosol $(16,18)$.

In Arabidopsis, three protein complexes have been described: the COP1 complex, the COP9 signalosome and the CDD complex. Together they form a part of the regulatory network controlling the activity of the ubiquitin-proteasome system. COP1 appears to be directly involved in ubiquitinating protein targets for degradation, while the CDD complex and CSN appear to have a broader regulatory role in overseeing the ubiquitination and degradation process.

COP1 is the part of the SUPPESSOR OF PHYA SPA complex. The function of CULLIN 4 (CUL4)-DNA damage binding protein 1 (DDB1)-COP1-SPA complex is to suppress the photomorphogenic program.

The COP/DET/FUS genes encode proteins that form a large multisubunit complex, the COP9 signalosome (CSN). CSN components with the eight-subunits are conserved in both plants and animals. The third component of the CSN (CSN3) seem to act upstream of COP1 in mammalian cells stimulated by UV.

COP1 physically interacts with components of the COP10-DDB1-DET1 complex (CDD complex), which enhances E2 ubiquitin-conjugating activity in vitro, and which has so far only been found in plants (Fig. 3 a) (19). Both COP1 and the CDD complex can 
interact with the CSN in vivo (20). Although one of the CDD components, COP10, has not been identified in mammals, mammalian homologs of DET1 and DDB1 have been described (21). In humans, DDB1 has been shown to form additional cullin-4A containing E3 ubiquitin-protein ligase complexes that are regulated by the COP9 signalosome (Fig. 3 b) $(22,23)$. There is evidence that, similar to AtCOP1, human COP1 promotes the ubiquitylation of at least some of its substrates by promoting their recruitment to the DDB1-CUL4A E3 ligase complexes (21).
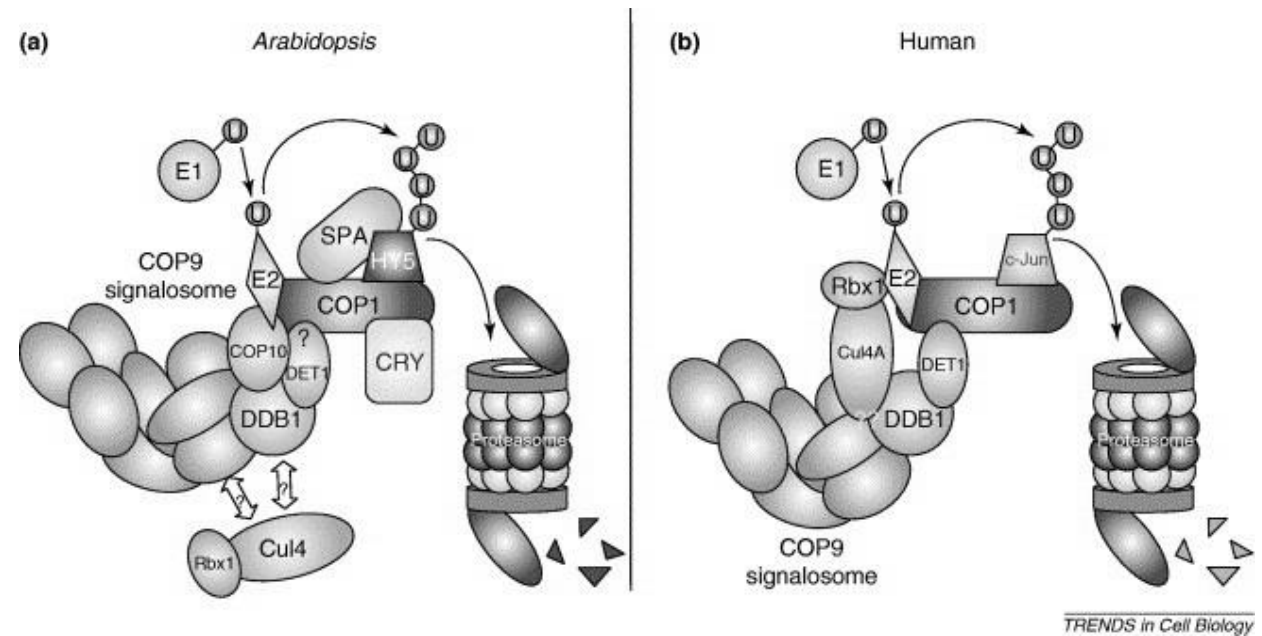

Figure 3. COP/DET/FUS proteins function collaboratively in mediating protein ubiquitination. The majority of the COP/DET/FUS proteins are conserved in both plants (a) and mammals (b). COP1 is able to target the bZIP transcription factors HY5 (in Arabidopsis) and c-Jun (in human) for ubiquitination and proteasome-mediated degradation (5).

\subsubsection{Functions of mammalian COP1}

The role of mammalian COP1 (also known as RFWD2) has been revealed from experiments carried out mostly on mouse model. MmCOP1 is a member of the COPDET-FUS (CONSTITUTIVE PHOTOMORPHOGENIC/DE-ETIOLATED/FUSCA) protein family (15). COP1 is an E3 ubiquitin ligase that is ubiquitously expressed, although not at high levels. It mainly resides in the nucleus and a small amount may also be present in the cytosol (16). COP1 is primarily involved in the ubiquitylation of various protein substrates and itself to trigger their proteasomal degradation $(16,17)$. COP1 contributes to UVB-induced signalling in plants and also in human keratinocytes (24). Biochemical studies have identified putative targets of mammalian COP1 with relevant roles in tumourigenesis, including the oncoproteins JUN and ETV family members, as well as the p53 tumour suppressor. Recent genetic studies have identified mutations of COP1 in various human cancers. Several studies provided evidences that COP1 itself can 
be either a tumour suppressor or an oncoprotein, depending on the cellular context (17, $21,25)$.

\subsection{The role of COP1 in the UVB response of plant and human cells}

The epidermis, our first line of defence from UV light, bears the majority of photo damage, which results in skin thinning, wrinkling, keratosis, and malignancy. The clinical and histological manifestations of UV damage have been well known for some time, but the molecular mechanisms that cause them have only recently become a focus of concerted studies (26). UVB represents one of the most important environmental hazards affecting human skin (3).

\subsubsection{COP1 in the UVB response of plants}

In contrast the negative regulation observed for visible-light responses, AtCOP1 is a critical positive regulator of responses to low levels of UVB. Genome-wide expression changes in response to UVB are blocked to a large extent in the Arabidopsis cop1-4 mutant, and, in addition, AtCOP1 is required for HY5 gene activation (27). According to the latest data, UVB triggers the physical and functional disassociation of the AtCOP1SPA core complex from CUL4-DDB1 and the formation of a new complex containing the UVB photoreceptor, UV Resistance Locus 8 (UVR8). This UVB-induced machinery is associated with the positive role of AtCOP1 in facilitating HY5 stability and activity (Fig. 4) (28).

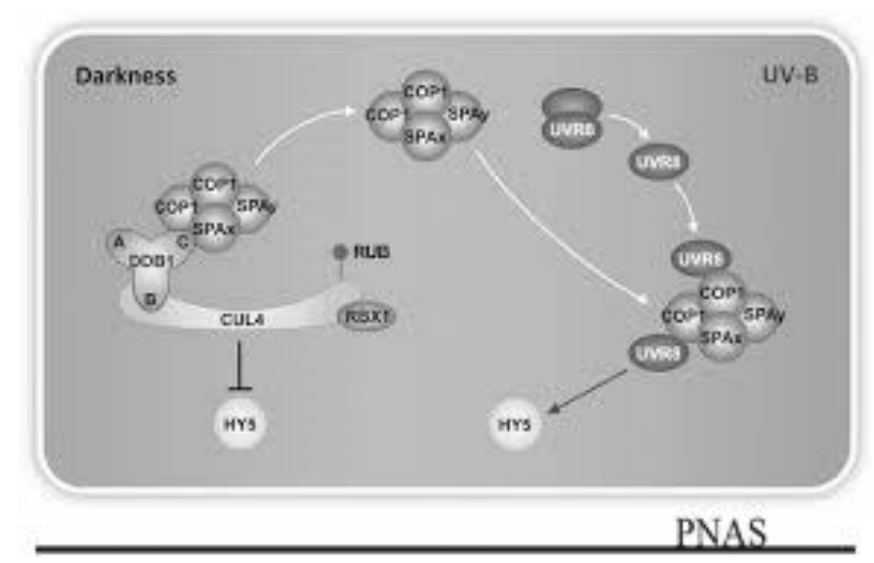

Figure 4. Model for the function of COP1 complex toward HY5 in darkness and under photomorphogenic UVB. White arrows indicate the organization of protein complexes. Black bars indicate negative regulation. The black arrow indicates positive regulation (28). 


\subsubsection{The role of huCOP1 in the UVB response of keratinocytes and its mechanism}

The UVB-dependent molecular network in which p53 plays a pivotal role has not been completely revealed yet. TP53 is a transcription factor that functions as a central component of most cellular stress responses. Our research group has previously demonstrated that one of the p53-interacting partners, the E3 ubiquitin ligase, huCOP1 is expressed in keratinocytes in an UVB-regulated manner and is a negative regulator of p53 as a post-translational modifier $(24,25)$. The regulation of $\mathrm{p} 53$ by huCOP1 in keratinocytes is of particular importance, as this role suggests involvement in both cellular UV responses and carcinogenesis. MmCOP1 has also been shown to repress cJUN mediated AP-1 transcription by linking these substrates to the CUL4A-DDB1RBX1-DET1 E3 ligase complex through direct interaction with DET1 (Fig. 5) (17, 21, 29, 30). COP1 also promotes its own ubiquitylation and degradation, and this process is accelerated by DNA damage (31). Lee et al. discovered that the constitutive photomorphogenesis 9 signalosome (CSN) plays a role in the control of DNA damage and carcinogenesis caused by UV light $(32,33)$. The COP9 signalosome (CSN) is thought to lie upstream of COP1, and several of its components, such as CSN6, interact and regulate COP1 stability and activity (34).

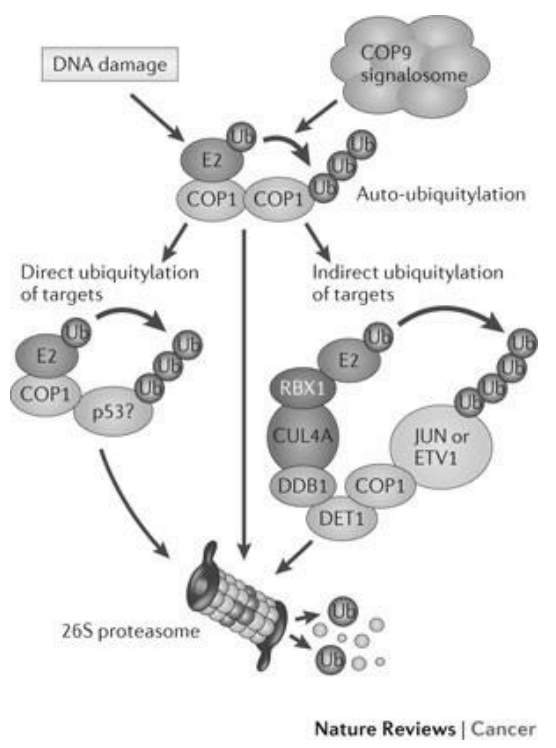

Figure 5. COP1 promotes ubiquitylation and proteasome-mediated degradation after DNA damage. COP1 possesses intrinsic E3 ligase activity and can directly promote the transfer of ubiquitin from E2 proteins to some of its substrates such as mammalian p53. COP1 also promotes the degradation of JUN and ETS variant 1 (ETV1) by linking these substrates to the CUL4A-DDB1-RBX1-DET1 E3 ligase complex through direct interaction with DET1 $(18,21,30)$. 


\subsection{Gas discharge plasma, the therapeutic gas mixture}

The atmospheric pressure gas discharge plasmas are promising candidates for new therapeutic tools. Plasma medicine is a new emerging area of interdisciplinary research in plasma physics, combining biology, chemistry and physics (35). The gas discharge plasma is a mixture of ions, electrons, radicals (reactive oxygen species (ROS) and reactive nitrogen species (RNS)), excited species that contribute to the UV radiation, as well as is characterized by an electrical field (36). Research in plasma medicine has mainly focused on applications in dermatology and aesthetic surgery with the aim to support tissue regeneration to improve healing of infected and/or chronic wounds as well as to treat infective and inflamed skin diseases (37).

\subsubsection{Low-temperature gas discharge plasma for medical application}

Low-temperature gas discharge plasmas can have a huge potential in medical application through stimulation of living cells and tissues (38-40). It can also be used for therapeutic purposes, the treatment of chronic wounds by gas discharge plasmas may have selective antimicrobial or antiseptic effect without damaging the surrounding tissue, while stimulating the tissue regeneration (37). It has been shown that cold atmospheric plasma (CAP) entails no risk on humans in terms of temperature increase, UV radiation or by free radical formation by the gas discharge plasma, while can considerably decrease the bacterial load of the skin (41).

Several studies have been conducted aiming to model the wound healing process, e.g. the penetration of gas discharge plasma or plasma generated species into the wound mimicking model surfaces, such as an agarose gel (42), as well as the transport of species and their interaction with the living cells $(43,44)$. Although the mechanisms of gas discharge plasma interaction with living tissues and cells are very complex, few attempts have been made to clarify the physical and biological mechanisms. These studies investigated the response of the biological system to the different charged species (45), neutral species (such as ROS and RNS) and UV radiation (46-48).

In vivo animal experiments have shown that gas discharge plasma treatment affects the genes that are involved in wound healing, tissue injury and repair (49), and promotes tissue healing (50). It has been found that gas discharge plasma treatment may promote the late phase of inflammation, accelerate re-epithelization and increase wound 
contraction (51). Clinical tests suggest that wound healing may be accelerated by gas discharge plasma treatment, particularly for chronic venous ulcers (52).

\subsubsection{Low-temperature gas discharge plasma for wound healing}

Investigations conducted at cellular level, such as using scratched cell cultures to mimic wounds, can give an insight into the elementary processes taking place during the gas discharge plasma treatment. Cell culture studies using human dermal fibroblasts showed improved cell migration by gas discharge plasma jet treatment, while cell proliferation was not altered (49). In the wound healing process the major contributors are the keratinocytes: they migrate to fill in the gap created by the wound.

Following the evolution after atmospheric plasma jet treatment of a scratch assay of HaCaT human keratinocytes cocultivated with Staphylococcus epidermidis it has been shown that the scratch can close, which indicates the increased cell death of $S$. epidermidis compared to HaCaT keratinocytes (53). The biological changes induced in human keratinocytes by direct and indirect treatment with different gas discharge plasma sources have been evaluated and discussed in details $(53,54)$. In vivo and in vitro (scratch) assay studies indicated that keratinocyte proliferation, migration and apoptotic mechanisms were not affected by the treatment with the cold atmospheric plasma generated with the MicroPlaSter plasma torch system (55). It has been concluded, that a two-minute treatment with this gas discharge plasma induces gene expression of key regulators important for inflammation and wound healing without causing proliferation, migration or cell death in keratinocytes (55).

\subsubsection{Gas discharge plasma needle}

The plasma needle is a plasma source with a non-thermal atmospheric glow discharge ignited at the tip of a needle. From its initial application (56) the plasma needle went through a series of transformations, which made it more and more suitable for biomedical applications (57-60). Several studies have been conducted, which aimed to investigate the effect of the plasma needle on biological samples, such as, reattachment and apoptosis of $3 \mathrm{~T} 3$ mouse fibroblast after plasma treatment (61), the proliferation and differentiation of mesenchymal stem cells $(60)$, as well as its bactericidal effect $(59,62)$. Since plasma needle insures the sample to be in direct contact with the active discharge 
plasma, in contrast with the atmospheric plasma jets where only afterglow species reach the sample, makes possible the study of the effect of the active plasma and electric field on the wound healing process. 


\section{AIMS}

UVB light is one of the most important physical carcinogens in the environment, and the skin is the first and major barrier to protect the body from its harmful effects. HuCOP1 is involved in the orchestrating of several cellular processes, and contributes to cellular stress response after DNA damage caused by UVB. Although it is evident from the available data that huCOP1 is a posttranslational regulator of late UV responses in a wide range of organisms, it was not known how huCOP1 acts on early transcriptional responses in human keratinocytes.

Low-temperature gas discharge plasmas can have a huge potential in medical applications by stimulating the living cells and tissues. In the process of wound healing the major contributors are the keratinocytes, which migrate to fill in the gap created by the wound. The active discharge plasma generated by the plasma needle gives the possibility to study the effect of plasma on the wound healing process.

Therefore, we aimed

- to establish and characterize a keratinocyte cell line in which the expression of huCOP1 is silenced (

- to investigate the effect of UVB on huCOP1 protein abundance in the siCOP1 cell line

- to characterize the role of huCOP1 in early UVB-induced signalling processes that lead to transcriptional changes in keratinocytes

- to characterize the effect of the gas discharge plasma needle on the proliferation and migration of human keratinocytes

- to verify the influence of a non-thermal atmospheric pressure plasma on the wound healing process in human keratinocytes 


\section{MATERIALS AND METHODS}

\subsection{Cell cultures}

HPV-KER cells were maintained in keratinocyte serum-free medium (Gibco ${ }^{\circledR}$ Keratinocyte SFM Kit; Life Technologies, Copenhagen, Denmark) supplemented with $1 \%$ antibiotic/antimycotic solution (PAA, Pasching, Austria) and 1\% L-glutamine (PAA, Pasching, Austria) at $37{ }^{\circ} \mathrm{C}$ in a humidified atmosphere containing $5 \% \mathrm{CO}_{2}$. The medium was changed every two days. Stable transformation of HPV-KER II/15 was performed at approximately $70 \%$ confluency in supplement-free medium with either the empty vector (pSuperior puro vector) or a vector harbouring huCOP1 silencing sequences (24). Plasmid DNA for transfection was purified with the QIAGEN Plasmid Maxi Kit (QIAGEN, Hilden, Germany). Transfection was carried out with the X-tremeGENE 9 DNA Transfection Reagent (Roche Applied Science, Mannheim, Germany) and the Human Keratinocyte Nucleofector Kit (Lonza Cologne AG, Cologne, Germany) according to the manufacturer's instruction.

\subsection{Cell viability measurements}

Keratinocytes were plated into the special golden-coated plates of the xCELLigence system (96-well plates) with a density of 10,000 cell/well in a keratinocyte serum-free medium (Gibco® Keratinocyte SFM Kit; Life Technologies, Copenhagen, Denmark), which contains EGF (epidermal growth factor) and BPE (bovine pituitary extract) as supplements. For the plasma treatment $5 \times 10^{3}$ cells per well were seeded into the 96 -well plates $48 \mathrm{~h}$ before performing the irradiation. Growth of the cells was followed for 6 days. Cell viability of the established keratinocyte cell lines was measured with the xCELLigence RTCA System (63) following the manufacturer's instructions (Roche Applied Science, Mannheim, Germany). This system makes use of impedance detection for continuous monitoring of cell viability.

Staining by propidium iodide (PI) is an applicable technic to distinguish dead cells from living ones. Forty-eight hours after plasma treatment, keratinocytes were stained with PI (BD Pharmingen, Heidelberg, Germany). After washing with calcium- and magnesium-free phosphate-buffered saline (PBS), the cells were incubated with PI (final 
concentration: $1 \mathrm{ug} / \mathrm{ml}$ ) for $30 \mathrm{~min}$ in the darkness. The cells were observed afterwards using an Olympus Fluoview FV1000 confocal laser scanning microscope (Olympus Life Science Europa GmbH, Hamburg, Germany). The microscope configuration was the following: the objective was UPlanSApo 10× (dry, numerical aperture: 0.4 ), the excitation source was a $543 \mathrm{~nm}$ HeNe laser, the laser transmissivity was 50\%; and the PI (propidium iodide) filter settings of the Olympus Fluoview software were used for detection.

\subsection{UVB irradiation}

For irradiation, the medium covering the keratinocytes was replaced with $500 \mu \mathrm{l}$ phosphate-buffered saline (PBS). In preliminary experiments, 10, 20, $40 \mathrm{~mJ} / \mathrm{cm}^{2} \mathrm{UVB}$ doses were used to determine the most appropriate dose for further studies. The $40 \mathrm{~mJ} / \mathrm{cm}^{2}$ dose resulted in a decrease in cell viability, whereas the $20 \mathrm{~mJ} / \mathrm{cm}^{2}$ found to be the highest nonlethal UVB dose. It was also demonstrated that the $20 \mathrm{~mJ} / \mathrm{cm}^{2}$ dose effected the expression of well-known UVB-inducible genes (G0S2, JUNB, JUND). Cells were irradiated with a $20 \mathrm{~mJ} / \mathrm{cm}^{2}$ dose of $312 \mathrm{~nm}$ UVB in subsequent experiments from an FS20 lamp (Westinghouse, Pittsburgh, PA). This instrument emits radiation of wavelength ranging between 250 and $400 \mathrm{~nm}$, peaking at $310 \mathrm{~nm}$. After UVB treatment, PBS was replaced with $2 \mathrm{ml}$ fresh medium. Control cells were subjected to the identical procedure without UVB treatment.

\subsection{Western blot analysis}

Cells were washed twice with PBS and protein was extracted by suspending 1.0 million cells in a $100 \mu \mathrm{l}$ solution containing $20 \mathrm{mM}$ HEPES (4-(2-hydroxyethyl)-1piperazineethanesulfonic acid), $150 \mathrm{mM} \mathrm{KCl}, 1 \mathrm{mM} \mathrm{MgCl}_{2}, 1 \mathrm{mM}$ DTT (dithiothreitol), 0.5\% Triton-X 100, 10\% Glycerol, 0.1\% NP-40 (nonyl phenoxypolyethoxylethanol) and 0.5\% SDS, $1 \%$ Protease Inhibitor Cocktail, 1\% PMSF (phenylmethylsulfonyl fluoride). Protein lysates were incubated for $30 \mathrm{~min}$ on ice, then the cell debris was removed by centrifugation at $10.000 \mathrm{~g}$ for $10 \mathrm{~min}$ at $4{ }^{\circ} \mathrm{C}$. For the Western blot analysis, equal amounts of total protein extracts were run on SDS-PAGE and then transferred onto a nitrocellulose (Bio-Rad Laboratories) or PVDF membrane (Merck Millipore Corporation, Billerica, MA, USA). Membranes were blocked by incubation in Tris-buffered saline 
(150 mM NaCl, $25 \mathrm{mM}$ Tris, pH 7.5) containing 0.05\% Tween 20 (Sigma-Aldrich) and $3 \%$ nonfat dry milk (Fluka Chemie AG, Neu-Buchs, Switzerland) for 2 hours at room temperature and subsequently incubated overnight at $4{ }^{\circ} \mathrm{C}$ with primary antibody (Table 1). After incubating with secondary antibody (Table 2), the blots were washed, than developed using 5-bromo-4-chloro-3-indolyl phosphate/nitro blue tetrazolium as a substrate (Sigma-Aldrich, St Louis, MO) or with the Immobilon Western Chemiluminescent HRP substrate (Merck Millipore Corporation, Billerica, MA, USA). Luminescent signals were detected using a liquid-nitrogen-cooled charge-coupled-device camera (Micromax; Roper Scientific Canada). The subsequent semiquantitative analysis was carried out using the Metamorph software (Universal Imaging Corp., Sunnyvale, California, United States).

\begin{tabular}{|l|c|c|c|c|}
\hline Primery antibodies \\
\hline Specificity of the antibody & Dilution & Produced in & Producer & Development \\
\hline COP1 & 400 & rabbit & Bethyl Laboratories & Chemiluminescens \\
\hline$\alpha$-Actin & 500 & rabbit & Sigma-Aldrich & Chemiluminescens \\
\hline
\end{tabular}

Table 1. Properties of the primer antibodies used for western blot

\begin{tabular}{|l|c|c|c|}
\hline \multicolumn{4}{|l|}{ Secondary antibodies } \\
\hline Specificity of the antibody & Dilution & Produced in & Producer \\
\hline anti-rabbit IgG-HRP & 20000 & goat & Dako \\
\hline
\end{tabular}

Table 2. Properties of the secondary antibodies used for western blot

\subsection{Immunocytochemistry}

Keratinocytes were grown on culture slides (BD Falcon, Bedford, MA) and were immunostained 48 hours after seeding (in other case 24 hours after UVB irradiation). The cells were fixed with $2 \%$ paraformaldehyde for 5 minutes, and incubated in 2\% PFAPBS-Triton-X 100 for 10 minutes. Blocking was carried out in a staining solution containing Tris-buffered saline (TBS) containing 0.05\% Triton-X (Sigma, St. Louis, MO, USA) and 0.5\% BSA (Sigma, St. Louis, MO, USA) supplemented with $1 \%$ goat serum. Samples were incubated with primary antibody overnight at $4{ }^{\circ} \mathrm{C}$ (Table 3). After rinsing with TBS, sections were incubated with Alexa Fluor 488- or 647-labeled secondary antibody (Life Technologies, Carlsbad, CA) at a dilution of 1:400 for 3 hours in the dark at room temperature. DNA was stained with 4,6-diamidino-2-phenylindole (DAPI) (Sigma Aldrich, St. Louis, MO, USA) at a dilution of 1:100 to detect nuclei. A Zeiss 
AxioImager fluorescent light microscope (Carl Zeiss MicroImaging, Thornwood, NY, USA) fitted with a PixeLINK CCD camera (PixeLINK, Ottawa, ON, Canada) was used for detection. The subsequent semiquantitative analysis was performed with Metamorph software (Universal Imaging Corp., Sunnyvale, California, United States).

\begin{tabular}{|l|c|c|c|c|}
\hline Primery antibody & \multicolumn{4}{|l|}{} \\
\hline Specificity of the antibody & Dilution & Produced in & Producer & Development \\
\hline COP1 & 400 & rabbit & Bethyl Laboratories & Fluorescent \\
\hline Secondary antibody & \multicolumn{4}{|l}{} \\
\hline Specificity of the antibody & Dilution & Produced in & Producer & Development \\
\hline Alexa Fluor-488 & 400 & goat & Life Technologies & Fluorescent \\
\hline
\end{tabular}

Table 3 Properties of the antibodies used for immunocitochemistry

\subsection{Real-time RT-PCR array}

Total RNA was isolated from the cells using the Direct-zol ${ }^{\mathrm{TM}}$ RNA MiniPrep (Zymo Research Corporation, Irvine, CA, USA) following the manufacturer's instructions. cDNA was synthesized from $5 \mu \mathrm{g}$ total RNA with the Maxima First Strand cDNA Synthesis Kit for RT-PCR (Thermo Scientific, Waban, MA, USA). Gene expression profiling was carried out with the custom-made StellARray ${ }^{\mathrm{TM}}$ Gene Expression System (Bar Harbor BioTechnology, Trenton, ME) carrying 30 UVBregulated genes. RT-PCR array was carried out using the Dynamo Flash SYBR Green RT-PCR Kit (Thermo Scientific, Waban, MA, USA). The RT-PCR arrays were performed with the ABI Prism 7300 PCR machine (Life Technologies, Copenhagen, Denmark). The expression of each gene was normalized to the 18S ribosomal RNA gene. Results are averages of three parallel experiments. The relative mRNA expression levels were calculated by the ${ }^{\Delta \Delta} \mathrm{C}_{\mathrm{t}}$ method (64).

\subsection{Validation of the real-time RT-PCR experiments}

The validation real-time RT-PCR experiments were carried out with the Universal Probe Library system (F. Hoffmann-La Roche AG, Basel, Switzerland). Sequences of the primers used for PCR amplification of the FOS, GOS2, JUNB, JUND ZFP36, SIK1, ERK, CREB1, IL1B, IL6 and NFkB1 genes are listed in Table 4. The expression of each gene was normalized to the $18 \mathrm{~S}$ ribosomal RNA gene. Results are averages of three parallel 
experiments. The relative mRNA expression levels were calculated by the ${ }_{\Delta \Delta} \mathrm{C}_{\mathrm{t}}$ method (64).

\begin{tabular}{|c|c|c|}
\hline Gene name & Primers (5'-3') & $\begin{array}{l}\text { Probe } \\
\text { number }\end{array}$ \\
\hline JUND & $\begin{array}{l}\text { FWD: CAGCGAGGAGCAGGAGTT } \\
\text { REV: GAGCTGGTTCTGCTTGTGTAAAT }\end{array}$ & 81 \\
\hline GOS2 & $\begin{array}{l}\text { FWD: GGAGGAGAACGCTGAGGTC } \\
\text { REV: TTTCCATCTCGGCTCTGG }\end{array}$ & 15 \\
\hline JUNB & $\begin{array}{l}\text { FWD: ATACACAGCTACGGGATACGG } \\
\text { REV: GCTCGGTTTCAGGAGTTTGT }\end{array}$ & 45 \\
\hline FOS & $\begin{array}{l}\text { FWD: CCCAAGTGTGCAAGCTCAG } \\
\text { REV: CCCCAAGAACCTCGGAAG }\end{array}$ & 67 \\
\hline ZFP36 & $\begin{array}{l}\text { FWD: ACTACCACTCACCCGCAGAC } \\
\text { REV: CCAGGTCCGTGCAGAAGT }\end{array}$ & 58 \\
\hline SIK1 & $\begin{array}{l}\text { FWD: CATCCCCTTCTTCATGTCTCA } \\
\text { REV: GATCTGGGCGATGGTGAT }\end{array}$ & 77 \\
\hline ERK & $\begin{array}{l}\text { FWD: CAAAGAACTAATTTTTGGAAGAGACTGC } \\
\text { REV: TCCTCTGAGCCCTTGTCCT } \\
\end{array}$ & 20 \\
\hline CREB & $\begin{array}{l}\text { FWD: GGAGCTTGTACCACCGGTAA } \\
\text { REV: GCATCTCCACTCTGCTGGTT }\end{array}$ & 50 \\
\hline$I L 1 B$ & $\begin{array}{l}\text { FWD: AAAGCTTGGTGATGTCTGGTC } \\
\text { REV: AAAGGACATGGAGAACACCACT }\end{array}$ & 10 \\
\hline IL6 & $\begin{array}{l}\text { FWD: CAGGAGCCCAGCTATGAACT } \\
\text { REV: GAAGGCAGCAGGCAACAC }\end{array}$ & 45 \\
\hline$N F K B$ & $\begin{array}{l}\text { FWD: ACCCTGACCTTGCCTATTTG } \\
\text { REV: AGCTCTTTTTCCCGATCTCC }\end{array}$ & 39 \\
\hline
\end{tabular}

Table 4. Primer sequences used for the validation real-time RT-PCR detection.

\subsection{Pathway analysis}

Pathway analysis was performed using the Ingenuity Pathway Analysis software (IPA, Ingenuity Systems, Stanford, USA). This software analyses mRNA expression data in the context of known biological responses and regulatory networks as well as other higher-order response pathways. Ingenuity functional analysis is capable of identifying biological functions and/or diseases that are most significant to the detected gene expression changes. Genes from the data set that met the twofold $(\mathrm{P}<0.01)$ change cut-off and were associated with biological functions in the Ingenuity Pathways Knowledge Base were considered for analysis. For all analyses, Fisher's exact test was used to calculate a P-value determining the probability that each biological function assigned to that data set was due to chance alone. All edges are supported by at least one published reference or from canonical information stored in the Ingenuity Pathways Knowledge Base. IPA uses 
a z-score algorithm to make predictions. The z-score algorithm is designed to reduce the chance that random data will generate significant predictions.

\subsection{Gas discharge plasma treatment}

In order to investigate the effect of the gas discharge plasma on the cells the gas discharge generated at the tip of the needle, the so-called plasma needle was used. The needle consisted of a $0.3 \mathrm{~mm}$ diameter central electrode made of wolfram. The needle was covered by a slightly larger ceramic tube - except for a $2 \mathrm{~mm}$ segment at the tip - and placed in a glass tube of $4 \mathrm{~mm}$ inner and $6 \mathrm{~mm}$ outer diameter. The tip of the needle was placed in line with the edge of the glass tube. The needle body was made of Teflon. Helium was flowing between the ceramic and the glass tube, the flow rates used were in the $1-1.45 \mathrm{slm}$ (standard liters per minute) range. In order to make sure that the needle was kept always at the safe distance from the sample during treatments, the plasma needle has been mounted onto a holder (Fig. 6-7). This distance has been set to $1.5 \mathrm{~mm}$, which assured a stable glow discharge operation without considerably increasing the temperature of PBS during the treatment time. The discharge was operated in the 15-30W input power range and the dissipated plasma power was estimated to be less than $0.5 \mathrm{~W}$. Optical emission spectra in the $250-800 \mathrm{~nm}$ spectral range showed the dominance of the He lines, accompanied by the $\mathrm{O}$ atomic line, the $\mathrm{OH}$ and low intensity $\mathrm{N}_{2}$ and $\mathrm{N}_{2}{ }^{+}$bands (65).

Two types of cell treatment experiments were conducted: (i) wound-healing model and (ii) proliferation experiments, which required the use of two different types of cell plates. All the experiments have been performed in a sterile biosafety cabinet. In the first case, for the wound-healing assay treatment we used a 24-well plate (Corning, SigmaAldrich, USA), which had wells of $16 \mathrm{~mm}$ diameter and $20 \mathrm{~mm}$ height. Here the cells attached to the bottom of the well were covered with a PBS layer of $1.5 \mathrm{~mm}$ thickness, and the needle was approached to $1.5 \mathrm{~mm}$ distance to the PBS surface. The flow rate of helium was $1 \mathrm{slm}$. During treatments the visible plasma glow covered a $5 \mathrm{~mm}$ diameter circular area of the sample. In order to limit the treatment environment to predominantly helium, the well was covered with a glass lid (Fig. 6). 


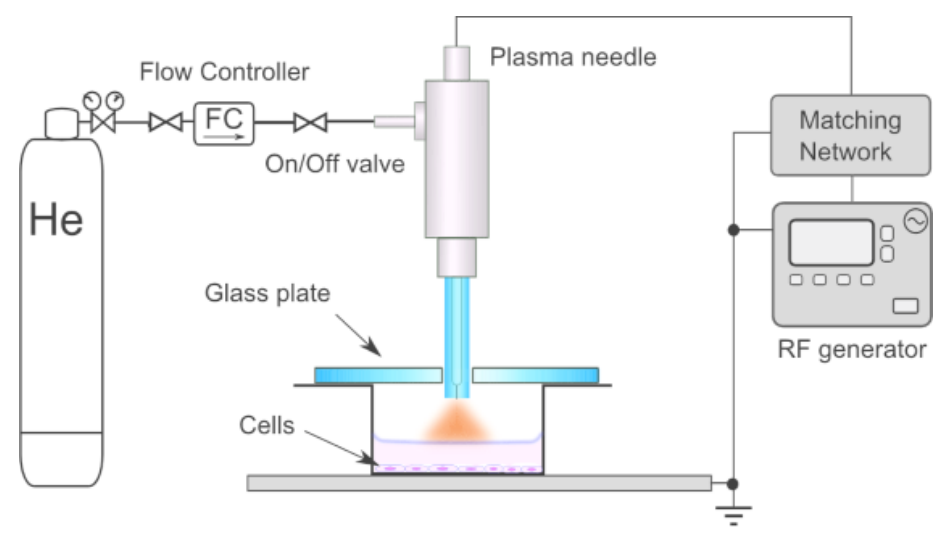

Figure 6. Schematic representation of the experimental set-up used in scratched cell assay experiments.

In the case of the proliferation assay, the cells were treated in 96-well plates, protected by $100 \mu \mathrm{L}$ PBS, using input powers in the range of $18-30 \mathrm{~W}$ and treatment times in the 5-20 s range. The 96-well plates were placed back into the xCELLigence biosensor after all the wells have been treated and the PBS have been changed back to cell medium (Fig. 7).

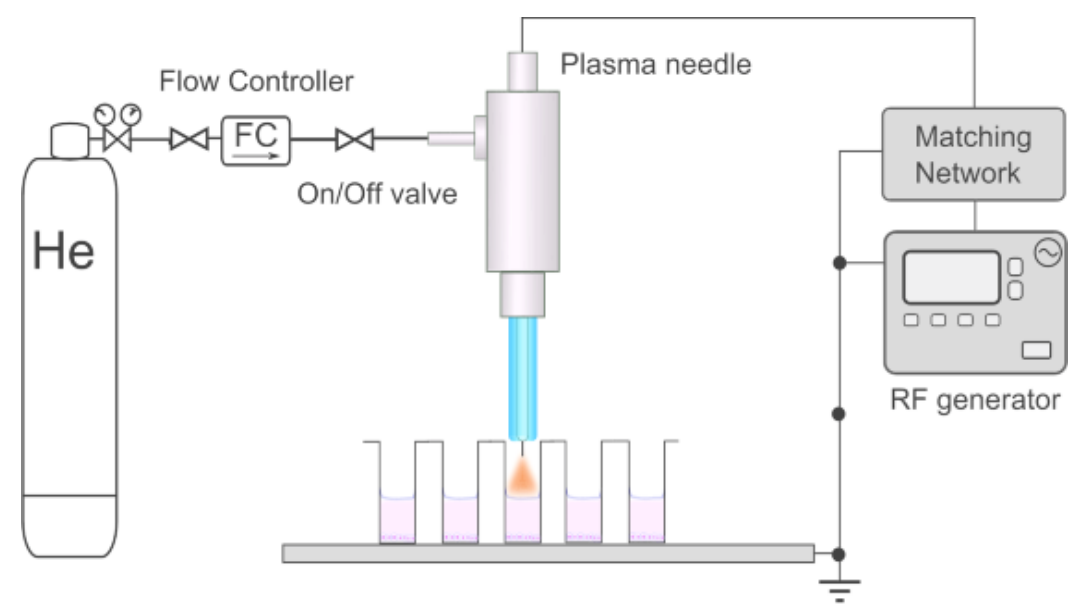

Figure 7. Schematic representation of the experimental set-up used in proliferation experiments with cells treated in 96-well plates.

\subsection{Scratch assay for wound-healing model}

In the case of the wound-healing model experiments $1 \times 10^{5}$ cells per well were seeded into 24-well plates. Before treatment a scratch wounding was performed with a cell scraper of $4 \mathrm{~mm}$ width, according to a well-established in vitro wound-healing assay (Fig. 8) (66). For plasma treatment, the medium covering the keratinocytes were replaced with PBS. The treatment conditions were set as follows: (i) cells were covered with $300 \mu \mathrm{L}$ PBS; (ii) the input power was changed in the $18-30 \mathrm{~W}$ range and (iii) the treatment 
time was varied in the 5-30 s range. The evolution of the scratch in time was observed and recorded using a Nikon Eclipse TS100 inverted routine microscope (Nikon Incorporation, Melville, USA) fitted with a Nikon Coolpix 4500 camera (Nikon Incorporation, Melville, USA). The width of the scratch was measured using the Gimp2 software (Web Networks Inc., Tampa, FL, USA). The scratch width reduction was calculated by subtraction of scratch width at $\mathrm{t}=\mathrm{n}$ hours from scratch width at $\mathrm{t}=0 \mathrm{~h}$.

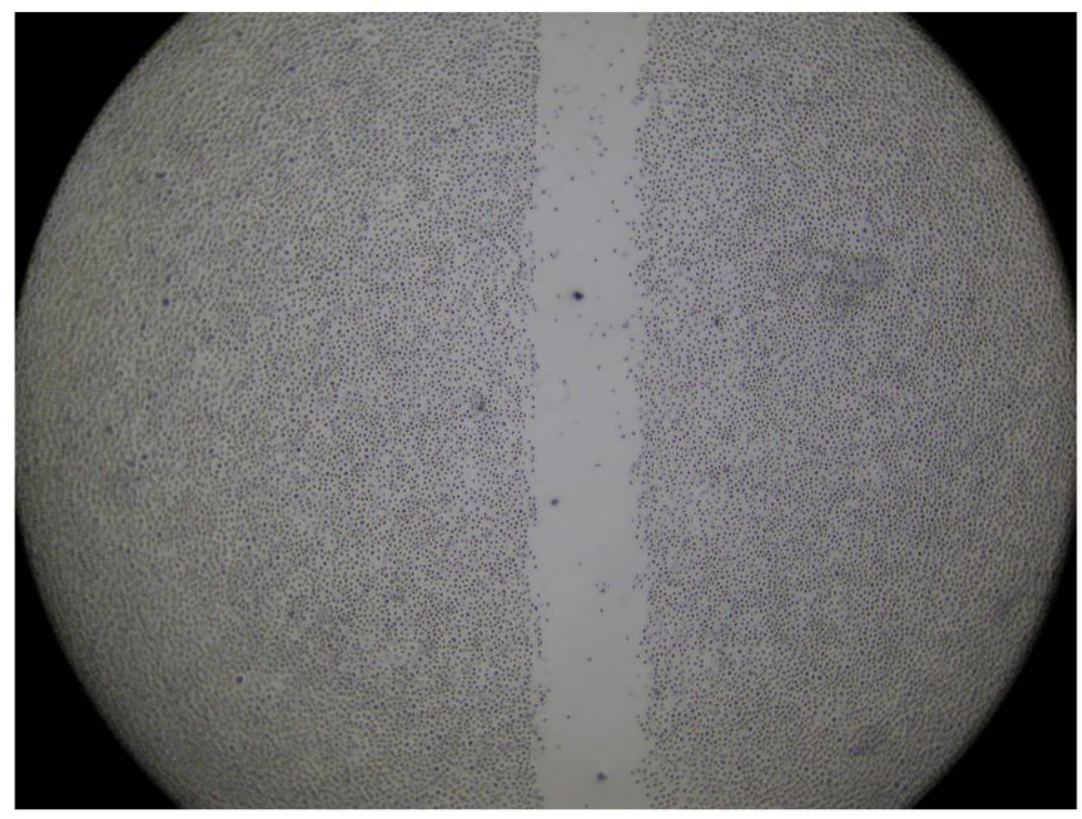

Figure 8. Image of the scratched cell culture. For a better contrast the assay was painted with Trypan Blue. Four-fold magnification.

\subsection{Cocultivation of Propionibacterium acnes and keratinocytes}

$P$. acnes (ATCC 11828) was cultivated in KER-SFM medium with supplements during $24 \mathrm{~h}$. In order to determine the concentration of P.acnes in suspension its optical density at $600 \mathrm{~nm}$ was measured by spectrophotometry. The bacterial suspension was diluted with PBS to $1 \times 10^{9} \mathrm{cfu} / \mathrm{ml}$ cell density. This suspension was transferred into the medium covering the keratinocytes, achieving the multiplicity of infection (MOI - the ratio of bacteria per cell) 50 microorganisms. The scratch on the cell culture was performed before the transfer of suspension, the size of it and the general cell performance were observed during $24 \mathrm{~h}$. One day after plasma treatment, keratinocytes were stained with Trypan Blue solution $0.4 \%$ (Sigma Aldrich, St. Louis, MO, USA) to distinguish the dead cells from living ones. 


\section{RESULTS}

4.1. The role of human Constitutive Photomorphogenic Protein 1 in the UVB light response of human keratinocytes

\subsubsection{Establishment and characterization of siCOP1 keratinocyte cell lines}

To determine the role of huCOP1 in the early UVB response and its influence in the p53 or NFkB pathways, we created keratinocyte cell lines in which the expression level of huCOP1 was stably decreased (67). For this purpose, we used the HPV-immortalized keratinocyte cell line in which the UVB response of p53 is intact (68). Four cell lines harbouring the empty vector and three cell lines carrying the huCOP1 silencing sequences were established.

To select the most appropriate cell lines for further investigation, the degree of huCOP1 silencing and the proliferation of the cell lines were compared. Based on the results of these preliminary experiments, two cell lines - control and siCOP1 - were selected. Semiquantitative analysis of chemiluminescent western blot experiments demonstrated that the expression of huCOP1 in the siCOP1 cell line was decreased by $70 \%$ compared to the control line (Fig. 9 a-b). The silencing of huCOP1 did not affect cell proliferation (Fig. 10).
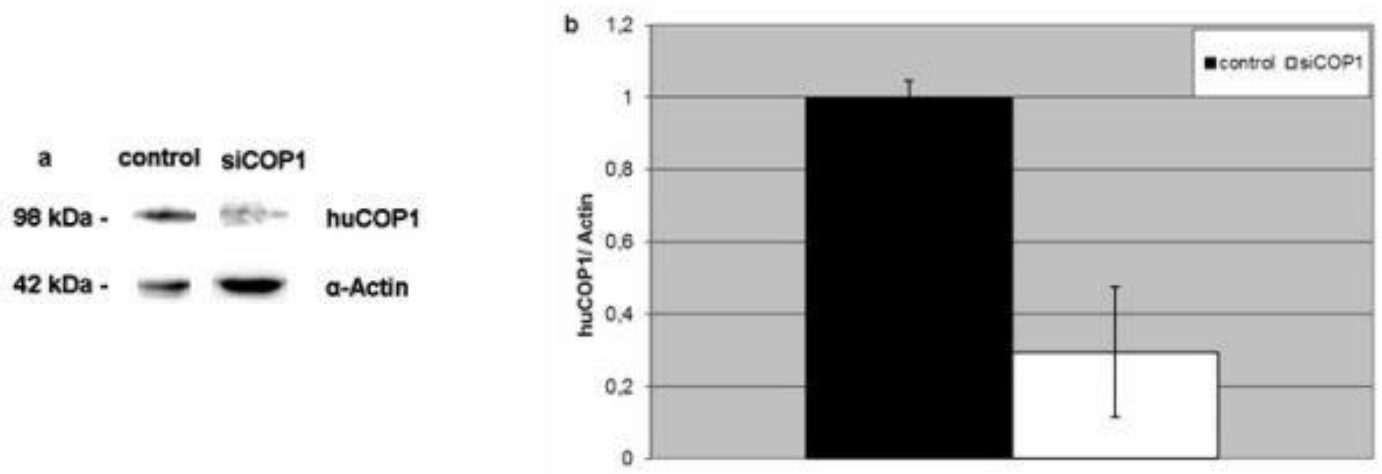

Figure 9. HuCOP1 protein expression in keratinocytes. (a) HuCOP1 protein levels from control and siCOP1 cell lines were detected by chemiluminescent western blot analysis. (b) The huCOP1 expression was subjected to semiquantitative analysis. The expression of huCOP1 was normalized to the expression of $\alpha$-actin. The average of three independent experiments is shown. 


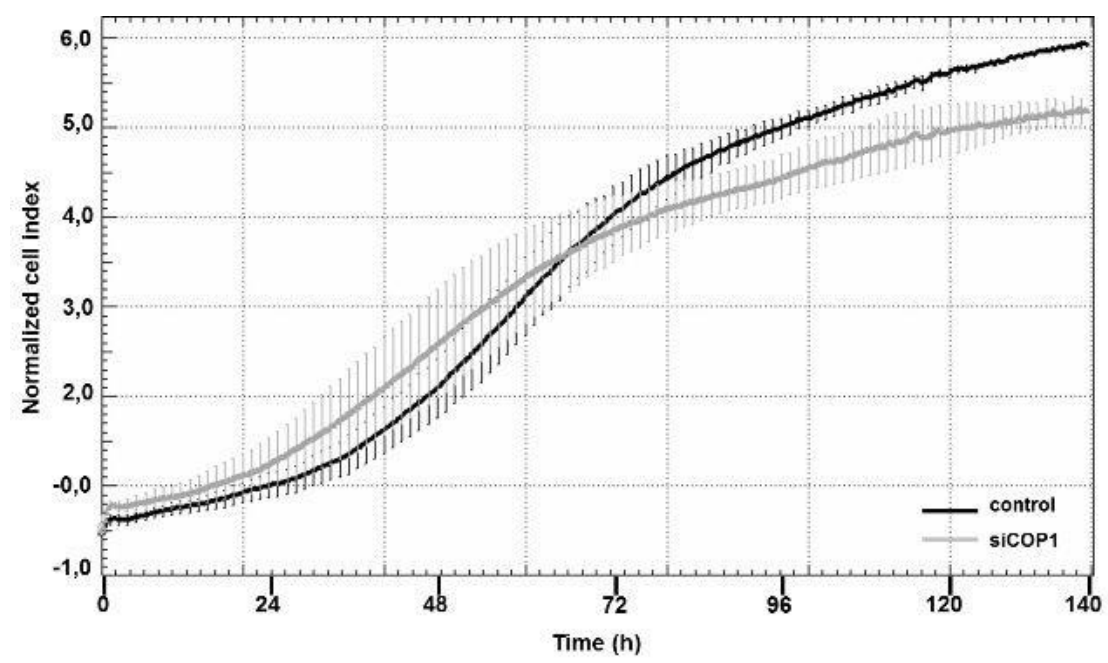

Figure 10. Dynamic proliferation curves for siCOP1 and control cells. Cell viability of the established keratinocyte cell lines was measured with the xCELLigence RTCA System. Black line: control cells; gray line: siCOP1 cells.

\subsubsection{UVB irradiation decreased huCOP1 protein abundance in transformed cell lines}

We previously reported that huCOP1 levels decreased in human keratinocytes after UVB irradiation $(24,67)$. To confirm that the stably transformed cell lines react similarly to UVB irradiation, we compared unirradiated and UVB-irradiated control and siCOP1 cells using the semiquantitative immunocytochemical approach to detect huCOP1 expression. The $40 \mathrm{~mJ} / \mathrm{cm}^{2}$ dose resulted in a decrease in cell viability, whereas the $20 \mathrm{~mJ} / \mathrm{cm}^{2}$ found to be the highest nonlethal UVB dose. It was also demonstrated that the $20 \mathrm{~mJ} / \mathrm{cm}^{2}$ dose effected the expression of well-known UVB-inducible genes (GOS2, $J U N B, J U N D)$. The applied UVB $\left(20 \mathrm{~mJ} / \mathrm{cm}^{2}\right)$ did not have a significant effect on the viability or proliferation of the cells (Fig. 11). 


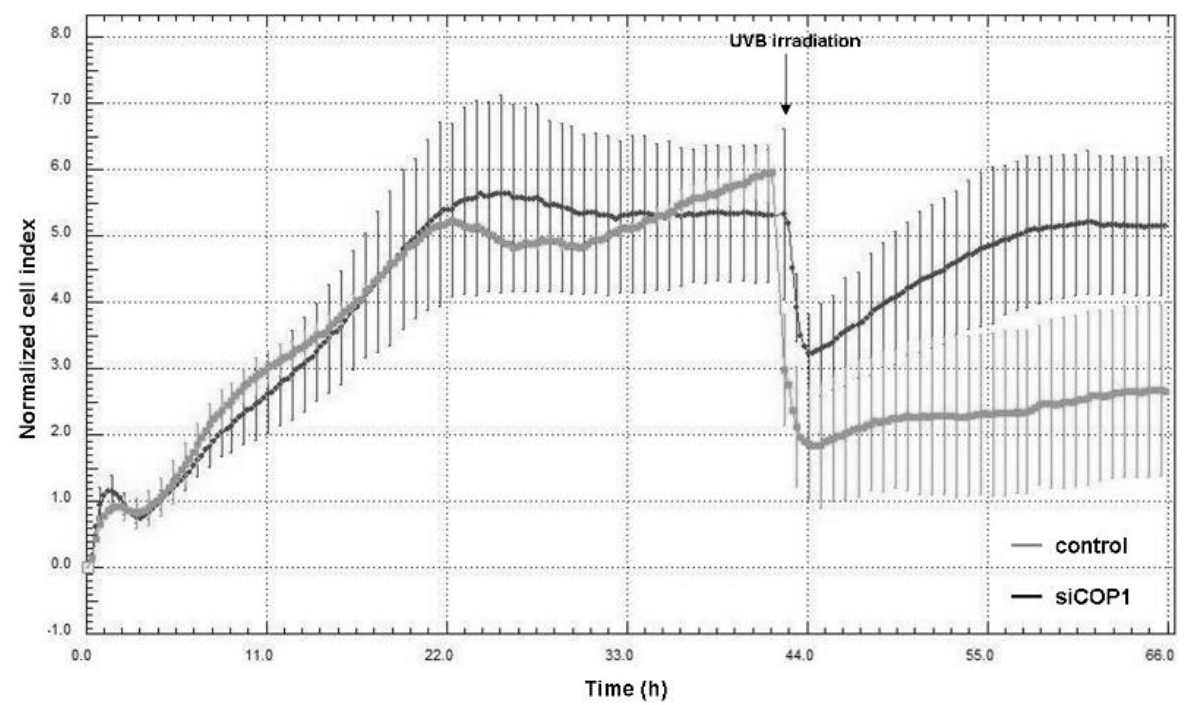

Figure 11. Dynamic proliferation curves for siCOP1 and control cells following UVB irradiation. Cell viability of the established keratinocyte cell lines was measured with the xCELLigence RTCA System. Gray line: control cells; black line: siCOP1 cells.

An approximately 50\% decrease in huCOP1 expression was detected in both cell lines $24 \mathrm{~h}$ after UVB irradiation (Fig. 12).
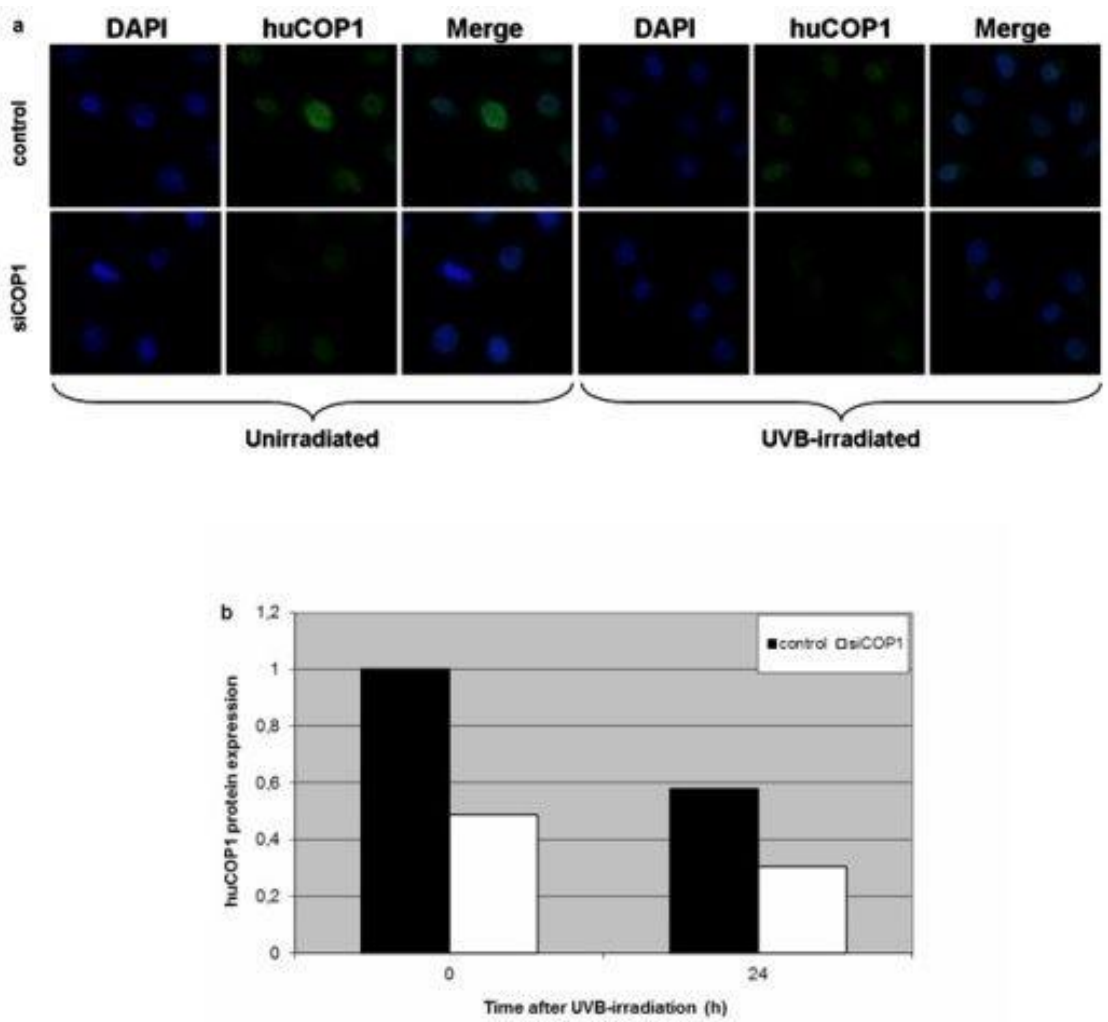

Figure 12. UVB irradiation decreases huCOP1 protein level in keratinocytes. (a) Unirradiated and UVBirradiated control and siCOP1 cells $24 \mathrm{~h}$ after treatment. (b) Semiquantitative analysis of huCOP1 protein level detected by immunocytochemistry before and at $24 \mathrm{~h}$ after UVB irradiation. Results are the averages of the huCOP1 expression after UVB irradiation from 30 independent cells normalized to the control cell line. 


\subsubsection{Array analysis of selected genes differentially expressed in early UVB response revealed a transcriptional regulatory role for huCOP1 in keratinocytes}

To understand the role of huCOP1 in the UVB-induced early signalling processes of human keratinocytes, we performed an expression profile analysis. For this purpose, the siCOP1 and control cell lines were evaluated using the StellARray ${ }^{\mathrm{TM}}$ Gene Expression System.

At first, we determined the appearance of the early robust UVB-caused gene expression changes in keratinocytes. To measure the kinetic changes in mRNA expression of well-known UVB-inducible genes (GOS2, JUNB and JUND), control keratinocytes were harvested at various time points $(0,1,2,3,4$ and 6 hours $)$ after exposure to $10,20,40 \mathrm{~mJ} / \mathrm{cm}^{2}$ UVB doses $(\mathrm{n}=3)$. The GOS2, JUNB and JUND mRNA expressions were determined by real-time RT-PCR. It was demonstrated that the $20 \mathrm{~mJ} / \mathrm{cm}^{2}$ dose effected the expression of well-known UVB-inducible genes (GOS2, $J U N B$ and $J U N D$ ) and the most robust changes appeared at 2 hours after UVB (Fig. 13).

Based on published data (1-3), we selected a set of genes showing 2-4-fold changes in gene expression within $2 \mathrm{~h}$ after UVB irradiation (14 up- and 16 down-regulated genes). The expression of the selected genes was compared in unirradiated and UVBirradiated cells $2 \mathrm{~h}$ after treatment. Changes in gene expression in the control cells were in good agreement with published results for most genes. The decreased abundance of huCOP1 protein in the siCOP1 cells further modulated this UVB effect, resulting in an overall higher gene expression level. Expression of the genes was similar in unirradiated siCOP1 and control lines, indicating that the silencing of COP1 had no direct effect on the expression of these genes in the absence of UVB (Table 5). 


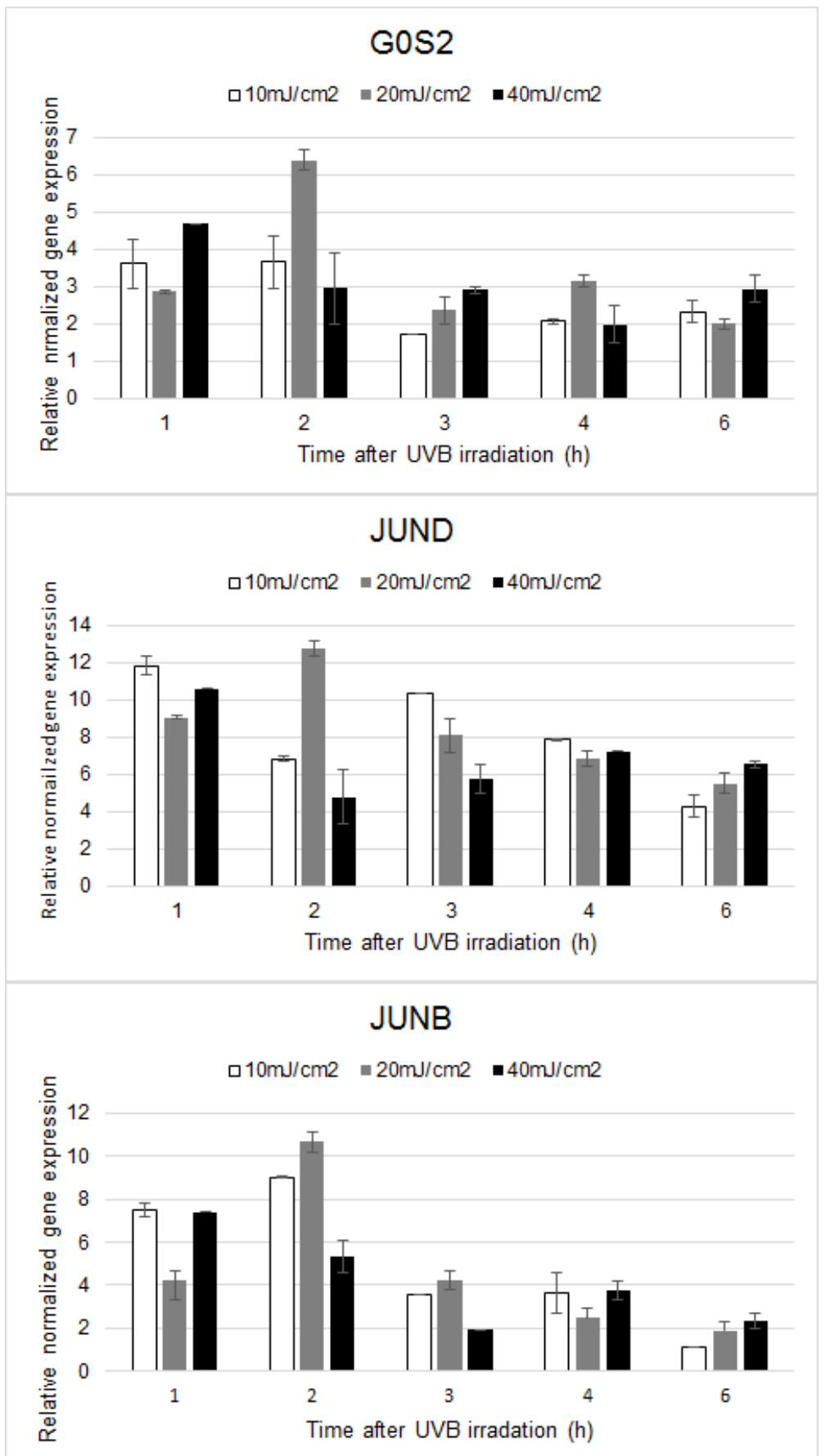

Figure 13. Determination of UVB-regulated mRNA expressions in keratinocytes. The GOS2, JUNB and JUND mRNA expression after the UVB treatment was determined by real-time RT-PCR. The average of three independent experiments is shown. 


\begin{tabular}{|c|c|c|c|c|c|c|c|c|}
\hline \multirow{2}{*}{$\begin{array}{c}\begin{array}{c}\text { Gene } \\
\text { symbol }\end{array} \\
\text { Upregulated } \\
\text { genes }\end{array}$} & \multirow[t]{2}{*}{$\begin{array}{c}\text { Entrez } \\
\text { Gene } \\
\text { ID } \\
\end{array}$} & \multirow[t]{2}{*}{ Gene name } & \multicolumn{2}{|c|}{ Without UVB } & \multicolumn{2}{|c|}{$\begin{array}{l}\text { UVB irradiated } \\
\text { Change, fold }\end{array}$} & \multicolumn{2}{|c|}{ P-values } \\
\hline & & & Control & sicOP1 & Control & sicOP1 & Control & sicoP1 \\
\hline FOS & 2353 & $\begin{array}{l}\text { FBJ murine osteosarcoma viral } \\
\text { oncogene homolog }\end{array}$ & 13,53 & 14,20 & 4,95 & 10,14 & 0,004 & 0,006 \\
\hline DUSP1 & 1843 & Dual specificity phosphatase 1 & 11,99 & 11,94 & 6,62 & 6,35 & 0,004 & 0,020 \\
\hline BTG2 & 7832 & $\begin{array}{l}\text { Antiproliferative DNA damage } \\
\text { response }\end{array}$ & 11,77 & 12,28 & 3,43 & 5,65 & 0,038 & 0,021 \\
\hline BTG1 & 694 & $\begin{array}{l}\text { Antiproliferative DNA damage } \\
\text { response }\end{array}$ & 16,13 & 16,45 & 2,27 & 3,35 & 0,047 & 0,084 \\
\hline ZFP36 & 7538 & $\begin{array}{lll}\text { Zinc } & \text { finger } & \text { transcriptional } \\
\text { regulator }\end{array}$ & 14,02 & 14,33 & 2,39 & 4,15 & 0,050 & 0,073 \\
\hline JUNB & 3726 & Jun B proto-oncogene & 10,42 & 11,30 & 2,05 & 2,58 & 0,058 & NS \\
\hline JUND & 3727 & Jun $\mathrm{D}$ proto-oncogene & 10,54 & 11,32 & 1,85 & 4,92 & NS & NS \\
\hline G0S2 & 50486 & Go/G1 switch gene & 10,38 & 10,52 & 1,56 & 2,68 & NS & NS \\
\hline GADD45A & 1647 & $\begin{array}{l}\text { Growth arrest and DNA- } \\
\text { damage-inducible }\end{array}$ & 12,10 & 11,28 & 2,39 & 2,19 & NS & NS \\
\hline ID3 & 3399 & $\begin{array}{ll}\begin{array}{l}\text { HLH1R21 helix-loop-helix } \\
\text { protein }\end{array} \\
\end{array}$ & 12,63 & 13,08 & 1,41 & 1,91 & NS & NS \\
\hline NOS1 & 4842 & Neuronal nitric oxide synthase & 19,78 & 19,51 & 1,23 & 1,65 & NS & NS \\
\hline SERPINA1 & 5265 & $\begin{array}{l}\text { Serine (or cysteine) proteinase } \\
\text { inhibitor A1 }\end{array}$ & 12,65 & 11,75 & 1,10 & 1,60 & NS & NS \\
\hline IFI27 & 3429 & IFN-inducible & 18,14 & 18,41 & 1,04 & 2,14 & NS & NS \\
\hline TAF10 & 6881 & Transcription factor tafll30 & 10,78 & 10,70 & 1,08 & 1,58 & NS & NS \\
\hline $\begin{array}{l}\text { Downregulated } \\
\text { genes }\end{array}$ & & & & & & & & \\
\hline SIK1 & 150094 & $\begin{array}{l}\text { SWI/SWF complex } 170 \mathrm{kDa} \\
\text { subunit (BAF170) }\end{array}$ & 12,17 & 12,54 & $-2,59$ & $-1,48$ & 0,019 & 0,055 \\
\hline PDLIM5 & 10611 & LIM domain & 11,33 & 12,13 & $-1,98$ & 1,04 & 0,043 & NS \\
\hline KLF5 & 688 & GC box binding protein BTEB2 & 9,92 & 11,00 & $-1,96$ & 1,40 & 0,057 & NS \\
\hline SRF & 6722 & Serum response factor & 12,99 & 13,37 & $-1,75$ & $-1,10$ & NS & 0,061 \\
\hline$M L L$ & 4297 & $\begin{array}{l}\text { Translocation T(4:11) of ALL-1 } \\
\text { gene to chr, } 4\end{array}$ & 13,50 & 13,56 & $-1,75$ & $-1,20$ & NS & NS \\
\hline FKBP5 & 2289 & $\begin{array}{ll}\begin{array}{l}\text { Progesteron } \\
\text { associated FJBP54 }\end{array} & \text { receptor- } \\
\end{array}$ & 11,28 & 11,40 & $-1,67$ & 1,08 & NS & NS \\
\hline CSNK2A1 & 1457 & Casein kinase II A & 11,13 & 10,82 & $-1,58$ & 1,07 & NS & NS \\
\hline CSNK1A1 & 1452 & Casein kinase $1 \mathrm{~A}$ & 11,31 & 11,16 & $-1,52$ & 1,05 & NS & NS \\
\hline METAP2 & 10988 & $\begin{array}{l}\text { Methionin aminopeptidase, } \\
\text { translation inhibitor }\end{array}$ & 10,57 & 10,50 & $-1,48$ & 1,22 & NS & NS \\
\hline HES1 & 3280 & Transcription factor HRY & 10,21 & 10,70 & $-1,09$ & 1,67 & NS & NS \\
\hline$P P A R G$ & 5468 & PPAR gamma & 14,31 & 13,80 & $-1,21$ & 1,47 & NS & NS \\
\hline PKMYT1 & 9088 & $\begin{array}{l}\text { Myt1 kinase (preferentially } \\
\text { phosphhorylates Cdc2) }\end{array}$ & 14,48 & 14,36 & $-1,13$ & 1,44 & NS & NS \\
\hline$D A X X$ & 1616 & FAS binding protein & 12,54 & 12,67 & $-1,26$ & 1,51 & NS & NS \\
\hline$H 2 A F Z$ & 3015 & Histone & 8,36 & 8,03 & $-1,07$ & 1,70 & NS & NS \\
\hline PCNA & 5111 & $\begin{array}{lll}\begin{array}{l}\text { Proliferating } \\
\text { antigen }\end{array} & \text { cell } & \text { nuclear } \\
\end{array}$ & 9,23 & 9,49 & $-1,15$ & 1,89 & NS & NS \\
\hline ARF6 & 382 & $\begin{array}{l}\text { ADP ribosilation factor } 6 \text { GTP } \\
\text { binding }\end{array}$ & 10,64 & 10,23 & $-1,20$ & 1,12 & NS & NS \\
\hline
\end{tabular}

Table 5. Changes in gene expression of unirradiated and UVB-irradiated control and siCOP1 keratinocytes 
To verify the array results, we performed real-time RT-PCR analyses of four genes: FBJ murine osteosarcoma viral oncogene homolog (FOS), JUND, zinc finger transcriptional regulator (ZFP36), and salt-inducible kinase 1 (SIK1) - based on the robust UVB-induced changes in gene expression observed in the array experiment. The real-time RT-PCR assay of independent biological samples $(n=3)$ confirmed that the detected differential expression was a transcriptional consequence of huCOP1 silencing (Fig. 14).

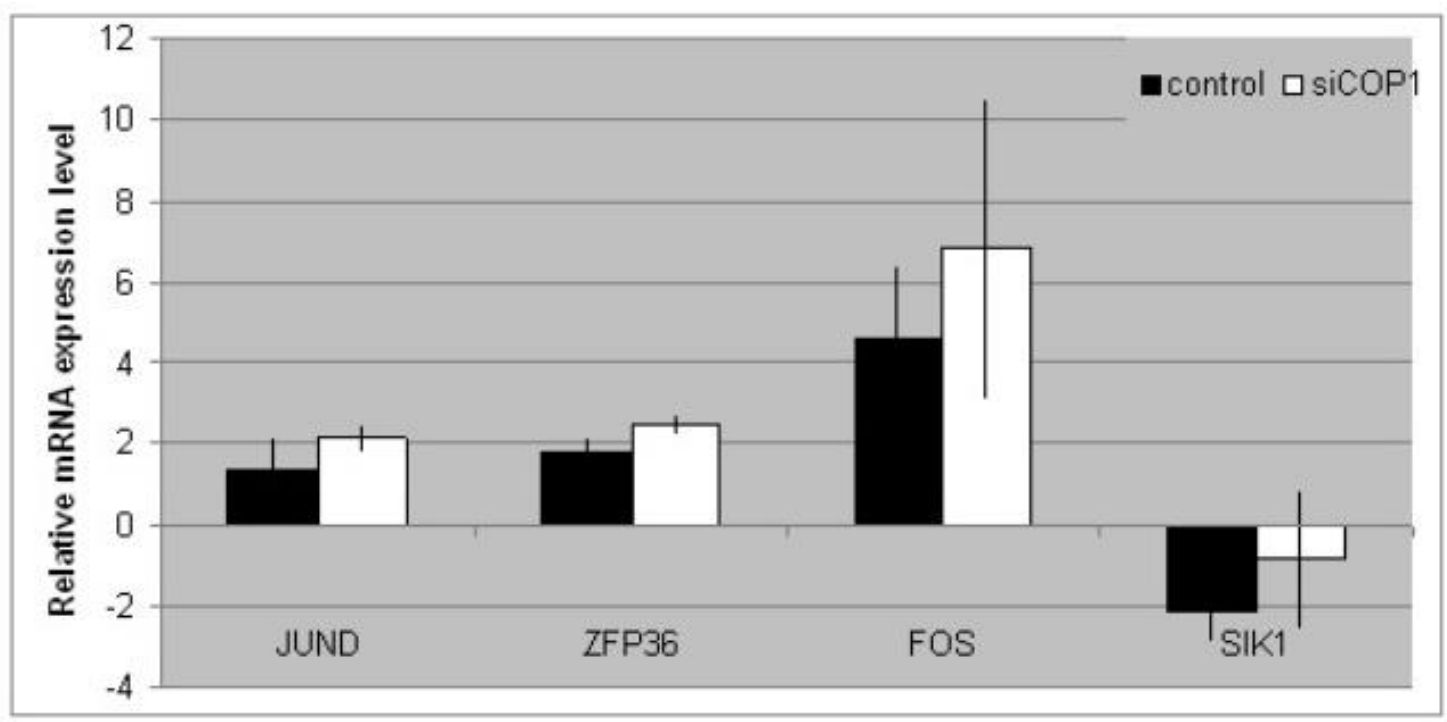

Figure 14. Validation of the array data by real-time RT-PCR analysis. Relative transcript levels of JUND, ZFP36, FOS and SIK1 are compared for UVB-irradiated siCOP1 (white bars) and control (black bars) cells. Expression levels were normalized to the $18 \mathrm{~S}$ ribosomal RNA gene. Values reflect the fold change between the irradiated control and siCOP1 cells. The average of three independent experiments is shown.

\subsubsection{A UVB regulatory network identified by pathway analysis was modified by huCOP1 expression}

Using the Ingenuity Pathway Analysis software (IPA, Ingenuity Systems, Stanford, USA), we identified a regulatory network of UVB-regulated genes in which 13 of the selected and analysed 30 genes participated (Fig. 15 a). Mitogen-activated protein kinase (ERK1/2), cAMP responsive element binding protein (CREB) and ubiquitin (not included in the array experiment) were identified as central organizers of this network. Expression of all 13 selected genes increased after UVB irradiation in the siCOP1 cell line, indicating that huCOP1 modulates the expression of these genes. To clarify whether the gene expression of $E R K 1 / 2$ and $C R E B$ is UVB-regulated, we carried out real-time RT-PCR 
experiments. UVB irradiation reduced the mRNA level of the central organizers in the control cell line and this affect was moderated by huCOP1 silencing (Fig. 15 b).

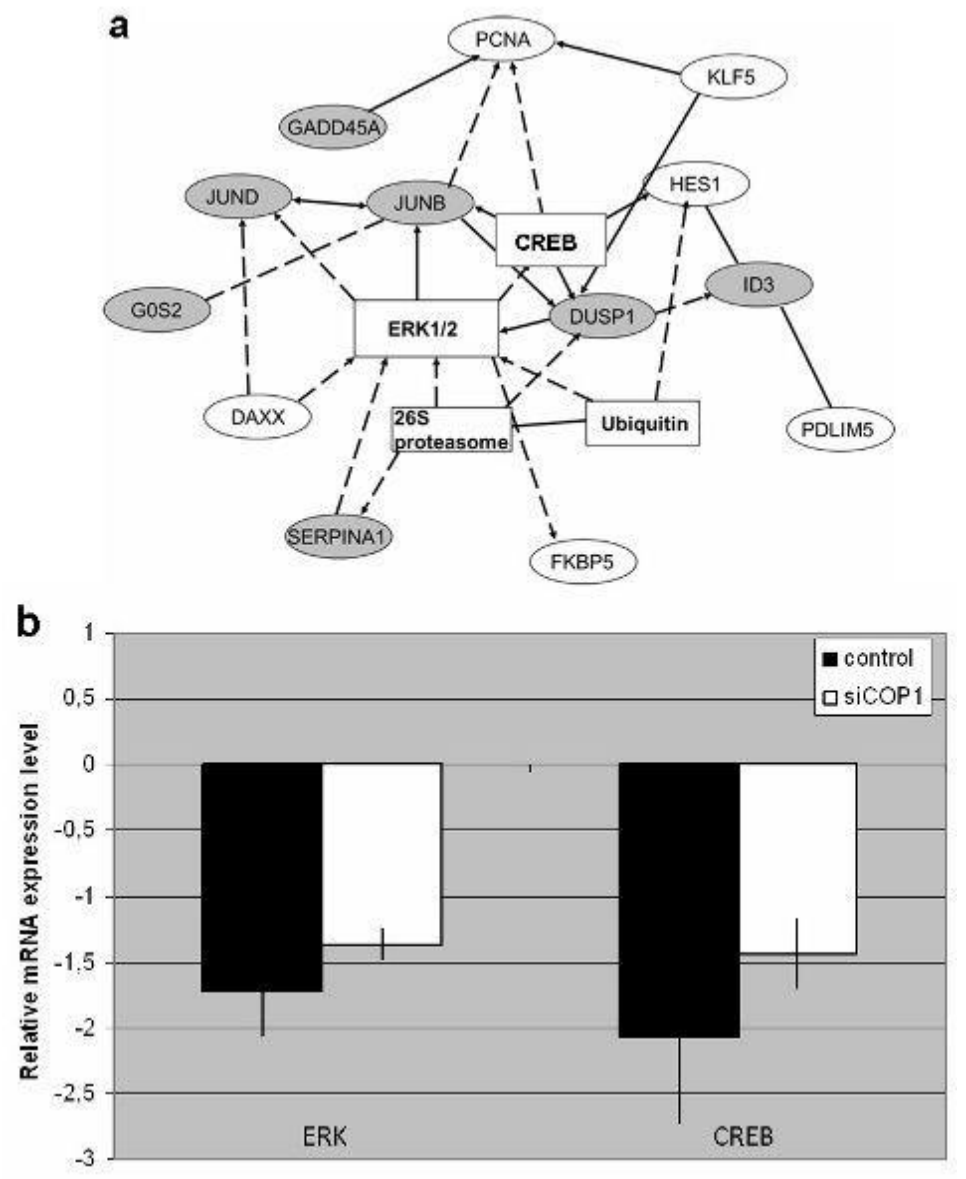

Figure 15. The UVB-regulatory network identified by the Ingenuity Pathway Analysis. (a) Arrows with continuous lines indicate well established direct regulatory connections between the members of the network. Arrows with dashed lines refer to well established indirect connections between the members of the network. Gray ovals: UVB upregulated genes; white ovals: UVB down-regulated genes; white rectangles: predicted key regulatory molecules. Single-headed arrows: one-way connection. Double-headed arrows: determined interaction. Lines without arrows: connection with yet undetermined direction. (b) Relative transcript levels of $E R K$ and $C R E B$ are compared for UVB-irradiated siCOP1 (white bars) and control (black bars) cells. Expression levels were normalized to the 18S ribosomal RNA gene. Values reflect the fold change between the untreated and irradiated control and siCOP1 cells from three independent irradiation experiments. The applied statistical analysis (Student's two-tailed heteroscedastic ttest) did not reveal significant difference in UVB-induced gene expression between the control and siCOP1 cells, however the tendency is clearly demonstrated.

The pathway analysis also revealed the following upstream regulators of the identified network: epidermal growth factor $(E G F)$, nerve growth factor $(N G F)$, fibroblast growth factor 2 (FGF2), interferon gamma (IFNG), interleukin-1 beta (IL1B), interleukin6 (ILO) cytokines and nuclear factor of kappa beta (NFKB) (Fig. 16 a). According to the analysis, these regulators are in an activated state to trigger the UVB response through the identified network but the relationships among the upstream 
regulators were not assessed. We choose three upstream regulator molecules (IL1B, IL6 and $N F K B$ ) to test whether the corresponding genes exhibit UVB-induced changes in expression. In agreement with published data $(2,69,70)$, our results demonstrated that the transcription of these genes is UVB sensitive and that huCOP1 silencing had an effect on their transcription levels after UVB irradiation (Fig. 16 b).
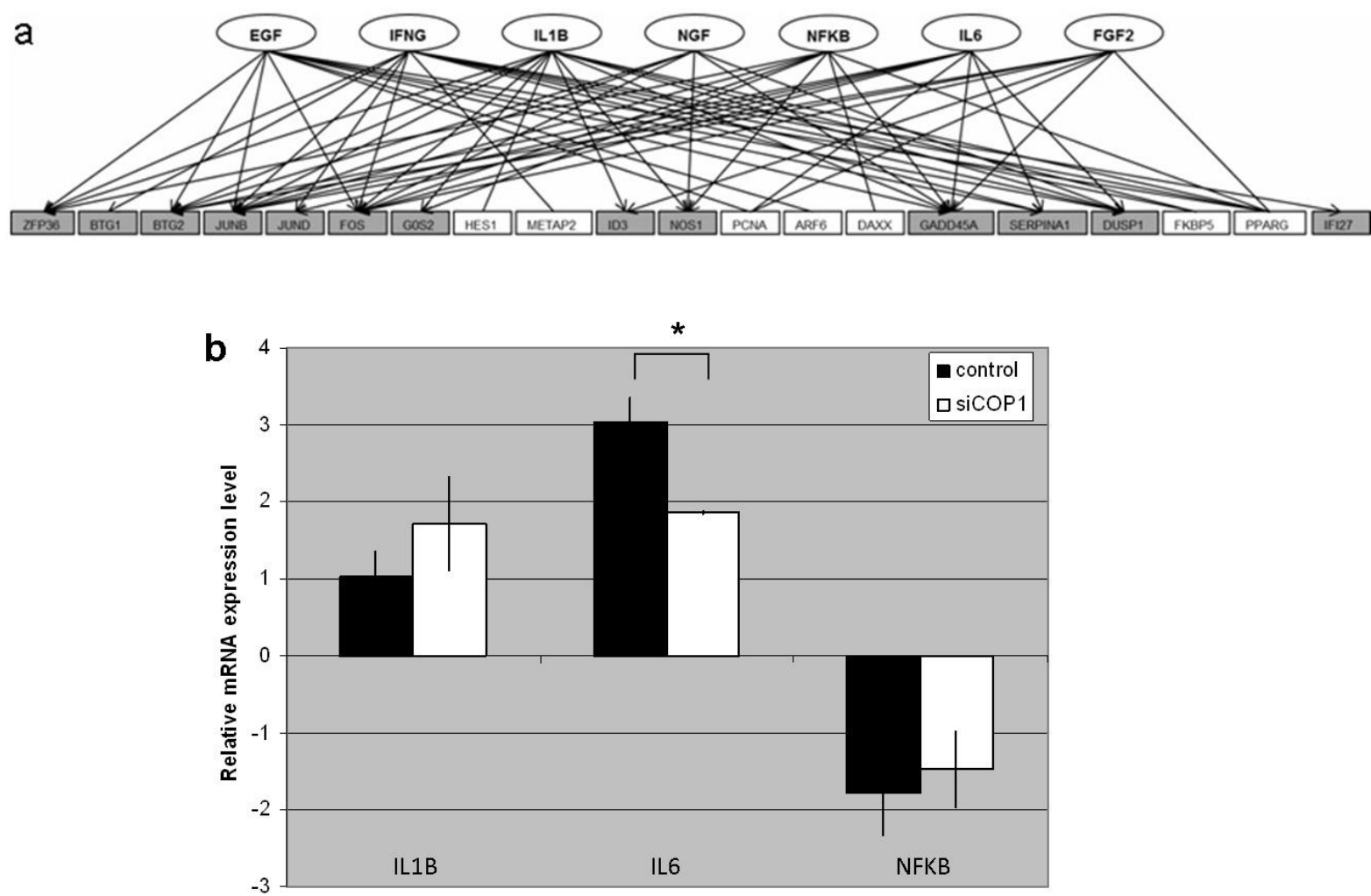

Figure 16. Predicted upstream regulators of the identified network. (a) White ovals: upstream regulators; gray rectangles: UVB-upregulated genes of identified network; white rectangles: UVB-downregulated genes of the identified network. All of the upstream regulators were in an activated state, but the relationships among them were not investigated. (b) Relative transcript levels of IL1B, IL6 and NFKB are compared for UVB-irradiated siCOP1 (white bars) and control (black bars) cells. Expression levels were normalized to the $18 \mathrm{~S}$ ribosomal RNA gene. Values reflect the fold change between the untreated and irradiated control and siCOP1 cells in three independent irradiation experiments. The applied statistical analysis (Student's two-tailed heteroscedastic t test) revealed a significant $(\mathrm{p}<0.05)$ difference in the expression of the IL6 gene after UVB irradiation of control and siCOP1 cells and demonstrated a nonsignificant but tendencious difference in the case of $I L 1 B$ and NFKB gene expression. 


\subsection{The effect of the gas discharge plasma needle on the human keratinocytes related to the wound healing processes}

\subsubsection{Effect of gas discharge plasma treatment on cell viability}

In order to optimize the wound-healing model experiments and the safe treatment conditions - which do not lead to cell death - viability experiments were performed. For this purpose 24 -well plates were used with $1 \times 10^{5}$ cells per well. The treatment parameters that could influence the cell survival were: (i) input rf power, (ii) the thickness of PBS layer protecting the cells from desiccation, (iii) treatment time and (iv) the distance between the tip of the needle and PBS layer, which was set to $1.5 \mathrm{~mm}$. Cells were treated under different conditions by varying the input power (18-35 W), PBS layer thickness and treatment time (5-30 s). The viability of cells at different conditions were analysed with staining methods using trypan blue and propidium iodide.

First, cells were stained with trypan blue immediately after gas discharge plasma treatment to visualize the effect of the plasma's structure on the cell culture (dead cells take up trypan blue). Figure 17 (a) shows the image of the cell culture treated in $200 \mu \mathrm{l}$ PBS - corresponding to a $1 \mathrm{~mm}$ thick PBS layer - for $7 \mathrm{~s}$ at $30 \mathrm{~W}$ input power. Here we could see a pattern of dead cells in the area covered by the plasma glow. More precisely, most of the cells died in the treated region, while the cells in contact with the edge of the

glow detached and diffused towards the central region. On the other hand when $300 \mu \mathrm{l}$ PBS was used instead of $200 \mu$ PBS most of the cells remained viable (Fig. 17 b). 

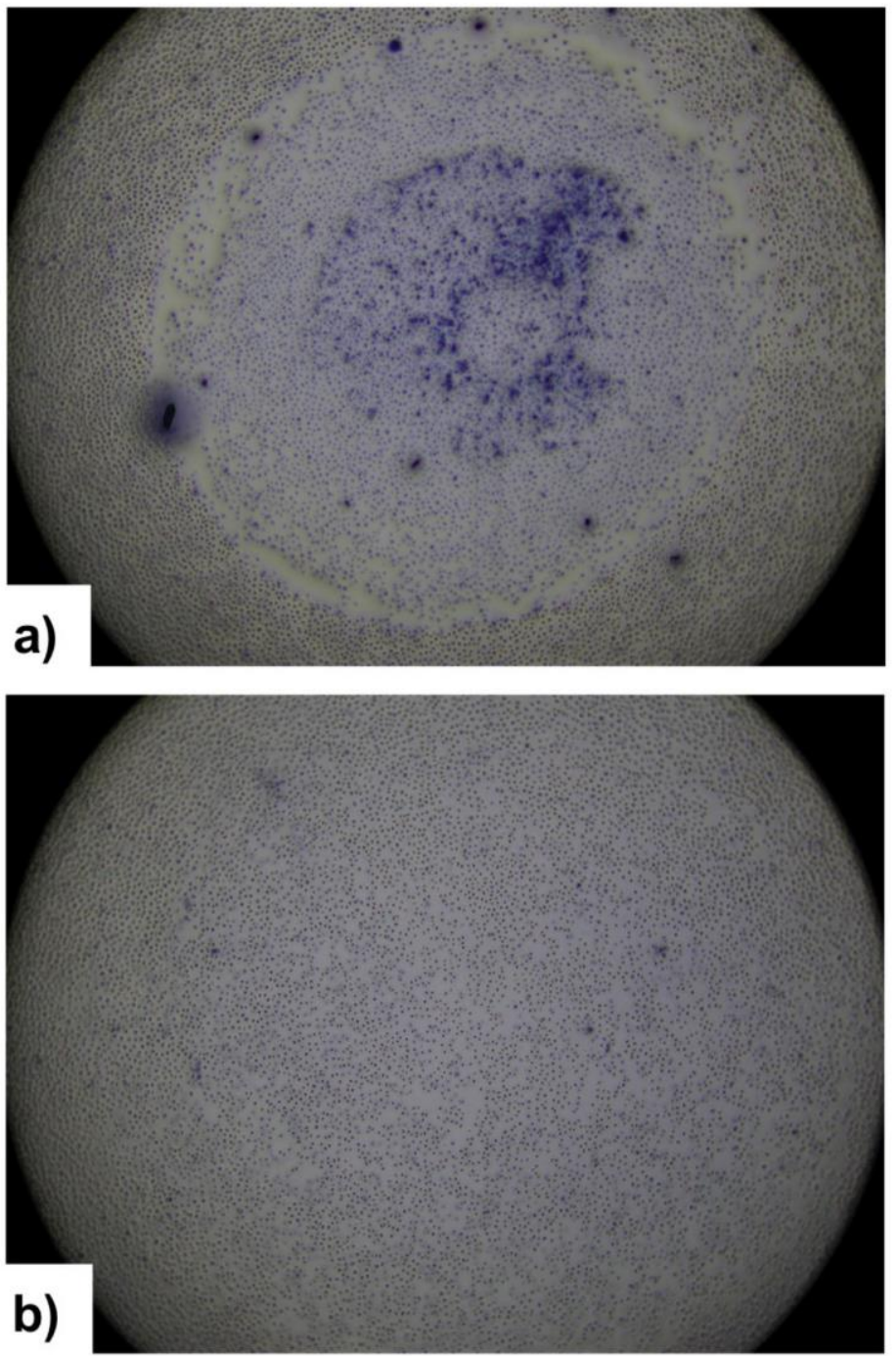

Figure 17. (a) The pattern of dead cells caused by gas discharge plasma treatment on cell culture protected with $200 \mu \mathrm{l}$ PBS, equivalent to $1 \mathrm{~mm}$ thick layer, when treated for $7 \mathrm{~s}$ at $30 \mathrm{~W}$ input power. (b) The image of cell culture treated in $300 \mu \mathrm{l}$ PBS for $7 \mathrm{~s}$ at $30 \mathrm{~W}$ input power. The cells were stained with trypan blue, which is taken up by the dead cells. Four-fold magnification.

A more systematic analysis was carried out with the propidium iodide staining method. The treated cells were stained $48 \mathrm{~h}$ after plasma treatment. The recorded images of the cells, indicating the viability of cells) the dead cells stained with propidium iodide appear as red) are presented in Figure 18. We have found that the cells covered with $200 \mu$ PBS can survive only very short treatments, such as $5 \mathrm{~s}$ at an input power of maximum $20 \mathrm{~W}$. The increase of the treatment time or the input power, both led to cell death. By increasing the PBS to $250 \mu \mathrm{l}$ the cells could survive longer treatments at $20 \mathrm{~W}$ input power, however higher powers were still lethal. When using $300 \mu \mathrm{l}$ PBS the cells could survive treatments as long as $20 \mathrm{~s}$, even at powers as high as $35 \mathrm{~W}$. 


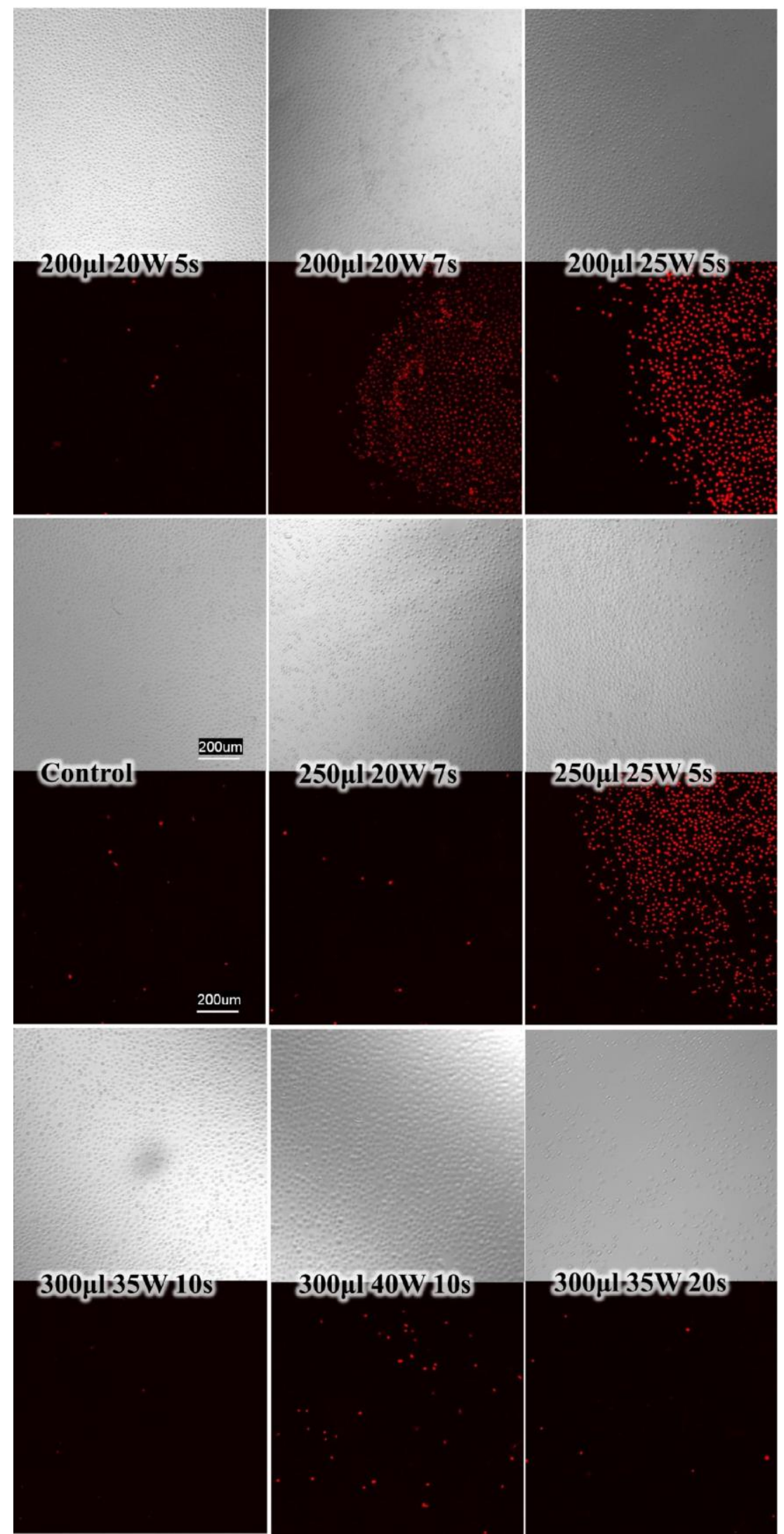

Figure 18. Keratinocytes $48 \mathrm{~h}$ after gas discharge plasma treatment. Image of cells recorded by phasecontrast light microscopy (1st, 3rd and 5th rows), and confocal laser scanning microscopy image of dead cells stained with propidium iodide (2nd, 4th and 6th rows). The treatment conditions, such as PBS layer thickness, input power and treatment time, are marked on the images. 
Viability experiments have also been carried out in 6-well plates, with wells of $35 \mathrm{~mm}$ diameter. The volume of the PBS has been scaled up in order to obtain the same PBS layer thickness as in the case of the 24-well plate experiments. While in the 24-well plate the $1 \mathrm{~mm}$ PBS layer corresponded to $200 \mu \mathrm{L}$, in the 6 -well plate $962 \mu \mathrm{L}$ needed to be added to obtain the same layer thickness. After treating the cells in the 6-well plate at conditions leading to cell death in the 24-well plate - such as $5 \mathrm{~s}$ treatment at $25 \mathrm{~W}$ (shown in Fig. 18 first row last column) - most of the cells stayed viable.

This result indicated that it was not only the PBS layer thickness, but also the liquid surface and volume, which influenced the density of active species reaching the cells. Important parameters could also be the heat transport and the heat dissipation increased with the volume of the liquid.

\subsubsection{Effect of gas discharge plasma treatment on cell proliferation}

The effect of the gas discharge plasma treatment on keratinocyte proliferation was followed with the xCELLigence microelectronics biosensor. Each well of the plate belonging to the device contained integral sensor electrode arrays allowing the monitoring of cells. For comparison reasons and to verify whether the liquid composition influences the effect of the treatment, cells were also treated in the cell medium.

Figure 19 shows the proliferation of keratinocytes treated under different conditions in PBS (first column) and cell medium (second column). The error bars has been omitted from the figures for better visibility. The maximum error is about $12 \%$. We found that treatment of keratinocytes at $18 \mathrm{~W}$ and $20 \mathrm{~W}$ can positively influence cell proliferation (Fig. 19 a, c-d). A more significant increase of proliferation could be observed for the PBS covered cells in the case of the $10 \mathrm{~s}$ and $15 \mathrm{~s}$ long treatments at $20 \mathrm{~W}$ (Fig. $19 \mathrm{c}$ ). However in the case of treated cells, the proliferation fell below the control ones after 60h. This behaviour suggests that periodical treatments could keep the cell proliferation above the normal level. At the same time the increase of the treatment time above $15 \mathrm{~s}$, as well as the input power (Fig. 19 e-f) cause the diminishing of the proliferation. 

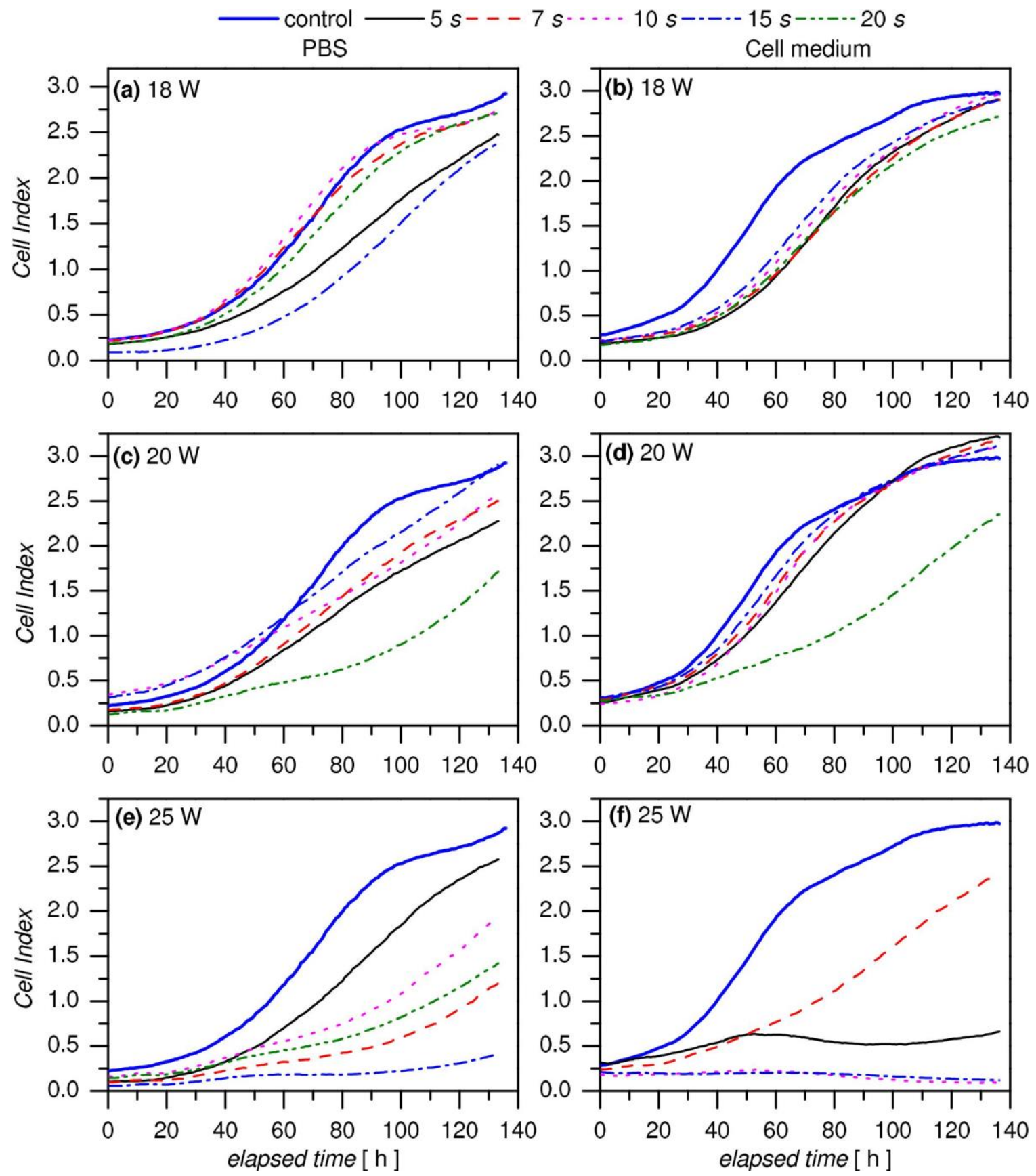

Figure 19. Cell Index, showing the cell proliferation, as given arbitrary unit by the xCELLigence microelectronics biosensor. For initial $5 \times 10^{3}$ cells are shown treated in PBS (first column) and cell medium (second column) for conditions of different treatment times in the 5-20 s range at input powers of $18 \mathrm{~W}, 20$ $\mathrm{W}(\mathrm{c}-\mathrm{d})$ and $25 \mathrm{~W}$, respectively. $\mathrm{t}=0$ marks the time moment when the cells have been recovered after the plasma treatment.

In the case of keratinocytes treated in cell medium we could observe a slightly different behaviour, i.e. cell proliferation enhanced at a much higher elapsed time after plasma treatment. At $20 \mathrm{~W}$ this occurred at $100 \mathrm{~h}$ after the treatment, except for the longest $20 \mathrm{~s}$ treatment. This different behaviour showed that due to plasma treatment the liquid chemistry of the two liquid mediums - i.e. the created active species, which interacted with the cells - was different. We note that the results shown here should not be 
used for quantitative comparison of the different conditions. All the treatments have been performed in a single 96-well plate, i.e. the cells being treated under different conditions in a row. The treatments were done in the following order: (1.) $\mathrm{P}=18 \mathrm{~W}$ from $5 \mathrm{~s}$ to $20 \mathrm{~s}$, (2.) $\mathrm{P}=20 \mathrm{~W}$ from $5 \mathrm{~s}$ to $20 \mathrm{~s}$, (3.) $\mathrm{P}=25 \mathrm{~W}$ from $5 \mathrm{~s}$ to $20 \mathrm{~s}$, and (4.) $\mathrm{P}=30 \mathrm{~W}$ from $5 \mathrm{~s}$ to $20 \mathrm{~s}$. As a result, the cells interacted with the treated liquid for different periods of time, which influenced the cellular response to the treatment, as also shown in the next section.

\subsubsection{Effect of gas discharge plasma treatment on wound-healing}

For the wound-healing experiments keratinocytes were plated into 24-well plates. The viability of cells was protected by PBS under laboratory conditions during the treatment by gas discharge plasma. The cells have been treated by two different treatment conditions by using six samples for each case. In the first case, the plates were treated two-by-two, meaning that the cell medium was replaced with PBS in two plates at a same time, and changed back to medium after both plates have been treated. At each input power two plates were treated consecutively as follows: in the 1 st plate the $5 \mathrm{~s}, 7 \mathrm{~s}, 20 \mathrm{~s}$ and $25 \mathrm{~s}$ treatment times were applied, while in the second plate the $10 \mathrm{~s}, 15 \mathrm{~s}$ and $30 \mathrm{~s}$ ones. In the second plate the forth row was occupied by the control samples (Table 6).

\begin{tabular}{|c|c|c|}
\hline $\begin{array}{c}\text { Treatment } \\
\text { order }\end{array}$ & $\begin{array}{c}\text { Treatment } \\
\text { time (s) }\end{array}$ & $\begin{array}{c}\text { Estimated } \\
\text { elapsed time (s) } \\
\text { in treated PBS }\end{array}$ \\
\hline 1 & 5 & 1100 \\
\hline 2 & 7 & 1000 \\
\hline 5 & 10 & 480 \\
\hline 6 & 15 & 320 \\
\hline 3 & 20 & 820 \\
\hline 4 & 25 & 600 \\
\hline 7 & 30 & 90 \\
\hline
\end{tabular}

Table 6. The estimated time while the cells have been covered with the treated PBS after the direct gas discharge plasma treatment of the PBS protected cells. The seven different length of treatments have been realized in two consecutively treated 24-well plates. The PBS was removed after both plates are fully treated. The different elapsed times occurred from the treatment order of the PBS covered cells.

Figure 20 shows the evolution of the scratch on the cell culture as a function of input power at different elapsed times after the gas discharge plasma treatment. At several treatment conditions - particularly at low treatment times and low powers - the scratch 
width reduction was higher than in the case of the untreated control, i.e. the closing of the scratch was faster. As time elapses, at certain conditions the closing of the scratch slowed down compared to the control case, more pronouncedly when $25 \mathrm{~W}$ and $30 \mathrm{~W}$ powers were used. In these cases, at the $48 \mathrm{~h}$ elapsed time the scratch width reduction, independently of the treatment time used, fell below the control one (Figure $20 \mathrm{~d}$ ). In the case of the lower powers - $18 \mathrm{~W}$ and $20 \mathrm{~W}-$, the conditions of low treatment times became dominant as time elapsed. This indicates that in order to stimulate the cells, short and low power treatments - which induce stress to the cells - may be adequate.

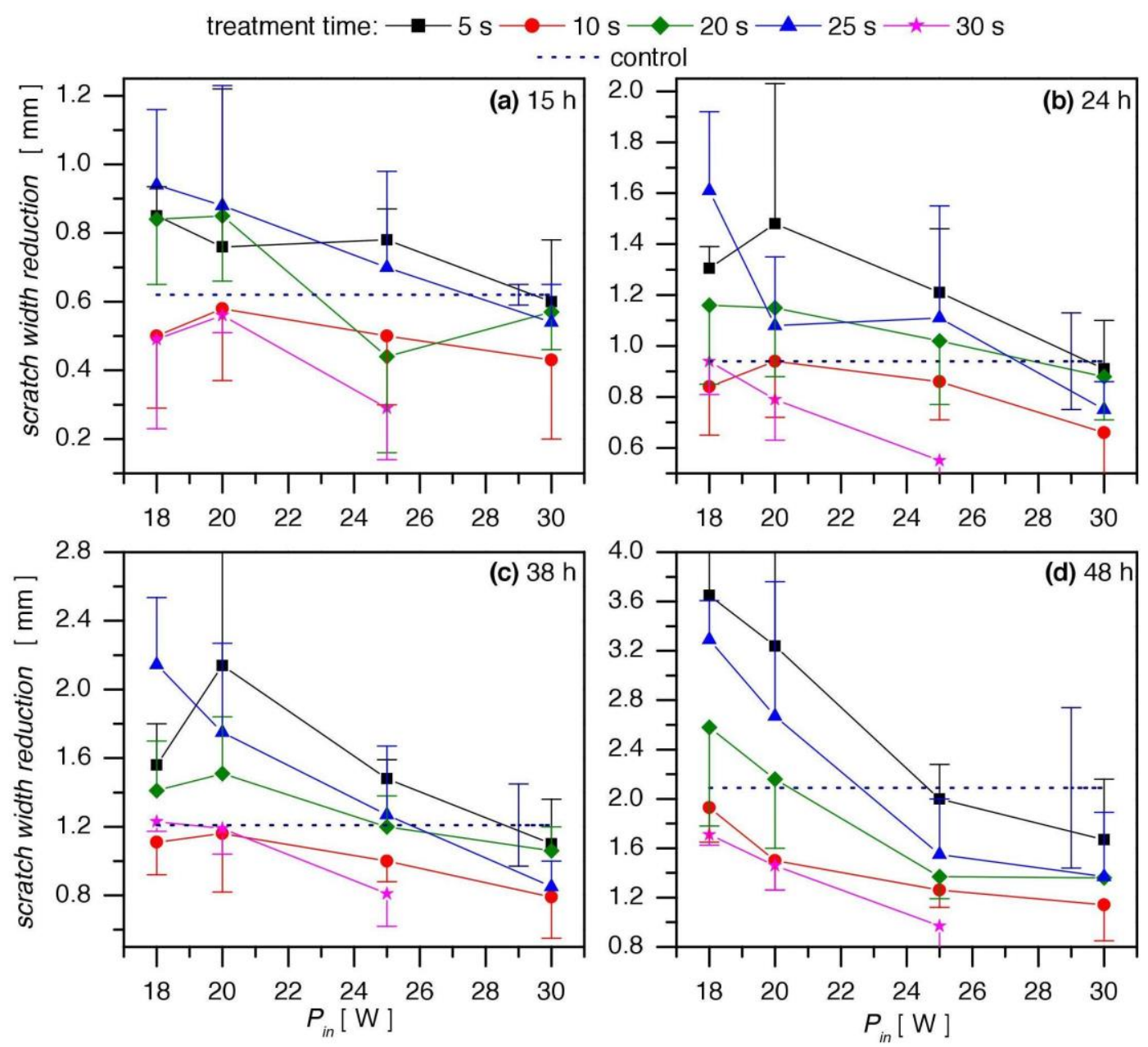

Figure 20. The scratch closure with (a) $15 \mathrm{~h}$, (b) $24 \mathrm{~h}$, (c) $38 \mathrm{~h}$ and (d) $48 \mathrm{~h}$ after the plasma treatment as a function of the input power. Different symbols mark the different treatment times.

In the second case, the plates were treated one-by-one ("plate-by-plate" protocol) and in each plate the PBS was replaced with the cell medium $10 \mathrm{~min}$ after the last treatment in the plate. Figure 21 presents the closing of the scratch after the low power $18 \mathrm{~W}$ and $20 \mathrm{~W}$ - treatments as a function of treatment time. In both cases the scratch width reduction showed similar non-monotonous behaviour. With $48 \mathrm{~h}$ after treatment, 
the highest scratch width reduction occurred in the case of the lowest treatment time $(5 \mathrm{~s})$, while the lowest was observed in the case of the $15 \mathrm{~s}$ treatment. Furthermore, in the case of the $25 \mathrm{~s}$ treatment a strong increase of the scratch closing could be observed. It is suspected, that this non-monotonous behaviour - with a sharp minimum and maximum could be the result of the treatment protocol used.
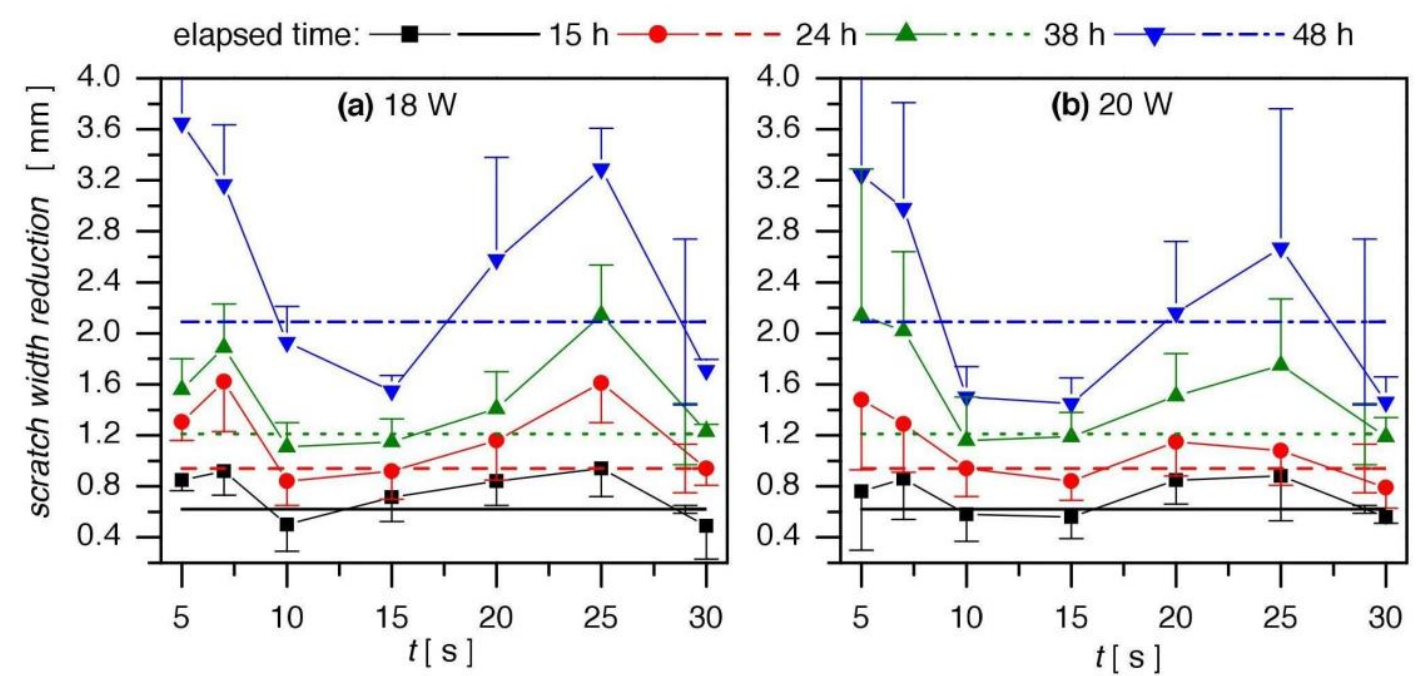

Figure 21. The scratch closure as a function of the treatment time for different elapsed times after treatment at (a) $18 \mathrm{~W}$ and (b) $20 \mathrm{~W}$.

As described in Table 6, two plates were treated consecutively ("two-by-two" protocol) when the cells at each condition stayed in the treated PBS for different periods of time. According to this, the minimum scratch width reduction could be observed at the conditions where the cells were kept in the treated medium for the shortest period of time. In order to verify this effect and to find out if the behaviour depicted in Figure 21 should be monotonous, a new protocol was chosen, where the plates are treated one by one ("plate-by-plate" protocol) and in each plate the PBS was replaced with the cell medium $10 \mathrm{~min}$ after the last treatment in the plate. Although in this way we can not equalize the interaction times of treated cells and PBS for all conditions, but by keeping most of the parameters the same the large differences can be diminished as presented in Table 7. More precisely, in the case of the $10 \mathrm{~s}$ and $15 \mathrm{~s}$ treatments (Table 7) - where the minimum in the scratch width reduction has been observed previously - the treated cell - PBS interaction time has been increased to the level of the $5 \mathrm{~s}$ treatment condition, where the highest scratch width reduction has been obtained previously using the "two-by-two" protocol (Table 6). 


\begin{tabular}{|c|c|c|c|}
\hline $\begin{array}{c}\text { Treatment } \\
\text { order }\end{array}$ & Plate ID & $\begin{array}{c}\text { Treatment } \\
\text { time (s) }\end{array}$ & $\begin{array}{c}\text { Estimated } \\
\text { elapsed time (s) } \\
\text { in treated PBS }\end{array}$ \\
\hline 1 & 1 & 5 & 1100 \\
\hline 2 & 1 & 7 & 1000 \\
\hline 1 & 2 & 10 & 1100 \\
\hline 2 & 2 & 15 & 950 \\
\hline 3 & 1 & 20 & 820 \\
\hline 4 & 1 & 25 & 600 \\
\hline 3 & 2 & 30 & 690 \\
\hline
\end{tabular}

Table 7. The estimated time while the cells have been covered with the treated PBS after the direct plasma treatment of the PBS protected cells, when the plates were treated one by one and PBS is removed with 10 min after the plate has been fully treated.

Figure 22 shows the evolution of the scratch after the new protocol treatments at $18 \mathrm{~W}$ input power. According to the results, the previously observed sharp minimum and maximum of the scratch width reduction as a function of treatment time disappeared. In the case of the $10 \mathrm{~s}$ and $15 \mathrm{~s}$ treatments the scratch width reduction increased considerably, comparing to the previous results shown in Figure 21, and as a result a faster closing was obtained than in the case of the control sample. This result indicates the importance of the treated cell - PBS interaction time. However, in the case of the longest investigated treatment - the $30 \mathrm{~s}$ treatment - the increase of the treated cell - PBS interaction time had no positive effect on the scratch closing. Finally, we could still observe a small peak in the scratch width reduction as a function of treatment time at $25 \mathrm{~s}$.

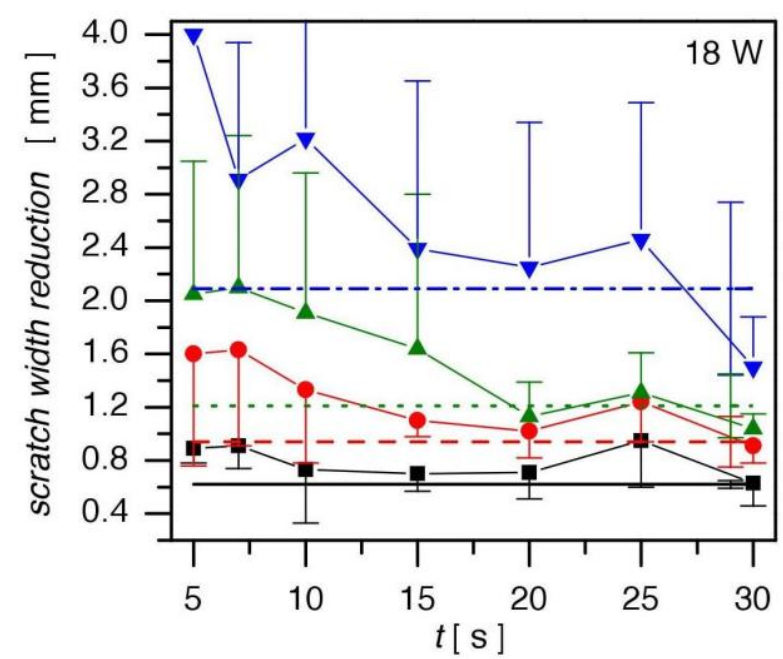

Figure 22. The scratch closure as a function of the treatment time for different elapsed times (marked with the same symbols as in Figure 20) after the plasma treatment at $18 \mathrm{~W}$ using the "plate-by-plate" treatment protocol described in the text. 
These results indicate that there was a complex association between the cell activation, treatment time and treated cell - PBS interaction time. The cell activation was influenced both by the direct interaction of cells with the plasma and with the species resulted from the plasma induced liquid chemistry. The effect of the treated cell - medium interaction time on the cells viability has been also observed by Wende et al (53).

\subsubsection{Cell selectivity of the gas discharge plasma treatment}

In order to mimic the natural microbial environment of human keratinocytes, they were cocultivated with the most common commensal bacteria of the skin, the Propionibacterium acnes (P.acnes) Gram-positive bacterium. Figure 23 shows the evolution of the scratch in the case of the untreated non-cocultivated and P.acnes cocultivated assays, respectively, and the plasma-treated P.acnes cocultivated assay. After $24 \mathrm{~h}$ the assay has been stained with trypan blue in order to distinguish the dead cells. We could see that while in the case of the untreated non-cocultivated and the plasma-treated P.acnes cocultivated assays the scratch closed, in the case of the untreated P.acnes cocultivated assay the scratch width did not decrease at all and the keratinocytes all died. On the other hand, in the case of the plasma-treated sample the keratinocytes did not die. This gave evidence that the plasma needle acted selectively regarding the keratinocytes and the Gram-positive bacteria. Similar effect has been observed in case of treatment of Staphylococcus epidermidis infected HaCaT cells with an argon highfrequency driven atmospheric-pressure plasma jet treatment (53).

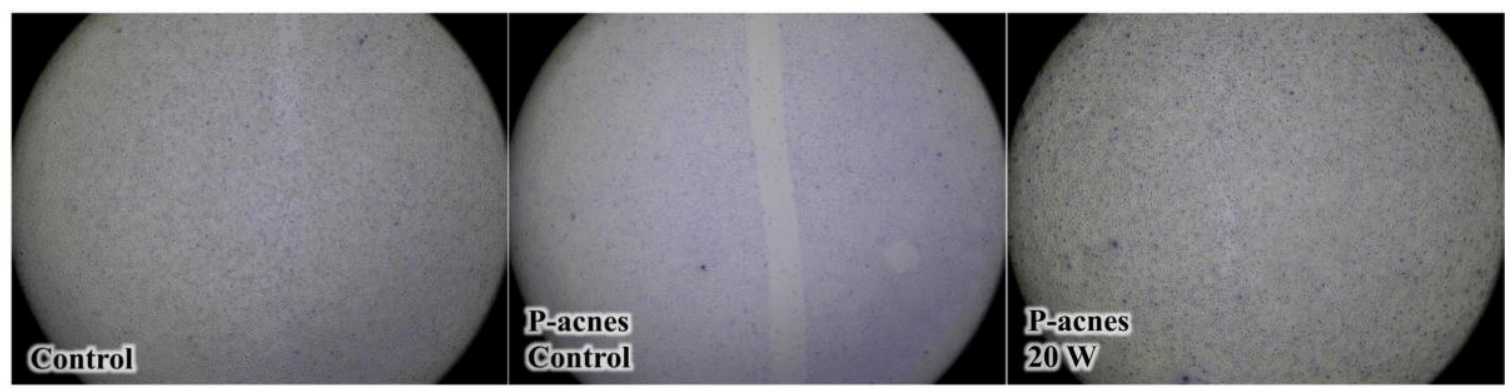

Figure 23. The evolution of the scratch in the case of the untreated non-cocultivated and P.acnes cocultivated assays, respectively and the plasma-treated P.acnes cocultivated assay. 


\section{DISCUSSION}

UVB light is undoubtedly the most important carcinogenic environmental stressor of human skin, and UV-induced changes in keratinocytes have been widely studied (3, $71)$.

COP1, the Constitutive Photomorphogenic Protein 1, is well conserved across species $(6,7,15-17)$. In plants, the function of COP1 is closely tied to the light signalling pathway. COP1 acts as a central repressor in the pathway, where it promotes the ubiquitination and degradation of the positive regulators and is itself regulated by multiple photoreceptors $(5,6)$. A recent study revealed that under UVB, however, COP1 acts as a positive regulator in the signalling pathway $(27,28)$. In mammalians, COP1 itself can be either a tumour suppressor or an oncoprotein, depending on the context, which has important implications for the therapeutic targeting of COP1 and other E3 ligases (18). Several data suggest that huCOP1 has been implicated in the negative regulation of important cancer-related genes acting in the cellular response to UVB (18, 29). Nevertheless, the possible role of huCOP1 in keratinocyte UVB response and tumourigenesis has not yet been investigated in detail. Our aim was therefore to investigate the function of huCOP1 in keratinocytes, the cell type most exposed to UVB irradiation.

To address these issues we produced transgenic cell lines in which the expression of huCOP1 was stably silenced (siCOP1). For this purpose, a novel, human papillomavirus type 16 E6 oncogene-immortalized keratinocyte cell line (HPV-KER) was used and characterized. Since this cell line exhibited a normal p53 UVB response, we considered it suitable for our purposes (67).

After establishing the huCOP1 silenced transgenic keratinocyte cell line, we carried out viability assays. Our experiments revealed that the silencing of huCOP1 did not affect cell viability before and with a short time after UVB irradiation. Next, we examined the expression of selected UVB-regulated genes with or without UVB irradiation. Very importantly, we found that the residual huCOP1 level was further reduced by UVB and the significantly reduced huCOP1 level resulted in more pronounced UVB-induced changes in the expression of genes as compared to non-transgenic keratinocytes. These data demonstrate that this cell line is a particularly suitable tool for studying huCOP1dependent UVB-induced changes in early gene expression responses. 
In order to elucidate the function of huCOP1 in the early UVB-response of human keratinocytes, we carried out array analysis. Our experiments revealed that the expression level of the selected genes was not affected by huCOP1 silencing in unirradiated cells. DNA array and validating real-time RT-PCR experiments confirmed that transcript levels of the selected genes exhibited changes as early as $2 \mathrm{~h}$ after UVB irradiation and that these changes were in good agreement with previously published data $(1-3,69)$.

To analyse the possible interactions among the examined genes we used the Ingenuity Pathway Analysis software. This software uses published interaction data for composing potential new networks based on novel experimental data. The pathway analysis identified a network in which 13 of the 30 examined genes were organized around three central molecules, ERK1/2, CREB and ubiquitin. Functional connections between certain members of the identified network have already been described (72-75). All 13 genes were differentially expressed after UVB irradiation, and their expression was increased in siCOP1 cells compared to control. Similar changes have been detected in ERK1/2 and CREB gene expression, affirming their central role in the identified network. Some of the components of the identified network have already been implicated in huCOP1-mediated processes: Liu et al. have recently demonstrated that huCOP1 promotes the ubiquitination and degradation of the cAMP responsive CREB-regulated transcription coactivator 2 (76). HuCOP1 has also been shown to play a role in the degradation of the c-Jun protein $(17,18,29,30)$. Our array identified two other functional components of the activator protein-1 (AP-1) transcription factor complex: JUNB and JUND. HuCOP1 might regulate these two genes through an as yet unidentified mechanism. On the basis of these data, we hypothesize that huCOP1 might contribute to the regulation of the AP-1 transcription complex at different levels: by altering the expression of the JUNB and JUND genes and by promoting the degradation of c-Jun via its E3 ubiquitin ligase activity. Such functional interactions were suggested as early as 2003, when Bianchi and co-workers identified huCOP1 as the human ortholog of AtCOP1 and performed the primary functional characterization of the gene and its protein product (17). Subsequently, Migliorini et al. demonstrated the direct c-Jun-COP1 interaction. AP-1-related transcription factors have long been implicated in tumourigenesis; therefore, the putative role of huCOP1 in the pathogenesis of human cancers emerged early $(17,29)$.

Our results and the data available in the literature indicate that decreased huCOP1 levels sensitize the cells to UVB damage or oxidative stress and modify the UVB-induced 
stress response of keratinocytes. The loss of some members in the identified network increases the sensitivity of the cells to UVB. Maeda et al., for example, demonstrated that GADD45A-/- keratinocytes are more sensitive to UVB than GADD45A+/+ cells due to reduced DNA repair and lack of G2/M arrest (77). It is also well known that the symptoms of systemic lupus erythematosus are exacerbated by sun exposure. Pflegerl et al. reported that challenging $\mathrm{JUNB}^{\mathrm{ep}}$ mice (mice with epidermal loss of JunB) with UVB irradiation enhanced the severity of their lupus-like lesions (78). It has also been published that DAXX-depleted fibroblasts are resistant to UVB- and oxidative-stressinduced cell death (79). Presumably, the absence of certain members of the huCOP1mediated transcriptional cascade leads to an abnormal UVB response.

The expression of huCOP1 is altered in non-melanoma skin cancers and several members of the identified regulatory network have been implicated in the pathogenesis of these skin diseases (80-84). Thus, huCOP1 emerges as a potential target molecule for the treatment of BCC and/or SCC.

The devices based on atmospheric pressure gas discharge plasmas are good candidates for future medical tools. Physical plasma is a mixture of ions, electrons, radicals (ROS and RNS), electric and magnetic fields and UV radiation (36). Lowtemperature gas discharge plasmas can have a huge potential in dermatological application based on their unique mixture of reactive components sparking both stimulatory as well as inhibitory processes (38-40). During the therapeutic application, the treatment of chronic wounds by gas discharge plasmas may have selective antimicrobial or antiseptic effect without damaging the surrounding tissue, while stimulating the tissue regeneration (49-52). It has been shown that cold atmospheric plasma (CAP) entails no risk on humans in terms of temperature increase, UV radiation or by free radical formation by the gas discharge plasma, while can considerably decrease the bacterial load of the skin (41). Initial studies have been conducted aiming to model the wound healing process, e.g. the penetration of gas discharge plasma or plasma generated species into the wound mimicking model surfaces $(43,44)$. However, the mechanisms of gas discharge plasma interaction with living tissues and cells are very complex, therefore further studies are needed to clarify the physical and biological mechanisms.

The plasma needle which is a gas discharge plasma source with a non-thermal atmospheric glow discharge ignited at the tip of a needle (56), is a suitable device for studying biomedical applications (57-60). Since plasma needle insures the sample to be in 
direct contact with the active discharge plasma - in contrast with the atmospheric plasma jets where only afterglow species reach the sample - it is a suitable device to study the effect of the active plasma on the wound healing process (53).

In the wound healing process the major contributors are the keratinocytes, which migrate to fill in the gap created by the wound. Therefore, we performed the direct treatment of HPV-immortalized human keratinocytes with the glow discharge generated in flowing helium by a plasma needle. The cells protected by a layer of phosphate buffered saline (PBS) solution were directly treated with the plasma needle. We conducted two types of experiments: (i) cell proliferation and (ii) wound-healing model experiments.

In order to choose the optimal plasma needle configuration, the plasma treatment conditions and the thickness of the protecting PBS layer, viability experiments were carried out. We found that the minimum PBS layer necessary to protect the cells during treatment depended on the wells' dimensions, namely, in larger wells thinner layer appeared to be sufficient to protect the cells. This shows the difficulty of scaling the treatment conditions.

The proliferation studies showed that short (5-10 s) and low power (18 W and $20 \mathrm{~W}$ input power treatments) could positively influence cell proliferation when keratinocytes were protected by PBS. We also found that the cells treated in cell medium were more affected than those treated in PBS (i.e. cell proliferation decreased), which shows that the plasma induced liquid chemistry - i.e. the created active species, which interact with the cells - in the two liquid mediums were different. Therefore we concluded that the choice of the interaction medium is very important when setting the treatment conditions.

To study the effect of the plasma needle on keratinocytes related to the wound healing process, we modelled it by an in vitro scratch assay. Monitoring the reduction of the scratch width after gas discharge plasma treatment for $48 \mathrm{~h}$, we found that there was a maximum in the wound reduction as a function of the input power and treatment time, namely, at $18 \mathrm{~W}$ and $5 \mathrm{~s}$. Nevertheless, favourable conditions were also found in the case of $18 \mathrm{~W}$ and $20 \mathrm{~W}$ input powers and 5-25 s long treatments. We also found that the wound reduction strongly depended on the treated cell - PBS interaction time. The effect of the treated cell - medium interaction time on the cells viability has been also observed by Wende et al (53).

In the case of the proliferation experiments conducted in the 96-well plates, as described, the cells were in contact with the full plasma spot, thus the cell culture was 
exposed to the whole radial electric field distribution of the plasma in contrast with the scratch assay experiments, where only the wings of the field distribution were in contact with the cells. Therefore, the differences in the two types of experiments may be attributed to the field effect. In what concerns the chemical change of the treated PBS, we did not observe any change in the PH level.

In order to mimic the natural microbial environment of human keratinocytes, they were cocultivated with the most common commensal bacteria of the skin, the Propionibacterium acnes (P.acnes) Gram-positive bacterium. The gas discharge plasma treatment of this assay resulted in closing of the scratch, while in the non-treated assay the wound did not close at all. Similar effect has been observed in case of treatment of Staphylococcus epidermidis infected HaCaT cells with an argon high-frequency driven atmospheric-pressure plasma jet treatment (53).

The results overall suggest, that for the activation of the healing process a minor stress induction of keratinocytes is sufficient, and the treatment medium should be carefully chosen. 


\section{SUMMARY}

COP1 (constitutive photomorphogenic protein 1) was described in the plant Arabidopsis thaliana, as an essential negative regulator of light-mediated plant development. COP1 also exists in non-plant multicellular organisms, although its function is less understood. The huCOP1 shows a high degree of sequence conservation and similar domain organization with AtCOP1, suggesting the possibility of a functional conservation as well. The huCOP1, like its plant counterpart, is involved in ubiquitination and is itself a substrate of its own ubiquitination activity. UVB light is the most prominent genotoxic stress for keratinocytes. Its effect on COP1 expression in human keratinocytes has not been investigated previously in details. Our experiments revealed, that huCOP1 contributes to the transcriptional regulation of the keratinocyte UVB response by the down-regulation of an UVB inducible network operating through three newly identified central organizers. This network is under the control of upstream regulators also showing UVB response. We hypothesize that huCOP1 operates as a negative factor of the identified transcriptional network by modifying the function of the upstream regulators. Mechanism underlying the UVB-induced cellular events may include a re-distribution of huCOP1 to different molecular complexes. Such a mechanism has recently been demonstrated for Arabidopsis. The expression of huCOP1 is altered in non-melanoma skin cancers and several members of the identified regulatory network have been implicated in the pathogenesis of these skin diseases. Thus, huCOP1 emerges as a potential target molecule for the treatment of BCC and/or SCC. COP1 possibly acts both as an oncogene and as a tumour suppressor.

Atmospheric pressure gas discharge plasmas are promising candidates for new therapeutic tools. In the present study we could verify the influence of a non-thermal atmospheric pressure plasma on the wound healing process. In this process the major contributors are the keratinocytes, which migrate to fill in the gap created by the wound. Therefore, we performed the direct treatment of HPV-immortalized human keratinocytes, protected by a layer of phosphate buffered saline (PBS) solution, with the glow discharge generated in flowing helium by a plasma needle. Our results revealed that plasma could positively influence cell proliferation when keratinocytes were protected by PBS. On the other hand, the plasma treatment of cell medium covered keratinocytes resulted in the 
decrease of proliferation. The wound-healing model studies showed that there was a maximum in the wound reduction as a function of the input power and treatment time, namely, at $18 \mathrm{~W}$ and $5 \mathrm{~s}$. Furthermore, the wound reduction strongly depended on the treated cell - PBS interaction time. To mimic the natural microbial environment of human keratinocytes, they were cocultivated with the most common commensal bacteria of the skin, the Propionibacterium acnes (P.acnes) Gram-positive bacterium. The gas discharge plasma treatment of this infected assay resulted in closing of the scratch, while in the nontreated assay the wound did not close at all. The results overall suggest, that for activation of the healing process a minor stress induction of keratinocytes is sufficient, and the treatment medium should be carefully chosen. 


\section{ACKNOWLEDGEMENT}

I would like to thank to Prof Dr Lajos Kemény for the opportunity to participate in their Ph.D. program and to perform these studies in the laboratory of the Department of Dermatology and Allergology, University of Szeged.

I would like to express my deepest and sincere gratitude to my mentors and advisors Prof Dr Márta Széll at the Department of Medical Genetics, MTA-SZTE Dermatological Research Group, University of Szeged and Dr Éva Ádám at the Institute of Plant Biology, Biological Research Centre of the Hungarian Academy of Sciences for their supervision of this work and for their constant support and advice. I admire their broad knowledge of science, their way of analyzing scientific problems, and their ability to come up with exciting new ideas. I am most grateful for their patient guidance and inspiration during my Ph.D. studies.

It also gives me great pleasure to acknowledge the support and help of Prof Dr Ferenc Nagy and Dr Michael P Carty for their excellent suggestions and invaluable advice.

I would like to thank Dr Kinga Kutasi and Dr Ihor Korolov for the opportunity to look inside the magic of plasma physics.

I am grateful to my colleagues Gábor Tax, Dr Attila Bebes, Katalin Farkas, Hilda Polyánka and Anikó Göblös for introducing me to all the research techniques and for their caring support during my first steps in the laboratory of Department of Dermatology and Allergology, University of Szeged. I owe warm thanks to all of my colleagues for their help in the preparative work and for having had the opportunity to work with them.

This work was supported by the TÁMOP-4.2.2/B-10/1-2010-0012 and TÁMOP4.2.2.A11/1/KONV-2012-0035 Grants.

I am also very grateful to all members of my family who helped me with their endless love, support and encouragement. 


\section{REFERENCES}

1. Li, D., Turi, T. G., Schuck, A., Freedberg, I. M., Khitrov, G., and Blumenberg, M. (2001) Rays and arrays: the transcriptional program in the response of human epidermal keratinocytes to UVB illumination. FASEB journal : official publication of the Federation of American Societies for Experimental Biology 15, 2533-2535

2. Pisarchik, A., Wortsman, J., and Slominski, A. (2004) A novel microarray to evaluate stress-related genes in skin: effect of ultraviolet light radiation. Gene 341, 199-207

3. Enk, C. D., Jacob-Hirsch, J., Gal, H., Verbovetski, I., Amariglio, N., Mevorach, D., Ingber, A., Givol, D., Rechavi, G., and Hochberg, M. (2006) The UVBinduced gene expression profile of human epidermis in vivo is different from that of cultured keratinocytes. Oncogene 25, 2601-2614

4. Takao, J., Ariizumi, K., Dougherty, II, and Cruz, P. D., Jr. (2002) Genomic scale analysis of the human keratinocyte response to broad-band ultraviolet-B irradiation. Photodermatology, photoimmunology \& photomedicine 18, 5-13

5. Yi, C., and Deng, X. W. (2005) COP1 - from plant photomorphogenesis to mammalian tumorigenesis. Trends in cell biology 15, 618-625

6. Deng, X. W., Caspar, T., and Quail, P. H. (1991) cop1: a regulatory locus involved in light-controlled development and gene expression in Arabidopsis. Genes \& development 5, 1172-1182

7. Lau, O. S., and Deng, X. W. (2012) The photomorphogenic repressors COP1 and DET1: 20 years later. Trends in plant science 17, 584-593

8. Torii, K. U., McNellis, T. W., and Deng, X. W. (1998) Functional dissection of Arabidopsis COP1 reveals specific roles of its three structural modules in light control of seedling development. The EMBO journal 17, 5577-5587

9. Holm, M., and Deng, X. W. (1999) Structural organization and interactions of COP1, a light-regulated developmental switch. Plant molecular biology 41, 151158

10. Osterlund, M. T., Hardtke, C. S., Wei, N., and Deng, X. W. (2000) Targeted destabilization of HY5 during light-regulated development of Arabidopsis. Nature 405, 462-466

11. Liu, L. J., Zhang, Y. C., Li, Q. H., Sang, Y., Mao, J., Lian, H. L., Wang, L., and Yang, H. Q. (2008) COP1-mediated ubiquitination of CONSTANS is implicated in cryptochrome regulation of flowering in Arabidopsis. The Plant cell 20, 292306

12. Jang, S., Marchal, V., Panigrahi, K. C., Wenkel, S., Soppe, W., Deng, X. W., Valverde, F., and Coupland, G. (2008) Arabidopsis COP1 shapes the temporal pattern of $\mathrm{CO}$ accumulation conferring a photoperiodic flowering response. The EMBO journal 27, 1277-1288

13. Imaizumi, T., and Kay, S. A. (2006) Photoperiodic control of flowering: not only by coincidence. Trends in plant science 11, 550-558

14. Yu, J. W., Rubio, V., Lee, N. Y., Bai, S., Lee, S. Y., Kim, S. S., Liu, L., Zhang, Y., Irigoyen, M. L., Sullivan, J. A., Zhang, Y., Lee, I., Xie, Q., Paek, N. C., and Deng, X. W. (2008) COP1 and ELF3 control circadian function and photoperiodic flowering by regulating GI stability. Molecular cell 32, 617-630

15. Wang, H., Kang, D., Deng, X. W., and Wei, N. (1999) Evidence for functional conservation of a mammalian homologue of the light-responsive plant protein COP1. Current biology : CB 9, 711-714 
16. Yi, C., Wang, H., Wei, N., and Deng, X. W. (2002) An initial biochemical and cell biological characterization of the mammalian homologue of a central plant developmental switch, COP1. BMC cell biology 3, 30

17. Bianchi, E., Denti, S., Catena, R., Rossetti, G., Polo, S., Gasparian, S., Putignano, S., Rogge, L., and Pardi, R. (2003) Characterization of human constitutive photomorphogenesis protein 1 , a RING finger ubiquitin ligase that interacts with Jun transcription factors and modulates their transcriptional activity. The Journal of biological chemistry 278, 19682-19690

18. Marine, J. C. (2012) Spotlight on the role of COP1 in tumorigenesis. Nature reviews. Cancer 12, 455-464

19. Suzuki, G., Yanagawa, Y., Kwok, S. F., Matsui, M., and Deng, X. W. (2002) Arabidopsis COP10 is a ubiquitin-conjugating enzyme variant that acts together with COP1 and the COP9 signalosome in repressing photomorphogenesis. Genes \& development 16, 554-559

20. Yanagawa, Y., Sullivan, J. A., Komatsu, S., Gusmaroli, G., Suzuki, G., Yin, J., Ishibashi, T., Saijo, Y., Rubio, V., Kimura, S., Wang, J., and Deng, X. W. (2004) Arabidopsis COP10 forms a complex with DDB1 and DET1 in vivo and enhances the activity of ubiquitin conjugating enzymes. Genes \& development 18, 21722181

21. Wertz, I. E., O'Rourke, K. M., Zhang, Z., Dornan, D., Arnott, D., Deshaies, R. J., and Dixit, V. M. (2004) Human De-etiolated-1 regulates c-Jun by assembling a CUL4A ubiquitin ligase. Science 303, 1371-1374

22. Shiyanov, P., Nag, A., and Raychaudhuri, P. (1999) Cullin 4A associates with the UV-damaged DNA-binding protein DDB. The Journal of biological chemistry 274, 35309-35312

23. Groisman, R., Polanowska, J., Kuraoka, I., Sawada, J., Saijo, M., Drapkin, R., Kisselev, A. F., Tanaka, K., and Nakatani, Y. (2003) The ubiquitin ligase activity in the DDB2 and CSA complexes is differentially regulated by the COP9 signalosome in response to DNA damage. Cell 113, 357-367

24. Kinyo, A., Kiss-Laszlo, Z., Hambalko, S., Bebes, A., Kiss, M., Szell, M., BataCsorgo, Z., Nagy, F., and Kemeny, L. (2010) COP1 contributes to UVB-induced signaling in human keratinocytes. The Journal of investigative dermatology 130, 541-545

25. Dornan, D., Wertz, I., Shimizu, H., Arnott, D., Frantz, G. D., Dowd, P., O'Rourke, K., Koeppen, H., and Dixit, V. M. (2004) The ubiquitin ligase COP1 is a critical negative regulator of p53. Nature 429, 86-92

26. Garmyn, M., Degreef, H., and Gilchrest, B. A. (1995) The effect of acute and chronic photodamage on gene expression in human keratinocytes. Dermatology 190, 305-308

27. Oravecz, A., Baumann, A., Mate, Z., Brzezinska, A., Molinier, J., Oakeley, E. J., Adam, E., Schafer, E., Nagy, F., and Ulm, R. (2006) CONSTITUTIVELY PHOTOMORPHOGENIC1 is required for the UV-B response in Arabidopsis. The Plant cell 18, 1975-1990

28. Huang, X., Ouyang, X., Yang, P., Lau, O. S., Chen, L., Wei, N., and Deng, X. W. (2013) Conversion from CUL4-based COP1-SPA E3 apparatus to UVR8-COP1SPA complexes underlies a distinct biochemical function of COP1 under UV-B. Proceedings of the National Academy of Sciences of the United States of America 110, 16669-16674

29. Migliorini, D., Bogaerts, S., Defever, D., Vyas, R., Denecker, G., Radaelli, E., Zwolinska, A., Depaepe, V., Hochepied, T., Skarnes, W. C., and Marine, J. C. 
(2011) Cop1 constitutively regulates c-Jun protein stability and functions as a tumor suppressor in mice. The Journal of clinical investigation 121, 1329-1343

30. Vitari, A. C., Leong, K. G., Newton, K., Yee, C., O'Rourke, K., Liu, J., Phu, L., Vij, R., Ferrando, R., Couto, S. S., Mohan, S., Pandita, A., Hongo, J. A., Arnott, D., Wertz, I. E., Gao, W. Q., French, D. M., and Dixit, V. M. (2011) COP1 is a tumour suppressor that causes degradation of ETS transcription factors. Nature 474, 403-406

31. Dornan, D., Shimizu, H., Mah, A., Dudhela, T., Eby, M., O'Rourke, K., Seshagiri, S., and Dixit, V. M. (2006) ATM engages autodegradation of the E3 ubiquitin ligase COP1 after DNA damage. Science 313, 1122-1126

32. Kato, J. Y., and Yoneda-Kato, N. (2009) Mammalian COP9 signalosome. Genes to cells : devoted to molecular \& cellular mechanisms 14, 1209-1225

33. Lee, M. H., Zhao, R., Phan, L., and Yeung, S. C. (2011) Roles of COP9 signalosome in cancer. Cell cycle 10, 3057-3066

34. Choi, H. H., Gully, C., Su, C. H., Velazquez-Torres, G., Chou, P. C., Tseng, C., Zhao, R., Phan, L., Shaiken, T., Chen, J., Yeung, S. C., and Lee, M. H. (2011) COP9 signalosome subunit 6 stabilizes COP1, which functions as an E3 ubiquitin ligase for 14-3-3sigma. Oncogene 30, 4791-4801

35. Fridman, G., Friedman, G., Gutsol, A., Shekhter, A. B., Vasilets, V. N., and Fridman, A. (2008) Applied plasma medicine. Plasma Process Polym 5, 503-533

36. Blackert, S., Haertel, B., Wende, K., von Woedtke, T., and Lindequist, U. (2013) Influence of non-thermal atmospheric pressure plasma on cellular structures and processes in human keratinocytes (HaCaT). Journal of dermatological science $\mathbf{7 0}$, $173-181$

37. von Woedtke, T., Metelmann, H. R., and Weltmann, K. D. (2014) Clinical Plasma Medicine: State and Perspectives of in Vivo Application of Cold Atmospheric Plasma. Contrib Plasm Phys 54, 104-117

38. Yonson, S., Coulombe, S., Leveille, V., and Leask, R. L. (2006) Cell treatment and surface functionalization using a miniature atmospheric pressure glow discharge plasma torch. J Phys D Appl Phys 39, 3508-3513

39. Fridman, G., Peddinghaus, M., Ayan, H., Fridman, A., Balasubramanian, M., Gutsol, A., Brooks, A., and Friedman, G. (2006) Blood coagulation and living tissue sterilization by floating-electrode dielectric barrier discharge in air. Plasma Chem Plasma P 26, 425-442

40. Stoffels, E. (2007) "Tissue processing" with atmospheric plasmas. Contrib Plasm Phys 47, 40-48

41. Boekema, B. K. H. L., Hofmann, S., van Ham, B. J. T., Bruggeman, P. J., and Middelkoop, E. (2013) Antibacterial plasma at safe levels for skin cells. J Phys D Appl Phys 46

42. Dobrynin, D., Fridman, A., and Starikovskiy, A. Y. (2012) Reactive Oxygen and Nitrogen Species Production and Delivery Into Liquid Media by Microsecond Thermal Spark-Discharge Plasma Jet. Ieee T Plasma Sci 40, 2163-2171

43. Orazov, M., Sakiyama, Y., and Graves, D. B. (2012) Wound healing modeling: investigating ambient gas plasma treatment efficacy. J Phys D Appl Phys $\mathbf{4 5}$

44. Babaeva, N. Y., and Kushner, M. J. (2013) Reactive fluxes delivered by dielectric barrier discharge filaments to slightly wounded skin. J Phys D Appl Phys $\mathbf{4 6}$

45. Stoffels, E., Sakiyama, Y., and Graves, D. B. (2008) Cold atmospheric plasma: Charged species and their interactions with cells and tissues. Ieee T Plasma Sci 36, 1441-1457 
46. Dobrynin, D., Fridman, G., Friedman, G., and Fridman, A. (2009) Physical and biological mechanisms of direct plasma interaction with living tissue. New J Phys 11

47. Graves, D. B. (2012) The emerging role of reactive oxygen and nitrogen species in redox biology and some implications for plasma applications to medicine and biology. J Phys D Appl Phys $\mathbf{4 5}$

48. Graves, D. B. (2014) Reactive Species from Cold Atmospheric Plasma: Implications for Cancer Therapy. Plasma Process Polym 11, 1120-1127

49. Arndt, S., Unger, P., Wacker, E., Shimizu, T., Heinlin, J., Li, Y. F., Thomas, H. M., Morfill, G. E., Zimmermann, J. L., Bosserhoff, A. K., and Karrer, S. (2013) Cold Atmospheric Plasma (CAP) Changes Gene Expression of Key Molecules of the Wound Healing Machinery and Improves Wound Healing In Vitro and In Vivo. PloS one 8

50. Park, C. H., Lee, J. S., Kim, J. H., Kim, D. K., Lee, O. J., Ju, H. W., Moon, B. M., Cho, J. H., Kim, M. H., Sun, P. P., Park, S. J., and Eden, J. G. (2014) Wound healing with nonthermal microplasma jets generated in arrays of hourglass microcavity devices. J Phys D Appl Phys $\mathbf{4 7}$

51. Nastuta, A. V., Topala, I., Grigoras, C., Pohoata, V., and Popa, G. (2011) Stimulation of wound healing by helium atmospheric pressure plasma treatment. $J$ Phys D Appl Phys 44

52. Isbary, G., Morfill, G., Schmidt, H. U., Georgi, M., Ramrath, K., Heinlin, J., Karrer, S., Landthaler, M., Shimizu, T., Steffes, B., Bunk, W., Monetti, R., Zimmermann, J. L., Pompl, R., and Stolz, W. (2010) A first prospective randomized controlled trial to decrease bacterial load using cold atmospheric argon plasma on chronic wounds in patients. Brit J Dermatol 163, 78-82

53. Wende, K., Landsberg, K., Lindequist, U., Weltmann, K. D., and von Woedtke, T. (2010) Distinctive Activity of a Nonthermal Atmospheric-Pressure Plasma Jet on Eukaryotic and Prokaryotic Cells in a Cocultivation Approach of Keratinocytes and Microorganisms. Ieee T Plasma Sci 38, 2479-2485

54. Schmidt, A., Wende, K., Bekeschus, S., Bundscherer, L., Barton, A., Ottmuller, K., Weltmann, K. D., and Masur, K. (2013) Non-thermal plasma treatment is associated with changes in transcriptome of human epithelial skin cells. Free Radical Res 47, 577-592

55. Arndt, S., Landthaler, M., Zimmermann, J. L., Unger, P., Wacker, E., Shimizu, T., Li, Y. F., Morfill, G. E., Bosserhoff, A. K., and Karrer, S. (2015) Effects of Cold Atmospheric Plasma (CAP) on beta-Defensins, Inflammatory Cytokines, and Apoptosis-Related Molecules in Keratinocytes In Vitro and In Vivo. PloS one $\mathbf{1 0}$

56. Stoffels, E., Flikweert, A. J., Stoffels, W. W., and Kroesen, G. M. W. (2002) Plasma needle: a non-destructive atmospheric plasma source for fine surface treatment of (bio)materials. Plasma Sources Sci T 11, 383-388

57. Stoffels, E., Kieft, I. E., and Sladek, R. E. J. (2003) Superficial treatment of mammalian cells using plasma needle. J Phys D Appl Phys 36, 2908-2913

58. Kieft, I. E., van der Laan, E. P., and Stoffels, E. (2004) Electrical and optical characterization of the plasma needle. New J Phys 6

59. Goree, J., Liu, B., Drake, D., and Stoffels, E. (2006) Killing of S-mutans bacteria using a plasma needle at atmospheric pressure. Ieee T Plasma Sci 34, 1317-1324

60. Miletic, M., Mojsilovic, S., Dordevic, I. O., Maletic, D., Puac, N., Lazovic, S., Malovic, G., Milenkovic, P., Petrovic, Z. L., and Bugarski, D. (2013) Effects of non-thermal atmospheric plasma on human periodontal ligament mesenchymal stem cells. J Phys D Appl Phys $\mathbf{4 6}$ 
61. Kieft, I. E., Kurdi, M., and Stoffels, E. (2006) Reattachment and apoptosis after plasma-needle treatment of cultured cells. Ieee T Plasma Sci 34, 1331-1336

62. Goree, J., Liu, B., and Drake, D. (2006) Gas flow dependence for plasma-needle disinfection of S-mutans bacteria. J Phys D Appl Phys 39, 3479-3486

63. Limame, R., Wouters, A., Pauwels, B., Fransen, E., Peeters, M., Lardon, F., De Wever, O., and Pauwels, P. (2012) Comparative analysis of dynamic cell viability, migration and invasion assessments by novel real-time technology and classic endpoint assays. PloS one 7, e46536

64. Livak, K. J., and Schmittgen, T. D. (2001) Analysis of relative gene expression data using real-time quantitative PCR and the 2(-Delta Delta C(T)) Method. Methods 25, 402-408

65. Malovic, G., Puac, N., Lazovic, S., and Petrovic, Z. (2010) Mass analysis of an atmospheric pressure plasma needle discharge. Plasma Sources Sci T 19

66. Matsuura, K., Kuratani, T., Gondo, T., Kamimura, A., and Inui, M. (2007) Promotion of skin epithelial cell migration and wound healing by a 2-benzazepine derivative. Eur J Pharmacol 563, 83-87

67. Fazekas, B., Polyanka, H., Bebes, A., Tax, G., Szabo, K., Farkas, K., Kinyo, A., Nagy, F., Kemeny, L., Szell, M., and Adam, E. (2014) UVB-dependent changes in the expression of fast-responding early genes is modulated by huCOP1 in keratinocytes. Journal of photochemistry and photobiology. B, Biology 140, 215222

68. Polyanka, H., Szabo, K., Tax, G., Goblos, A., Agnes, K., Tubak, V., Ujfaludi, Z., Boros, I., Bata-Csorgo, Z., Kemeny, L., and Szell, M. (2013) Characterization of UV-B induced cellular processes in a keratinocyte cell line (HPV-KER) immortalized with the HPV-E6 oncogene. Journal of Investigative Dermatology 133, S218-S218

69. Murakami, T., Fujimoto, M., Ohtsuki, M., and Nakagawa, H. (2001) Expression profiling of cancer-related genes in human keratinocytes following non-lethal ultraviolet B irradiation. Journal of dermatological science 27, 121-129

70. Simon, M. M., Aragane, Y., Schwarz, A., Luger, T. A., and Schwarz, T. (1994) UVB light induces nuclear factor kappa B (NF kappa B) activity independently from chromosomal DNA damage in cell-free cytosolic extracts. The Journal of investigative dermatology 102, 422-427

71. Zhou, M. J., Zheng, L., Guo, L., Liu, W. L., Lv, C., Jiang, L. H., Ou, C. S., and Ding, Z. H. (2012) Differential responses to UVB irradiation in human keratinocytes and epidermoid carcinoma cells. Biomedical and environmental sciences : BES 25, 583-589

72. Hernandez, J. M., Floyd, D. H., Weilbaecher, K. N., Green, P. L., and BorisLawrie, K. (2008) Multiple facets of junD gene expression are atypical among AP-1 family members. Oncogene 27, 4757-4767

73. Hazzalin, C. A., and Mahadevan, L. C. (2002) MAPK-regulated transcription: a continuously variable gene switch? Nature reviews. Molecular cell biology 3, 3040

74. Smith, M. L., Chen, I. T., Zhan, Q., Bae, I., Chen, C. Y., Gilmer, T. M., Kastan, M. B., O'Connor, P. M., and Fornace, A. J., Jr. (1994) Interaction of the p53regulated protein Gadd45 with proliferating cell nuclear antigen. Science 266, 1376-1380

75. Chen, C., Benjamin, M. S., Sun, X., Otto, K. B., Guo, P., Dong, X. Y., Bao, Y., Zhou, Z., Cheng, X., Simons, J. W., and Dong, J. T. (2006) KLF5 promotes cell proliferation and tumorigenesis through gene regulation and the TSU-Pr1 human 
bladder cancer cell line. International journal of cancer. Journal international du cancer 118, 1346-1355

76. Liu, Y., Dentin, R., Chen, D., Hedrick, S., Ravnskjaer, K., Schenk, S., Milne, J., Meyers, D. J., Cole, P., Yates, J., 3rd, Olefsky, J., Guarente, L., and Montminy, M. (2008) A fasting inducible switch modulates gluconeogenesis via activator/coactivator exchange. Nature 456, 269-273

77. Maeda, T., Hanna, A. N., Sim, A. B., Chua, P. P., Chong, M. T., and Tron, V. A. (2002) GADD45 regulates G2/M arrest, DNA repair, and cell death in keratinocytes following ultraviolet exposure. The Journal of investigative dermatology 119, 22-26

78. Pflegerl, P., Vesely, P., Hantusch, B., Schlederer, M., Zenz, R., Janig, E., Steiner, G., Meixner, A., Petzelbauer, P., Wolf, P., Soleiman, A., Egger, G., Moriggl, R., Kishimoto, T., Wagner, E. F., and Kenner, L. (2009) Epidermal loss of JunB leads to a SLE phenotype due to hyper IL-6 signaling. Proceedings of the National Academy of Sciences of the United States of America 106, 20423-20428

79. Khelifi, A. F., D'Alcontres, M. S., and Salomoni, P. (2005) Daxx is required for stress-induced cell death and JNK activation. Cell death and differentiation 12, 724-733

80. Kaporis, H. G., Guttman-Yassky, E., Lowes, M. A., Haider, A. S., FuentesDuculan, J., Darabi, K., Whynot-Ertelt, J., Khatcherian, A., Cardinale, I., Novitskaya, I., Krueger, J. G., and Carucci, J. A. (2007) Human basal cell carcinoma is associated with Foxp3+ $\mathrm{T}$ cells in a Th2 dominant microenvironment. The Journal of investigative dermatology 127, 2391-2398

81. Barrett, T. L., Smith, K. J., Hodge, J. J., Butler, R., Hall, F. W., and Skelton, H. G. (1997) Immunohistochemical nuclear staining for p53, PCNA, and Ki-67 in different histologic variants of basal cell carcinoma. Journal of the American Academy of Dermatology 37, 430-437

82. Haider, A. S., Peters, S. B., Kaporis, H., Cardinale, I., Fei, J., Ott, J., Blumenberg, M., Bowcock, A. M., Krueger, J. G., and Carucci, J. A. (2006) Genomic analysis defines a cancer-specific gene expression signature for human squamous cell carcinoma and distinguishes malignant hyperproliferation from benign hyperplasia. The Journal of investigative dermatology 126, 869-881

83. Jeon, G. A., Lee, J. S., Patel, V., Gutkind, J. S., Thorgeirsson, S. S., Kim, E. C., Chu, I. S., Amornphimoltham, P., and Park, M. H. (2004) Global gene expression profiles of human head and neck squamous carcinoma cell lines. International journal of cancer. Journal international du cancer 112, 249-258

84. Nemeth, I. B., Krenacs, T., Kiszner, G., Varga, E., Kinyo, A., Nagy, F., and Kemeny, L. (2010) Expression of human constitutive photomorphogenic protein-1 in melanocytic and non-melanocytic skin lesions. Journal of Investigative Dermatology 130, S54-S54 


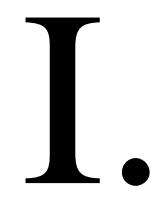




\title{
UVB-dependent changes in the expression of fast-responding early genes is modulated by huCOP1 in keratinocytes
}

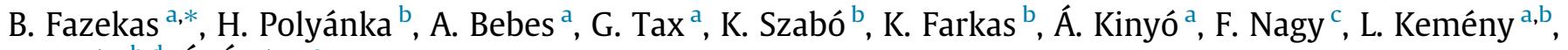 \\ M. Széll ${ }^{\text {b,d }}$,É. Ádám ${ }^{c}$ \\ a Department of Dermatology and Allergology, Faculty of Medicine, University of Szeged, Szeged, Hungary \\ ${ }^{\mathrm{b}}$ MTA-SZTE Dermatological Research Group, University of Szeged, Szeged, Hungary \\ 'Institute of Plant Biology, Biological Research Centre of the Hungarian Academy of Sciences, Szeged, Hungary \\ ${ }^{\mathrm{d}}$ Institute of Medical Genetics, Faculty of Medicine, University of Szeged, Szeged, Hungary
}

\section{A R T I C L E I N F O}

\section{Article history:}

Received 16 May 2014

Received in revised form 23 July 2014

Accepted 1 August 2014

Available online 9 August 2014

\section{Keywords:}

Constitutive photomorphogenic protein 1

Photobiology

UVB

Transcriptional regulation

Keratinocyte

\begin{abstract}
A B S T R A C T
Ultraviolet (UV) B is the most prominent physical carcinogen in the environment leading to the development of various skin cancers. We have previously demonstrated that the human ortholog of the Arabidopsis thaliana constitutive photomorphogenesis 1 (COP1) protein, huCOP1, is expressed in keratinocytes in a UVB-regulated manner and is a negative regulator of p53 as a posttranslational modifier. However, it was not known whether huCOP1 plays a role in mediating the UVB-induced early transcriptional responses of human keratinocytes. In this study, we report that stable siRNA-mediated silencing of huCOP1 affects the UVB response of several genes within $2 \mathrm{~h}$ of irradiation, indicating that altered huCOP1 expression sensitizes the cells toward UVB. Pathway analysis identified a molecular network in which 13 of the 30 examined UVB-regulated genes were organized around three central proteins. Since the expression of the investigated genes was upregulated by UVB in the siCOP1 cell line, we hypothesize that huCOP1 is a repressor of the identified pathway. Several members of the network have been implicated previously in the pathogenesis of non-melanoma skin cancers; therefore, clarifying the role of huCOP1 in these skin diseases may have clinical relevance in the future.
\end{abstract}

(c) 2014 Elsevier B.V. All rights reserved.

\section{Introduction}

Ultraviolet (UV) B light is one of the most important physical carcinogens in the environment, and the skin is the first and major barrier to protect the body from its harmful effects. At the molecular level, UVB causes DNA damage, transcriptional changes and apoptosis. Although epidermal keratinocytes, the main site of environmental UVB damage, provide a useful model system to study UVB-induced cellular responses, information on the molecular pathways mediating these processes is currently limited. UVB irradiation changes the expression of several genes in keratinocytes, including the p53 nuclear phosphoprotein [1-3]. This tumor suppressor functions as a transcription factor and has a central role in keratinocyte stress responses, including UV-induced responses [1-5]. The UVB-dependent molecular network in which p53 plays a pivotal role has not been revealed yet. One of the p53-interacting partners, the E3 ubiquitin ligase, COP1

\footnotetext{
* Corresponding author. Address: Department of Dermatology and Allergology, University of Szeged, Korányi fasor 6, H-6720 Szeged, Hungary. Tel.: +36 62 545278; fax: +3662545954 .

E-mail address: barbara.fazekas8@gmail.com (B. Fazekas).
}

(constitutive photomorphogenic 1), has been intensively studied in various organisms [6-11].

The COP1 protein was first identified as a central negative regulator of light-regulated development in Arabidopsis thaliana [12]. A. thaliana COP1 (AtCOP1) contains three conserved structural domains: a RING finger at the amino terminus mediating ligase activity, a coiled-coil domain in the middle mediating dimerization and seven WD40 repeat domains at the carboxyl-terminal end of the protein implicated in the binding of target proteins [13-15]. AtCOP1 functions as an E3 ubiquitin ligase targeting selected proteins for proteasomal degradation in plants [15]. Among its substrates are important transcription factors, such as the key regulators of photomorphogenesis under all light conditions, including UVB [16]. In contrast the negative regulation observed for visible-light responses, AtCOP1 is a critical positive regulator of responses to low levels of UVB. According to the latest data, UVB triggers the physical and functional disassociation of the AtCOP1-SPA core complex from CUL4-DDB1 and the formation of a new complex containing the UVB photoreceptor, UV Resistance Locus 8. This UVB-induced machinery is associated with the positive role of AtCOP1 in facilitating the stability and activity of key transcription factors [8]. 
Sequence analysis of COP1 orthologs from arabidopsis, human and mouse indicated that the COP1 domain structure is highly conserved in higher plants and vertebrates [16]. The mouse (MmCOP1) and human COP1 (huCOP1) sequences are located on chromosome 1 and the high degree of sequence conservation with AtCOP1 suggested functional conservation [12]. Both MmCOP1 and huCOP1 target bZIP transcription factors of the Jun family and p53 for degradation in a similar manner to AtCOP1 $[6,17]$. Lee et al. discovered that the constitutive photomorphogenesis 9 signalosome (CSN) plays a role in the control of DNA damage and carcinogenesis caused by UV light $[18,19]$. CSN components seem to act upstream of COP1 in mammalian cells stimulated by UV. Based on this observation, CSN components might act through huCOP1 in the negative regulation of important cancer genes, including p53, MDM2, P27, c-Jun, NFKB, SMAD7, RUNX3, ID1, SKP2 and HIFI $[18,19]$.

The function of huCOP1 has not yet been investigated in detail. We previously demonstrated that huCOP1 is expressed in keratinocytes in an UVB-regulated manner and is a negative regulator of p53 as a post-translational modifier [10]. The regulation of p53 by huCOP1 in keratinocytes is of particular importance, as this role suggests involvement in both cellular UV responses and carcinogenesis. MmCOP1 has also been shown to repress c-Jun mediated AP-1 transcription $[11,20]$.

The mechanisms by which the skin protects against UV damage have been investigated in detail. DNA arrays have been used to examine the UV-induced change in expression of 6800 genes in epidermal keratinocytes. Differential expression of 198 genes was detected in three waves occurring at $0.5-2 \mathrm{~h}, 4-8 \mathrm{~h}$ and $16-24 \mathrm{~h}$ after UV irradiation [1]. Although it is evident from the available data that huCOP1 and orthologs are posttranslational regulators of late UV responses in a wide range of organisms, it was not known how early huCOP1 acts on transcriptional responses. Based on these data and on the results obtained from a UVB-dependent transcriptome analysis performed with arabidopsis [21], we raised the question whether huCOP1 plays a role in early UVB-induced signaling processes that lead to transcriptional changes in keratinocytes.

In this study we report that stable siRNA-mediated silencing of huCOP1 sensitizes the keratinocyte cells toward UVB and affects the UVB response of several genes within $2 \mathrm{~h}$ of irradiation. Our results suggest that huCOP1 plays a role in modulating the early cellular UVB response at the transcriptional level in human keratinocytes.

\section{Materials and methods}

\subsection{Keratinocyte transformation}

HPV-immortalized human keratinocytes (HPV-KER clone II/15) were maintained as described [22]. Stable transformation of HPV-KER II/15 was performed at approximately $70 \%$ confluency in supplement-free medium with either the empty vector (pSuperior.puro vector) or a vector harboring huCOP1 silencing sequences [10]. Plasmid DNA for transfection was purified with the QIAGEN Plasmid Maxi Kit (QIAGEN, Hilden, Germany). Transfection was carried out with the X-tremeGENE 9 DNA Transfection Reagent (Roche Applied Science, Mannheim, Germany) and the Human Keratinocyte Nucleofector Kit (Lonza Cologne AG, Cologne, Germany) according to the manufacturer's instruction.

\subsection{Western blot analysis}

HuCOP1 protein was detected using previously described standard procedures [10] with the exception that anti-mouse IgG-HRP
(Dako Thermo Scientific Waban, MA, USA) was used as a secondary antibody at a dilution of 1:1000. Membranes were incubated overnight at $4{ }^{\circ} \mathrm{C}$ with purified rabbit polyclonal anti-huCOP1 antibody. After treating the membrane with the Immobilon Western Chemiluminescent HRP substrate (Merck Millipore Corporation, Billerica, MA, USA), luminescent signals were detected using a liquid-nitrogen-cooled charge-coupled-device camera (Micromax; Roper Scientific Canada).

\subsection{Cell viability measurements}

Keratinocytes were seeded in 96 -well plates at 10,000 cells per well. Growth of the cells was followed for 6 days. Cell viability of the established keratinocyte cell lines was measured with the xCELLigence RTCA System [39] following the manufacturer's instructions (Roche Applied Science, Mannheim, Germany). See Supplementary Methods online for details.

\subsection{Immunocytochemistry}

Unirradiated and UVB-irradiated control and siCOP1 cells were immunostained $24 \mathrm{~h}$ after UVB exposure. DNA was stained with 4,6-diamidino-2-phenylindole (DAPI). The primary antibody used for immunohistochemistry was rabbit polyclonal anti-huCOP1 (Bethyl Laboratories, Montgomery, USA). A Zeiss AxioImager fluorescent light microscope (Carl Zeiss MicroImaging, Thornwood, NY, USA) fitted with a PixeLINK CCD camera (PixeLINK, Ottawa, ON, Canada) was used for detection. The subsequent semiquantitative analysis was carried out using Metamorph software (Universal Imaging Corp., Sunnyvale, California, United States). See Supplementary Methods online for details.

\subsection{UVB irradiation}

For irradiation, the medium covering the keratinocytes was replaced with phosphate-buffered saline (PBS). In preliminary experiments, $10,20,40 \mathrm{~mJ} \mathrm{~cm}^{-2}$ UVB doses were used to determine the most appropriate dose for further studies. The $40 \mathrm{~mJ} \mathrm{~cm}^{-2}$ dose resulted in a decrease in cell viability, whereas the $20 \mathrm{~mJ} \mathrm{~cm}^{-2}$ did not affect cell viability (data not shown). It was also demonstrated that the $20 \mathrm{~mJ} \mathrm{~cm}^{-2}$ dose effected the expression of well known UVB-inducible genes (GOS2, JUNB, JUND, data not shown). Cells were irradiated with a $20 \mathrm{~mJ} \mathrm{~cm}^{-2}$ dose of 312 nm UVB [40] from an FS20 lamp (Westinghouse, Pittsburgh, PA). After UVB treatment, PBS was replaced with fresh medium. Control cells were subjected to the identical procedure without UVB treatment.

\subsection{Real-time RT-PCR array and validation experiments}

Real-time RT-PCR was performed with a custom-made StellARray $^{\mathrm{TM}}$ Gene Expression System (Bar Harbor BioTechnology, Trenton, ME) carrying 30 UVB-regulated genes. The validation realtime RT-PCR experiments were carried out with the Universal Probe Library system (F. Hoffmann-La Roche AG, Basel, Switzerland). Sequences of the primers used for PCR amplification of the FOS, JUND ZFP36 and SIK1 genes are listed in Table S1. The expression of each gene was normalized to the signal from the $18 \mathrm{~S}$ ribosomal RNA gene. Results are averages of three parallel experiments. The relative mRNA expression levels were calculated by the $\Delta \Delta C_{\mathrm{t}}$ method [41]. See Supplementary Methods online for details. 


\subsection{Pathway analysis}

Pathway analysis was performed using Ingenuity Pathway Analysis software (IPA, Ingenuity Systems, Stanford, USA). See Supplementary Methods online for details.

\section{Results}

\subsection{Characterization of siCOP1 keratinocyte cell lines}

To determine the role of huCOP1 in the early UVB response, we created keratinocyte cell lines in which the expression level of huCOP1 was stably decreased. For this purpose, we used an HPVimmortalized keratinocyte cell line in which the UVB response of p53 is intact: its UVB inducibility resembles that of normal human cultured keratinocytes. However, sequence analysis revealed that the p53 gene in this cell line harbors the codon 72 polymorphism of the protein (manuscript in preparation). G-banding analyses of the cell line revealed normal human karyogram (46, XX) [22]. Four cell lines harboring the empty vector and three cell lines carrying the huCOP1 silencing sequences were established. To select the most appropriate cell lines for further investigation, the degree of huCOP1 silencing and the proliferation of the cell lines were compared. Based on the results of these preliminary experiments (data not shown), two cell lines - control and siCOP1 - were selected. Semiquantitative analysis of chemiluminescent western blot experiments demonstrated that the expression of huCOP1 in the siCOP1 cell line was decreased by $70 \%$ compared to the control line (Fig. 1a and b). The silencing of huCOP1 did not affect cell proliferation (Fig. 2).

\subsection{UVB irradiation decreased huCOP1 protein abundance in transformed cell lines}

We previously reported that huCOP1 levels decrease in human keratinocytes after UVB irradiation [10]. To confirm that the stably transformed cell lines react similarly to UVB irradiation, we compared unirradiated and UVB-irradiated control and siCOP1 cells using the semiquantitative immunocytochemical approach to detect huCOP1 expression. The applied UVB $\left(20 \mathrm{~mJ} \mathrm{~cm}^{-2}\right)$ did not affect the viability or proliferation of the cells (data not shown). An approximately 50\% decrease in huCOP1 expression was detected in both cell lines $24 \mathrm{~h}$ after UVB irradiation (Fig. 3).

3.3. Array analysis of selected genes differentially expressed in early UVB response revealed a transcriptional regulatory role for huCOP1 in keratinocytes

To understand the role of huCOP1 in the UVB-induced early signaling processes of human keratinocytes, we performed an

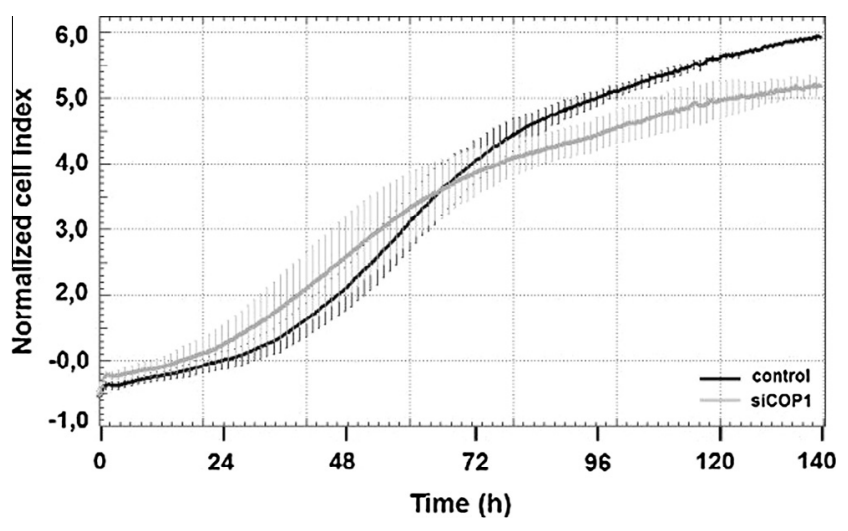

Fig. 2. Dynamic proliferation curves for siCOP1 and control cells. Cell viability of the established keratinocyte cell lines was measured with the xCELLigence RTCA System. Black line: control cells; gray line: siCOP1 cells.

expression profile analysis. For this purpose, the siCOP1 and control cell lines were evaluated using the StellARray ${ }^{\mathrm{TM}}$ Gene Expression System. Based on published data [1-3], we selected a set of genes showing a 2-4-fold change in gene expression within $2 \mathrm{~h}$ after UVB irradiation (14 up- and 16 down-regulated genes). The expression of the selected genes was compared in unirradiated and UVB-irradiated cells $2 \mathrm{~h}$ after treatment. Changes in gene expression in the control cells were in good agreement with published results for most genes. The decreased abundance of huCOP1 protein in the siCOP1 cells further modulated this UVB effect, resulting in an overall higher gene expression level. Expression of the genes was similar in unirradiated siCOP1 and control lines, indicating that the silencing of COP1 had no direct effect on the expression of these genes in the absence of UVB (Table 1).

To verify the array results, we performed real-time RT-PCR analyses of four genes, FBJ murine osteosarcoma viral oncogene homolog (FOS), JUND, zinc finger transcriptional regulator (ZFP36), and SIK1 (salt-inducible kinase 1) based on the robust UVB-induced changes in gene expression observed in the array experiment. The real-time RT-PCR assay of independent biological samples confirmed that the detected differential expression was a transcriptional consequence of huCOP1 silencing (Supplementary Fig. S1).

\subsection{A UVB regulatory network identified by pathway analysis was modified by huCOP1 expression}

Using the Ingenuity Pathway Analysis software (IPA, Ingenuity Systems, Stanford, USA), we identified a regulatory network of UVB-regulated genes in which 13 of the selected 30 genes

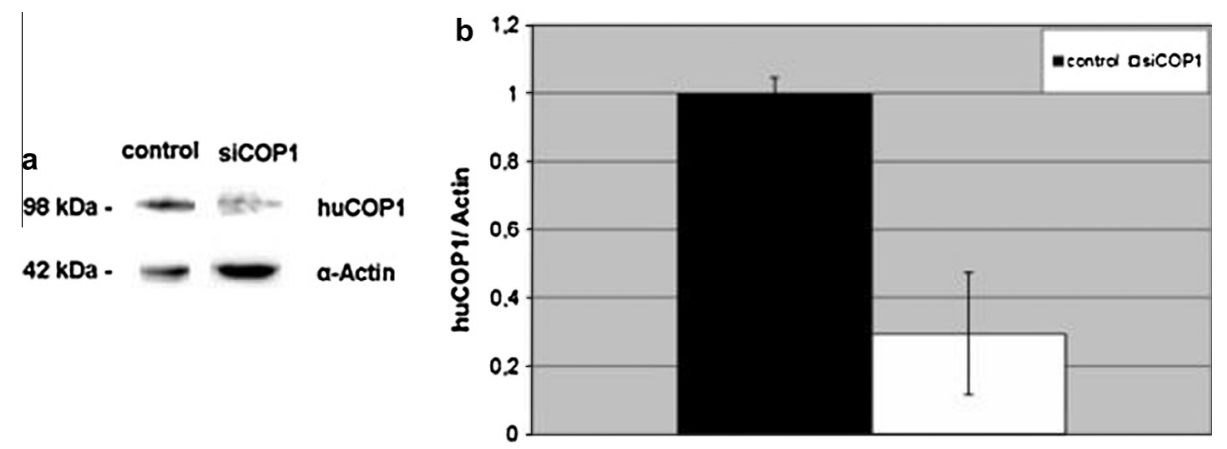

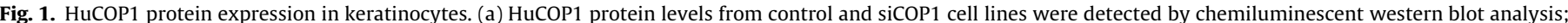

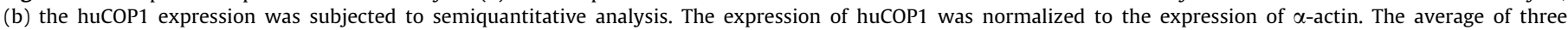
independent experiments is shown. 

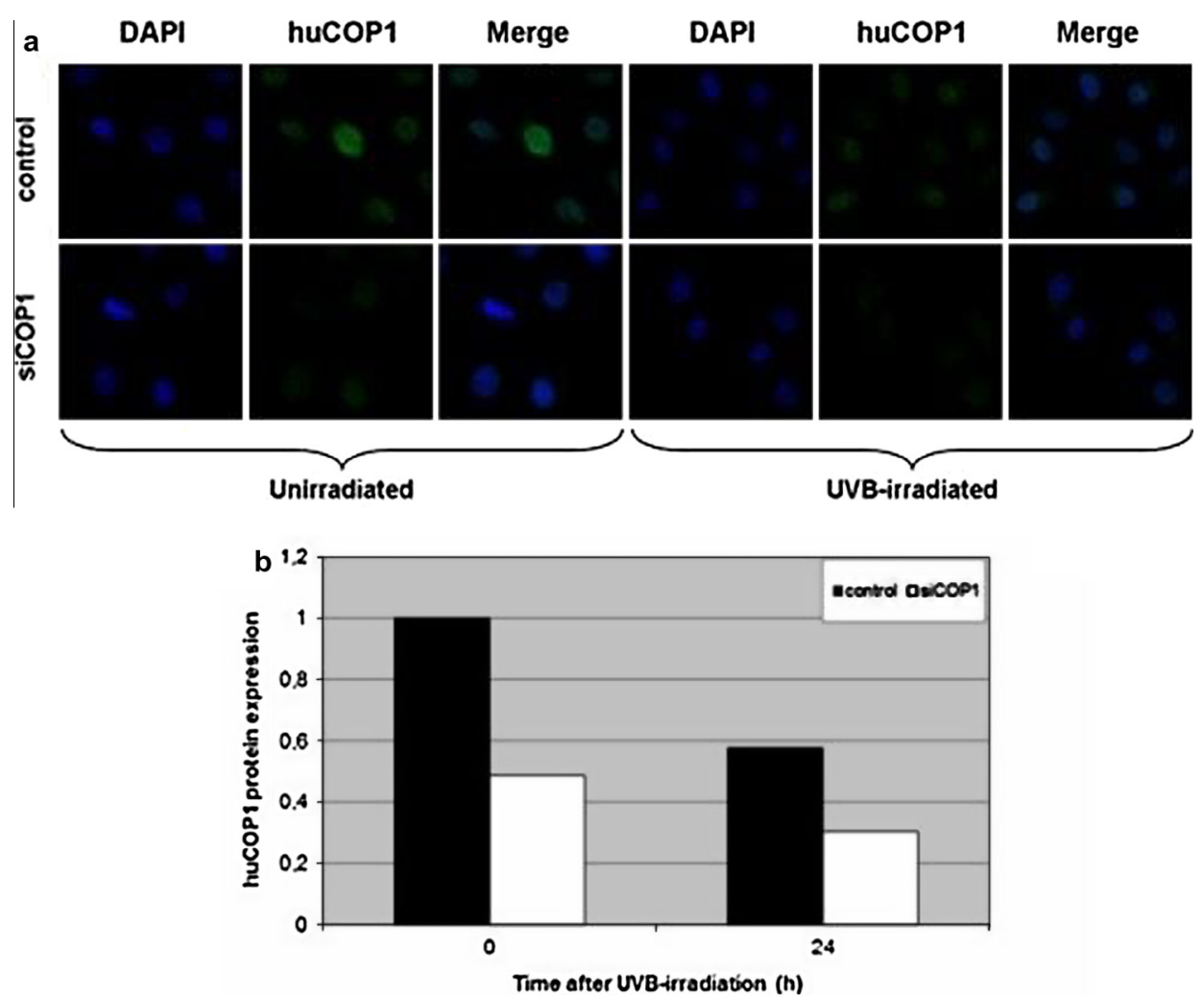

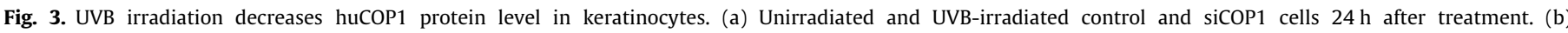

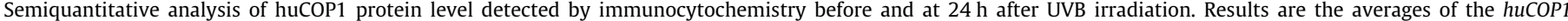
expression after UVB irradiation from 30 independent cells normalized to the control cell line.

Table 1

Changes in gene expression of unirradiated and UVB-irradiated control and siCOP1 keratinocytes.

\begin{tabular}{|c|c|c|c|c|c|c|c|c|}
\hline \multirow{2}{*}{$\begin{array}{l}\text { Gene symbol } \\
\text { Upregulated genes }\end{array}$} & \multirow[t]{2}{*}{ Entrez gene ID } & \multirow[t]{2}{*}{ Gene name } & \multicolumn{2}{|c|}{ Without UVB } & \multicolumn{2}{|c|}{ UVB irradiated change, fold } & \multicolumn{2}{|l|}{$p$-Values } \\
\hline & & & Control & siCOP1 & Control & siCOP1 & Control & siCOP1 \\
\hline FOS & 2353 & FBJ murine osteosarcoma viral oncogene homolog & 13,53 & 14,20 & 4,95 & 10,14 & 0,004 & 0,006 \\
\hline DUSP1 & 1843 & Dual specificity phosphatase 1 & 11,99 & 11,94 & 6,62 & 6,35 & 0,004 & 0,020 \\
\hline BTG2 & 7832 & Antiproliferative DNA damage response & 11,77 & 12,28 & 3,43 & 5,65 & 0,038 & 0,021 \\
\hline BTG1 & 694 & Antiproliferative DNA damage response & 16,13 & 16,45 & 2,27 & 3,35 & 0,047 & 0,084 \\
\hline ZFP36 & 7538 & Zinc finger transcriptional regulator & 14,02 & 14,33 & 2,39 & 4,15 & 0,050 & 0,073 \\
\hline JUNB & 3726 & Jun B proto-oncogene & 10,42 & 11,30 & 2,05 & 2,58 & 0,058 & NS \\
\hline JUND & 3727 & Jun D proto-oncogene & 10,54 & 11,32 & 1,85 & 4,92 & NS & NS \\
\hline GOS2 & 50,486 & G0/G1 switch gene & 10,38 & 10,52 & 1,56 & 2,68 & NS & NS \\
\hline GADD45A & 1647 & Growth arrest and DNA-damage-inducible & 12,10 & 11,28 & 2,39 & 2,19 & NS & NS \\
\hline ID3 & 3399 & HLH1R21 helix-loop-helix protein & 12,63 & 13,08 & 1,41 & 1,91 & NS & NS \\
\hline NOS1 & 4842 & Neuronal nitric oxide synthase & 19,78 & 19,51 & 1,23 & 1,65 & NS & NS \\
\hline SERPINA1 & 5265 & Serine (or cysteine) proteinase inhibitor A1 & 12,65 & 11,75 & 1,10 & 1,60 & NS & NS \\
\hline IFI27 & 3429 & IFN-inducible & 18,14 & 18,41 & 1,04 & 2,14 & NS & NS \\
\hline TAF10 & 6881 & Transcription factor taflI30 & 10,78 & 10,70 & 1,08 & 1,58 & NS & NS \\
\hline \multicolumn{9}{|c|}{ Downregulated genes } \\
\hline SIK1 & 150,094 & SWI/SWF complex 170 kDa subunit (BAF170) & 12,17 & 12,54 & $-2,59$ & $-1,48$ & 0,019 & 0,055 \\
\hline PDLIM5 & 10,611 & LIM domain & 11,33 & 12,13 & $-1,98$ & 1,04 & 0,043 & NS \\
\hline KLF5 & 688 & GC box binding protein BTEB2 & 9,92 & 11,00 & $-1,96$ & 1,40 & 0,057 & NS \\
\hline SRF & 6722 & Serum response factor & 12,99 & 13,37 & $-1,75$ & $-1,10$ & NS & 0,061 \\
\hline MLL & 4297 & Translocation $\mathrm{T}(4: 11)$ of ALL- 1 gene to chr, 4 & 13,50 & 13,56 & $-1,75$ & $-1,20$ & NS & NS \\
\hline FKBP5 & 2289 & Progesteron receptor-associated FJBP54 & 11,28 & 11,40 & $-1,67$ & 1,08 & NS & NS \\
\hline CSNK2A1 & 1457 & Casein kinase II A & 11,13 & 10,82 & $-1,58$ & 1,07 & NS & NS \\
\hline CSNK1A1 & 1452 & Casein kinase $1 \mathrm{~A}$ & 11,31 & 11,16 & $-1,52$ & 1,05 & NS & NS \\
\hline METAP2 & 10,988 & Methionine aminopeptidase, translation inhibitor & 10,57 & 10,50 & $-1,48$ & 1,22 & NS & NS \\
\hline HES1 & 3280 & Transcription factor HRY & 10,21 & 10,70 & $-1,09$ & 1,67 & NS & NS \\
\hline PPARG & 5468 & PPAR gamma & 14,31 & 13,80 & $-1,21$ & 1,47 & NS & NS \\
\hline PKMYT1 & 9088 & Myt1 kinase (preferentially phosphorylates Cdc2) & 14,48 & 14,36 & $-1,13$ & 1,44 & NS & NS \\
\hline DAXX & 1616 & FAS binding protein & 12,54 & 12,67 & $-1,26$ & 1,51 & NS & NS \\
\hline $\mathrm{H} 2 \mathrm{AFZ}$ & 3015 & Histone & 8,36 & 8,03 & $-1,07$ & 1,70 & NS & NS \\
\hline PCNA & 5111 & Proliferating cell nuclear antigen & 9,23 & 9,49 & $-1,15$ & 1,89 & NS & NS \\
\hline ARF6 & 382 & ADP ribosylation factor 6 GTP binding & 10,64 & 10,23 & $-1,20$ & 1,12 & NS & NS \\
\hline
\end{tabular}


$\mathbf{a}$
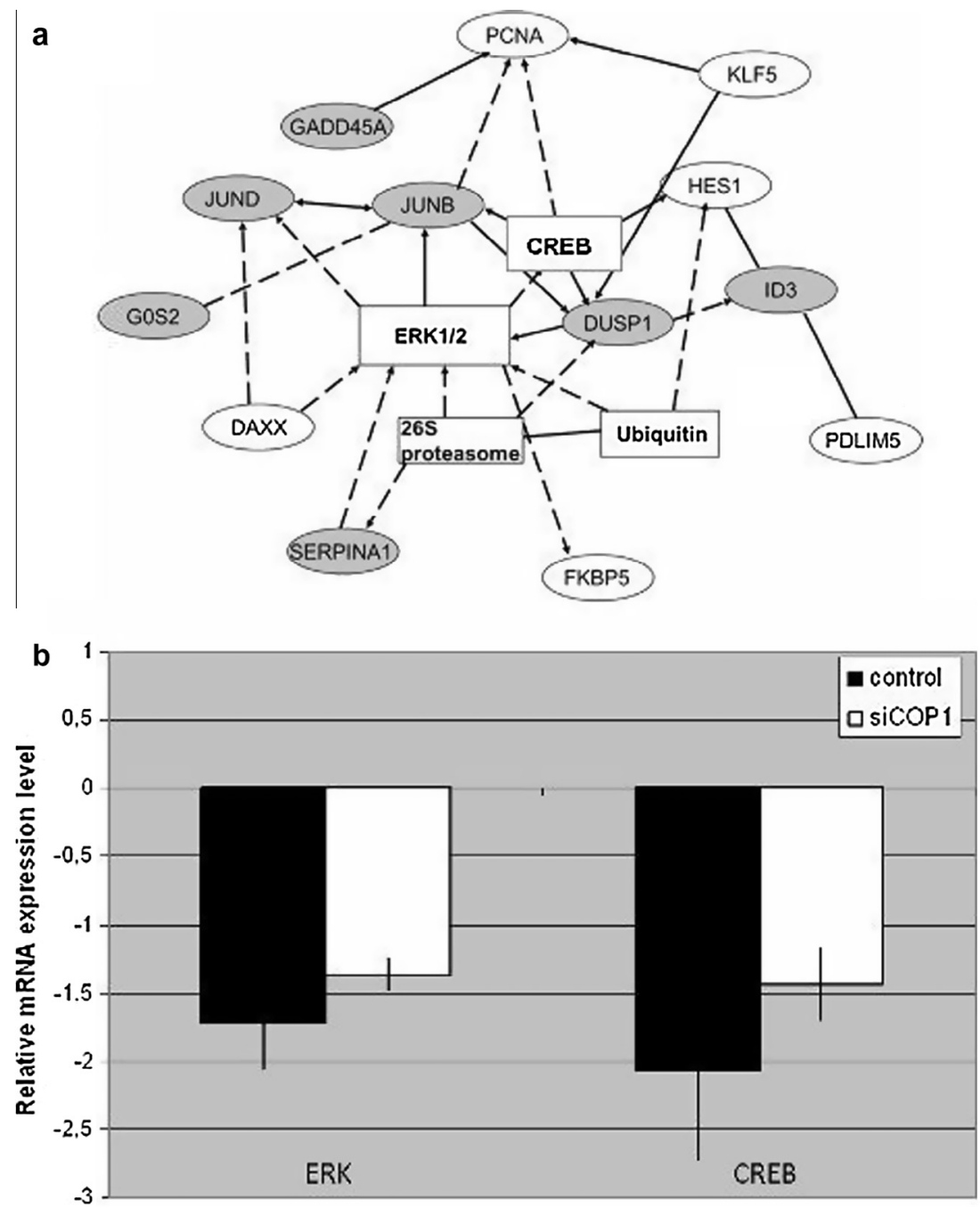

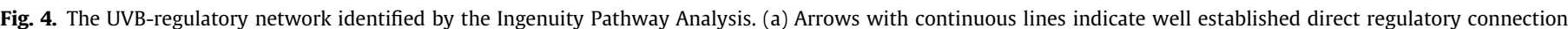

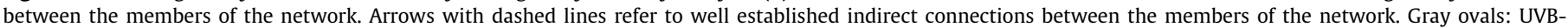

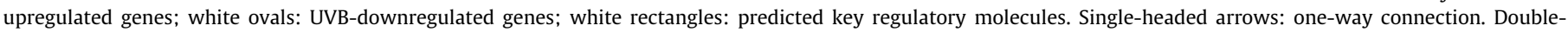

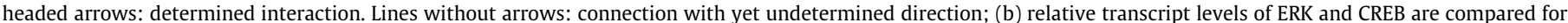

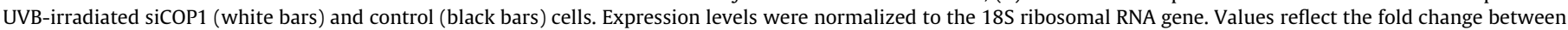

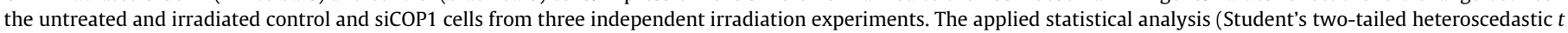
test) did not reveal significant difference in UVB-induced gene expression between the control and siCOP1 cells, however the tendency is clearly demonstrated.

participated (Fig. 4a). Mitogen-activated protein kinase (ERK1/2), cAMP responsive element binding protein (CREB) and ubiquitin (not included in the array experiment) were identified as central organizers of this network. Expression of all 13 selected genes increased after UVB irradiation in the siCOP1 cell line, indicating that huCOP1 modulates the expression of these genes. To clarify whether the gene expression of ERK $1 / 2$ and CREB is UVB-regulated, we carried out real-time RT-PCR experiments. UVB irradiation reduced the mRNA level of the central organizers in the control cell line and this affect was moderated by huCOP1 silencing (Fig. 4b).

The pathway analysis also revealed the following upstream regulators of the identified network: epidermal growth factor (EGF), nerve growth factor, fibroblast growth factor 2, interferon gamma, interleukin-1 beta, interleukin 6 cytokines and nuclear factor of kappa beta (NFKB) (Fig. 5a). According to the analysis, these regulators are in an activated state to trigger the UVB response through the identified network but the relationships among the upstream regulators were not assessed. We choose three upstream regulator molecules (IL1B, IL6 and NFKB) to test whether the corresponding genes exhibit UVB-induced changes in expression. In agreement with published data $[2,4,23]$, our results demonstrated that the transcription of these genes is UVB sensitive and that huCOP1 silencing had an effect on their transcription levels after UVB irradiation (Fig. 5b).

\section{Discussion}

UVB light is undoubtedly the most important carcinogenic environmental stressor of human skin, and UV-induced changes in keratinocytes have been widely studied $[3,24]$. HuCOP1 has been implicated in the negative regulation of important cancer-related genes acting in the cellular response to UVB $[11,25]$. Nevertheless, the possible role of huCOP1 in the keratinocyte UVB response has not yet been investigated in detail.

To address these issues we produced transgenic cell lines in which the expression of huCOP1 was stably silenced (siCOP1). For this purpose, we used an HPV-immortalized keratinocyte cell line carrying the codon 72 polymorphism of the p53 gene, a well-known and common polymorphism with yet unconfirmed significance in cancer risk. Since this cell line exhibited a normal 

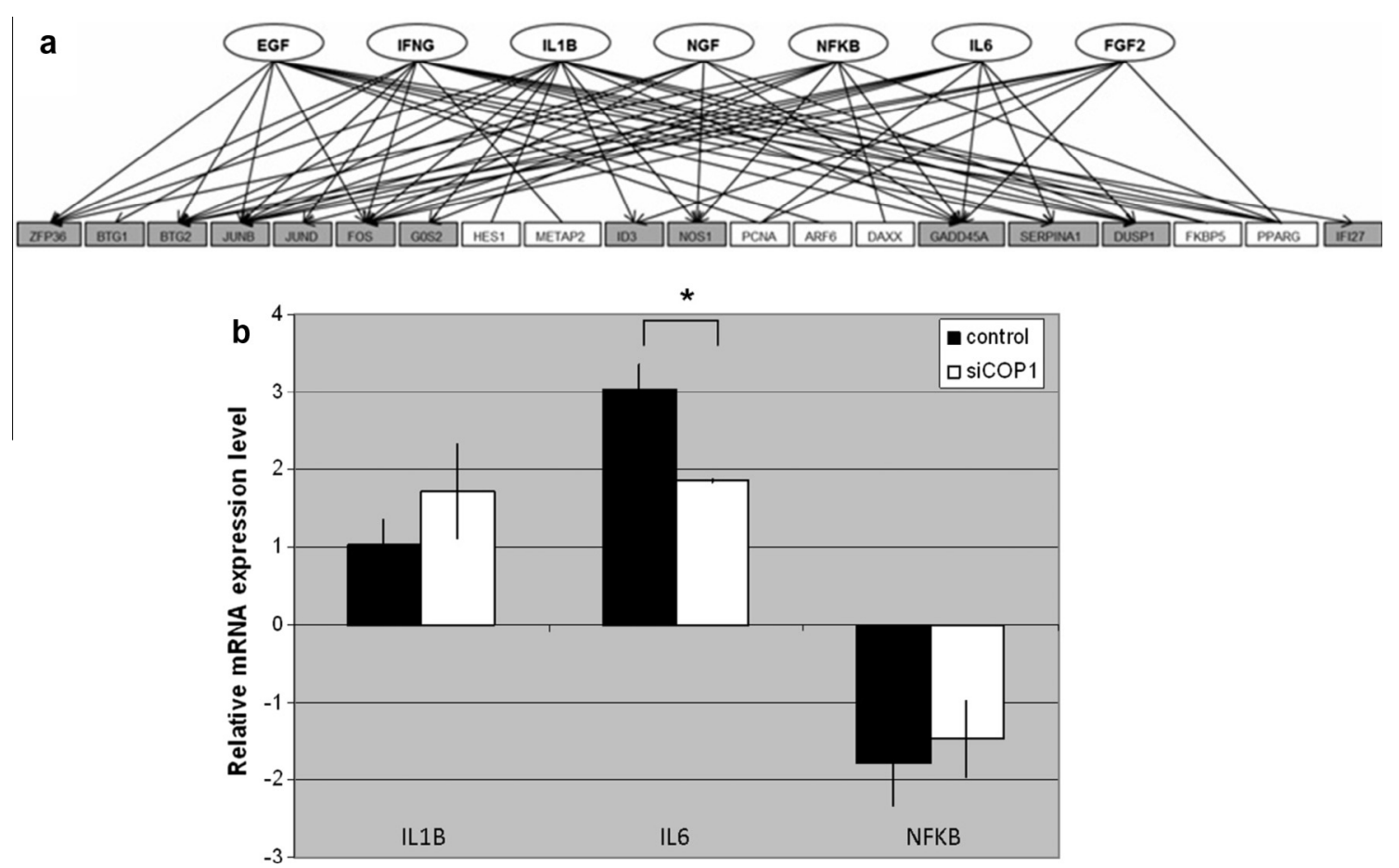

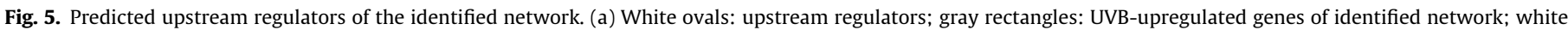

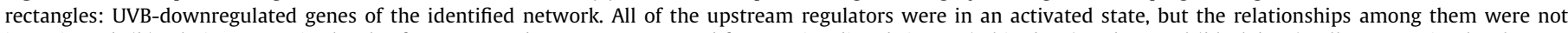

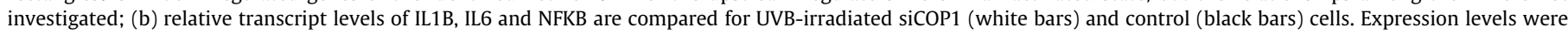

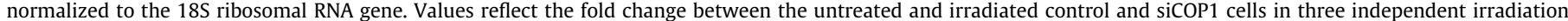

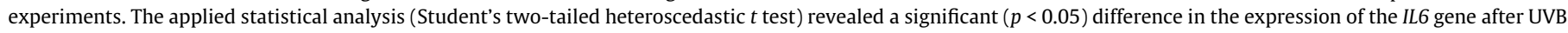
irradiation of control and siCOP1 cells and demonstrated a non-significant but tendencious difference in the case of IL1B and NFKB gene expression.

p53 UVB response, we considered it suitable for our purposes. After establishing the huCOP1 silenced transgenic keratinocyte cell line, we examined the expression of selected UVB-regulated genes with or without UVB irradiation. Our experiments revealed that (i) the silencing of huCOP1 did not affect cell viability, (ii) the expression level of the selected genes was not affected by huCOP1 silencing in unirradiated cells, and (iii) DNA array and validating real-time RTPCR experiments confirmed that transcript levels of the selected genes exhibited changes as early as $2 \mathrm{~h}$ after UVB irradiation and that these changes were in good agreement with previously published data [1-4]. However, very importantly, we found that (i) the residual huCOP1 level was further reduced by UVB and (ii) the significantly reduced huCOP1 level resulted in more pronounced UVB-induced changes in the expression of genes as compared to non-transgenic keratinocytes. These data demonstrate that this cell line is a particularly suitable tool for studying huCOP1-dependent UVB-induced changes in early gene expression responses.

The possible interactions among the examined genes were analyzed using Ingenuity Pathway Analysis software. This software uses published interaction data for composing potential new networks based on novel experimental data. The pathway analysis identified a network in which 13 of the 30 examined genes were organized around three central molecules, ERK1/2, CREB and ubiquitin.

Functional connections between certain members of the identified network have already been described [26-29]. All 13 genes were differentially expressed after UVB irradiation, and their expression was increased in siCOP1 cells compared to control. Similar changes have been detected in ERK1/2 and CREB gene expression, affirming their central role in the identified network.

Some of the components of the identified network have already been implicated in huCOP1-mediated processes: Liu et al. [30] have recently demonstrated that huCOP1 promotes the ubiquitination and degradation of the CAMP responsive CREB-regulated transcription coactivator 2 . COP1 has also been shown to play a role in the degradation of the c-Jun protein $[9,11,20,25]$.

Our array identified two other functional components of the activator protein-1 (AP-1) transcription factor complex: JUNB and JUND. HuCOP1 might regulate these two genes through an as yet unidentified mechanism. On the basis of these data, we hypothesize that huCOP1 might contribute to the regulation of the AP-1 transcription complex at different levels: by altering the expression of the JUNB and JUND genes and by promoting the degradation of c-Jun via its E3 ubiquitin ligase activity. Such functional interactions were suggested as early as 2003, when Bianchi and co-workers identified huCOP1 as the human ortholog of AtCOP1 and performed the primary functional characterization of the gene and its protein product [20]. Subsequently Migliorini et al. (2011) demonstrated the direct c-Jun-COP1 interaction.

AP-1-related transcription factors have long been implicated in tumorigenesis; therefore, the putative role of huCOP1 in the pathogenesis of human cancers emerged early [11,20]. Much evidence demonstrating that COP1 plays a major role in tumorigenesis has since accumulated [25]. However, it is still unclear whether COP1 is a tumor suppressor or an oncogene. Marine speculated in this recent review that COP1 may have a "dual face," functioning either as an oncogene or as a tumor suppressor, depending on the cellular context.

Our results and the data available in the literature indicate that decreased huCOP1 levels sensitize the cells to UVB damage or oxidative stress and modify the UVB-induced stress response of keratinocytes. The loss of some members in the identified network increases the sensitivity of the cells to UVB. Maeda et al. [31], for example, demonstrated that GADD45A-/- keratinocytes are more sensitive to UVB than GADD45A+/+ cells due to reduced DNA 
repair and lack of G2/M arrest. It is also well known that the symptoms of systemic lupus erythematosus are exacerbated by sun exposure. Pflegerl et al. [32] reported that challenging JUNB $\Delta^{\mathrm{ep}}$ mice with UVB irradiation enhanced the severity of their lupus-like lesions. It has also been published that DAXX-depleted fibroblasts are resistant to UVB- and oxidative-stress-induced cell death [33]. Presumably, the absence of certain members of the huCOP1-mediated transcriptional cascade leads to an abnormal UVB response.

Several members of the identified huCOP1-mediated UVB-responsive network have already been correlated with nonmelanoma skin cancers, such as basal cell carcinoma (BCC) and squamous cell carcinoma (SCC). Immunohistochemical studies recently performed by our workgroup [34] indicated that huCOP1 expression is altered in both non-melanoma skin cancers. Moreover, well established data are available on the differential expression of several members of the identified huCOP1-mediated UVB-responsive network both in BCC and SCC [34-38].

We demonstrated that huCOP1 contributes to the transcriptional regulation of the keratinocyte UVB response by the downregulation of an UVB inducible network operating through three newly identified central organizers. This network is under the control of upstream regulators also showing UVB response. We hypothesize that huCOP1 operates as a negative factor of the identified transcriptional network by modifying the function of the upstream regulators. Mechanism underlying the UVB-induced cellular events may include a re-distribution of huCOP1 to different molecular complexes. Such a mechanism has recently been demonstrated for arabidopsis [8]. The expression of huCOP1 is altered in non-melanoma skin cancers [34] and several members of the identified regulatory network have been implicated in the pathogenesis of these skin diseases [35-38]. Thus, huCOP1 emerges as a potential target molecule for BCC and/or SCC. Since COP1 possibly acts both as an oncogene and as a tumor suppressor, further studies should clarify the role of huCOP1 for human keratinocytes in photo-damaged skin and these skin diseases.

\section{Acknowledgements}

This work was supported by the TÁMOP-4.2.2/B-10/1-20100012 and TÁMOP-4.2.2.A-11/1/KONV-2012-0035 Grants.

\section{Appendix A. Supplementary data}

Supplementary data associated with this article can be found, in the online version, at http://dx.doi.org/10.1016/j.jphotobiol. 2014.08.002.

\section{References}

[1] D. Li, T.G. Turi, A. Schuck, I.M. Freedberg, G. Khitrov, M. Blumenberg, Rays and arrays: the transcriptional program in the response of human epidermal keratinocytes to UVB illumination, FASEB J. 15 (2001) 2533-2535.

[2] A. Pisarchik, J. Wortsman, A. Slominski, A novel microarray to evaluate stressrelated genes in skin: effect of ultraviolet light radiation, Gene 341 (2004) 199207.

[3] C.D. Enk, J. Jacob-Hirsch, H. Gal, I. Verbovetski, N. Amariglio, D. Mevorach, A. Ingber, D. Givol, G. Rechavi, M. Hochberg, The UVB-induced gene expression profile of human epidermis in vivo is different from that of cultured keratinocytes, Oncogene 25 (2006) 2601-2614.

[4] T. Murakami, M. Fujimoto, M. Ohtsuki, H. Nakagawa, Expression profiling of cancer-related genes in human keratinocytes following non-lethal ultraviolet B irradiation, J. Dermatol. Sci. 27 (2001) 121-129.

[5] J. Takao, K. Ariizumi, I.I. Dougherty, P.D. Cruz Jr., Genomic scale analysis of the human keratinocyte response to broad-band ultraviolet-B irradiation, Photodermatol. Photoimmunol. Photomed. 18 (2002) 5-13.

[6] D. Dornan, I. Wertz, H. Shimizu, D. Arnott, G.D. Frantz, P. Dowd, K. O’Rourke, H Koeppen, V.M. Dixit, The ubiquitin ligase COP1 is a critical negative regulator of p53, Nature 429 (2004) 86-92.

[7] Y.H. Lee, J.B. Andersen, H.T. Song, A.D. Judge, D. Seo, T. Ishikawa, J.U. Marquardt, M. Kitade, M.E. Durkin, C. Raggi, H.G. Woo, E.A. Conner, I. Avital, I. Maclachlan, V.M. Factor, S.S. Thorgeirsson, Definition of ubiquitination modulator COP1 as a novel therapeutic target in human hepatocellular carcinoma, Cancer Res. 70 (2010) 8264-8269.

[8] X. Huang, X. Ouyang, P. Yang, O.S. Lau, L. Chen, N. Wei, X.W. Deng, Conversion from CUL4-based COP1-SPA E3 apparatus to UVR8-COP1-SPA complexes underlies a distinct biochemical function of COP1 under UV-B, Proc. Natl. Acad. Sci. U. S. A. 110 (2013) 16669-16674.

[9] A.C. Vitari, K.G. Leong, K. Newton, C. Yee, K. O’Rourke, J. Liu, L. Phu, R. Vij, R. Ferrando, S.S. Couto, S. Mohan, A. Pandita, J.A. Hongo, D. Arnott, I.E. Wertz, W.Q. Gao, D.M. French, V.M. Dixit, COP1 is a tumour suppressor that causes degradation of ETS transcription factors, Nature 474 (2011) 403-406.

[10] A. Kinyo, Z. Kiss-Laszlo, S. Hambalko, A. Bebes, M. Kiss, M. Szell, Z. Bata-Csorgo, F. Nagy, L. Kemeny, COP1 contributes to UVB-induced signaling in human keratinocytes, J. Invest. Dermatol. 130 (2010) 541-545.

[11] D. Migliorini, S. Bogaerts, D. Defever, R. Vyas, G. Denecker, E. Radaelli, A. Zwolinska, V. Depaepe, T. Hochepied, W.C. Skarnes, J.C. Marine, Cop1 constitutively regulates c-Jun protein stability and functions as a tumor suppressor in mice, J. Clin. Invest. 121 (2011) 1329-1343.

[12] C. Yi, H. Wang, N. Wei, X.W. Deng, An initial biochemical and cell biological characterization of the mammalian homologue of a central plant developmental switch, COP1, BMC, Cell Biol. 3 (2002) 30.

[13] K.U. Torii, T.W. McNellis, X.W. Deng, Functional dissection of Arabidopsis COP1 reveals specific roles of its three structural modules in light control of seedling development, EMBO J. 17 (1998) 5577-5587.

[14] M. Holm, X.W. Deng, Structural organization and interactions of COP1, a lightregulated developmental switch, Plant Mol. Biol. 41 (1999) 151-158.

[15] C. Yi, X.W. Deng, COP1 - from plant photomorphogenesis to mammalian tumorigenesis, Trends Cell Biol. 15 (2005) 618-625.

[16] H. Wang, D. Kang, X.W. Deng, N. Wei, Evidence for functional conservation of a mammalian homologue of the light-responsive plant protein COP1, Curr. Biol. 9 (1999) 711-714.

[17] C.H. Su, R. Zhao, F. Zhang, C. Qu, B. Chen, Y.H. Feng, L. Phan, J. Chen, H. Wang, H. Wang, S.C. Yeung, M.H. Lee, 14-3-3Sigma exerts tumor-suppressor activity mediated by regulation of COP1 stability, Cancer Res. 71 (2011) 884-894.

[18] J.Y. Kato, N. Yoneda-Kato, Mammalian COP9 signalosome, Genes Cells 14 (2009) 1209-1225.

[19] M.H. Lee, R. Zhao, L. Phan, S.C. Yeung, Roles of COP9 signalosome in cancer, Cell Cycle 10 (2011) 3057-3066.

[20] E. Bianchi, S. Denti, R. Catena, G. Rossetti, S. Polo, S. Gasparian, S. Putignano, L. Rogge, R. Pardi, Characterization of human constitutive photomorphogenesis protein 1, a RING finger ubiquitin ligase that interacts with Jun transcription factors and modulates their transcriptional activity, J. Biol. Chem. 278 (2003) 19682-19690.

[21] A. Oravecz, A. Baumann, Z. Mate, A. Brzezinska, J. Molinier, E.J. Oakeley, E. Adam, E. Schafer, F. Nagy, R. Ulm, CONSTITUTIVELY PHOTOMORPHOGENIC1 is required for the UV-B response in Arabidopsis, Plant Cell 18 (2006) 19751990.

[22] H. Polyanka, K. Szabo, G. Tax, V. Tubak, E. Kusz, Z. Ujfaludi, I. Boros, Z. BataCsorgo, L. Kemeny, M. Szell, Primary characterization of a novel HPV-E6 oncogene immortalized keratinocyte cell line, J. Invest. Dermatol. 131 (Suppl. 2) (2011) S70.

[23] M.M. Simon, Y. Aragane, A. Schwarz, T.A. Luger, T. Schwarz, UVB light induces nuclear factor kappa B (NF kappa B) activity independently from chromosomal DNA damage in cell-free cytosolic extracts, J. Invest. Dermatol. 102 (1994) 422-427.

[24] M.J. Zhou, L. Zheng, L. Guo, W.L. Liu, C. Lv, L.H. Jiang, C.S. Ou, Z.H. Ding, Differential responses to UVB irradiation in human keratinocytes and epidermoid carcinoma cells, Biomed. Environ. Sci. 25 (2012) 583-589.

[25] J.C. Marine, Spotlight on the role of COP1 in tumorigenesis, Nat. Rev. Cancer 12 (2012) 455-464

[26] J.M. Hernandez, D.H. Floyd, K.N. Weilbaecher, P.L. Green, K. Boris-Lawrie, Multiple facets of junD gene expression are atypical among AP-1 family members, Oncogene 27 (2008) 4757-4767.

[27] C.A. Hazzalin, L.C. Mahadevan, MAPK-regulated transcription: a continuously variable gene switch?, Nat Rev. Mol. Cell Biol. 3 (2002) 30-40.

[28] M.L. Smith, I.T. Chen, Q. Zhan, I. Bae, C.Y. Chen, T.M. Gilmer, M.B. Kastan, P.M. O'Connor, A.J. Fornace Jr., Interaction of the p53-regulated protein Gadd45 with proliferating cell nuclear antigen, Science 266 (1994) 13761380.

[29] C. Chen, M.S. Benjamin, X. Sun, K.B. Otto, P. Guo, X.Y. Dong, Y. Bao, Z. Zhou, X Cheng, J.W. Simons, J.T. Dong, KLF5 promotes cell proliferation and tumorigenesis through gene regulation and the TSU-Pr1 human bladder cancer cell line, Int. J. Cancer 118 (2006) 1346-1355.

[30] Y. Liu, R. Dentin, D. Chen, S. Hedrick, K. Ravnskjaer, S. Schenk, J. Milne, D.J. Meyers, P. Cole, J. Yates III, J. Olefsky, L. Guarente, M. Montminy, A fasting inducible switch modulates gluconeogenesis via activator/coactivator exchange, Nature 456 (2008) 269-273.

[31] T. Maeda, A.N. Hanna, A.B. Sim, P.P. Chua, M.T. Chong, V.A. Tron, GADD45 regulates G2/M arrest, DNA repair, and cell death in keratinocytes following ultraviolet exposure, J. Invest. Dermatol. 119 (2002) 22-26.

[32] P. Pflegerl, P. Vesely, B. Hantusch, M. Schlederer, R. Zenz, E. Janig, G. Steiner, A. Meixner, P. Petzelbauer, P. Wolf, A. Soleiman, G. Egger, R. Moriggl, T. Kishimoto, E.F. Wagner, L. Kenner, Epidermal loss of JunB leads to a SLE phenotype due to hyper IL-6 signaling, Proc. Natl. Acad. Sci. U. S. A. 106 (2009) 20423-20428.

[33] A.F. Khelifi, M.S. D’Alcontres, P. Salomoni, Daxx is required for stress-induced cell death and JNK activation, Cell Death Differ. 12 (2005) 724-733. 
[34] I.B. Németh, T. Krenács, G. Kiszner, E. Varga, Á. Kinyó, F. Nagy, L. Kemény, Expression of human constitutive photomorphogenic protein-1 in melanocytic and non-melanocytic skin lesions, J. Invest. Dermatol. 130 (Suppl. 2) (2010) S54.

[35] H.G. Kaporis, E. Guttman-Yassky, M.A. Lowes, A.S. Haider, J. Fuentes-Duculan, K. Darabi, J. Whynot-Ertelt, A. Khatcherian, I. Cardinale, I. Novitskaya, J.G. Krueger, J.A. Carucci, Human basal cell carcinoma is associated with Foxp3+ T cells in a Th2 dominant microenvironment, J. Invest. Dermatol. 127 (2007) 2391-2398.

[36] T.L. Barrett, K.J. Smith, J.J. Hodge, R. Butler, F.W. Hall, H.G. Skelton, Immunohistochemical nuclear staining for p53, PCNA, and Ki-67 in different histologic variants of basal cell carcinoma, J. Am. Acad. Dermatol. 37 (1997) 430-437.

[37] A.S. Haider, S.B. Peters, H. Kaporis, I. Cardinale, J. Fei, J. Ott, M. Blumenberg, A.M. Bowcock, J.G. Krueger, J.A. Carucci, Genomic analysis defines a cancerspecific gene expression signature for human squamous cell carcinoma and distinguishes malignant hyperproliferation from benign hyperplasia, J. Invest. Dermatol. 126 (2006) 869-881.

[38] G.A. Jeon, J.S. Lee, V. Patel, J.S. Gutkind, S.S. Thorgeirsson, E.C. Kim, I.S. Chu, P. Amornphimoltham, M.H. Park, Global gene expression profiles of human head and neck squamous carcinoma cell lines, Int. J. Cancer 112 (2004) 249258.

[39] R. Limame, A. Wouters, B. Pauwels, E. Fransen, M. Peeters, F. Lardon, O. De Wever, P. Pauwels, Comparative analysis of dynamic cell viability, migration and invasion assessments by novel real-time technology and classic endpoint assays, PLoS ONE 7 (2012) e46536.

[40] K. Rankine, N.K. Gibbs, Evidence that lower epidermal layers of human skin have an inherent resistance to UVB-induced cyclobutane pyrimidine dimer formation, J. Invest. Dermatol. 133 (Suppl. 1) (2013) S218.

[41] K.J. Livak, T.D. Schmittgen, Analysis of relative gene expression data using real-time quantitative PCR and the 2(-Delta Delta C(T)) Method, Methods 25 (2001) 402-408. 


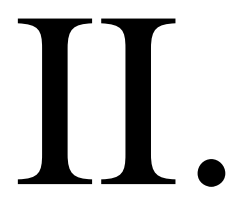




\title{
The effect of the plasma needle on the human keratinocytes related to the wound healing process
}

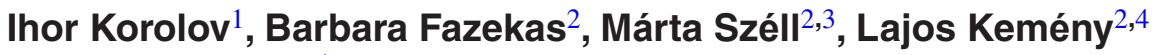 \\ and Kinga Kutasi ${ }^{1}$
}

${ }^{1}$ Wigner Research Centre for Physics, Institute for Solid State Physics and Optics, Hungarian Academy of Sciences, Konkoly-Thege Miklos str. 29-33, H-1121 Budapest, Hungary

2 Department of Dermatology and Allergology, Faculty of Medicine, University of Szeged, 6720 Szeged, Korányi fasor 6, Hungary

${ }^{3}$ Institute of Medical Genetics, Faculty of Medicine, University of Szeged, Szeged, Hungary

${ }^{4}$ MTA-SZTE Dermatological Research Group, University of Szeged, Szeged, Hungary

E-mail: kutasi.kinga@wigner.mta.hu

Received 18 August 2015, revised 13 November 2015

Accepted for publication 25 November 2015

Published

\begin{abstract}
In the present study we aim to verify the influence of a non-thermal atmospheric pressure plasma on the wound healing process. In this process the major contributors are the keratinocytes, which migrate to fill in the gap created by the wound. Therefore, we performed the direct treatment of HPV-immortalized human keratinocytes, protected by a layer of phosphate buffered saline (PBS) solution, with the glow discharge generated in flowing helium by a plasma needle. To mimick a wound, a $4 \mathrm{~mm}$ scratch was performed on the cell culture (scratch assay). We conducted two types of experiments: (i) cell proliferation and (ii) woundhealing model experiments. The plasma needle configuration, the plasma treatment conditions and the thickness of the protecting PBS layer were set based on viability experiments. The proliferation studies showed that short, 5-10 s, and low power treatments, such as $18 \mathrm{~W}$ and $20 \mathrm{~W}$ input power, could positively influence the cell proliferation when keratinocytes were protected by PBS. On the other hand, the plasma treatment of cell medium covered keratinocytes resulted in the decrease of proliferation. The wound-healing model (scratch assay) studies showed, that there was a maximum in the wound reduction as a function of the input power and treatment time, namely, at $18 \mathrm{~W}$ and $5 \mathrm{~s}$. Furthermore, the wound reduction strongly depended on the treated cell-PBS interaction time. To mimic an infected wound, the scratch assay was covered with a $1 \times 10^{9} \mathrm{cfu} \mathrm{ml}^{-1}$ Propionibacterium acnes suspension. The plasma treatment of this infected assay resulted in closing of the scratch, while in the nontreated assay the wound did not close at all.
\end{abstract}

Keywords: non-thermal atmospheric plasma, biomedical application, cell proliferation

(Some figures may appear in colour only in the online journal)

\section{Introduction}

During the last decade the attention of plasma community has turned towards the therapeutical application of atmospheric pressure non-thermal plasmas $[1,2]$. One important medical application where low-temperature plasmas can have a huge potential is the plasma stimulation of living cells and tissues [3-5]. Accordingly, the treatment of chronic wounds by plasmas may have selective antimicrobial or antiseptic effect without damaging the surrounding tissue, while stimulating the tissue regeneration. It has been shown that cold atmospheric plasma (CAP) entails no risk on humans in terms of

\begin{tabular}{|lllll}
\hline JNL:JPD & PIPS: AAOCOE & TYPE: PAP & TS: NEWGEN & DATE: 10/12/15
\end{tabular}


temperature increase, UV radiation or by free radical formation by the plasma, while can considerably decrease the bacterial load of the skin [6-8].

Several studies have been conducted aiming to model the wound healing process, e.g. the penetration of plasma or plasma generated species into the wound mimicking model surfaces, such as an agarose gel [9], as well as the transport of species and their interaction with the living cells [10, 11]. Although the mechanisms of plasma interaction with living tissues and cells are very complex, few attempts have been made to clarify the physical and biological mechanisms. It has been investigated the response of the biological system to the different charged species [12], neutral species (such as ROS and RNS) and UV radiation [13-15].

In vivo animal experiments have shown that plasma treatment affects the genes that are involved in wound healing, tissue injury and repair [16], and promotes tissue healing $[17,18]$. It has been found that plasma treatment may promote the late phase of inflammation, accelerate re-epithelization and increase wound contraction [18, 19]. Clinical tests suggest that wound healing may be accelerated by plasma treatment, particularly for chronic venous ulcers [20].

Investigations conducted at cellular level, such as using scratched cell cultures to mimic wounds, can give an insight into the elementary processes taking place during the plasma treatment. Cell culture studies using human dermal fibroblasts showed improved cell migration by plasma jet treatment, while the cell proliferation was not altered [16]. In the wound healing process the major contributors are the keratinocytes: they migrate to fill in the gap created by the wound.

Following the evolution after atmospheric plasma jet treatment of a scratch assay of HaCaT human keratinocytes cocultivated with Staphylococcus epidermidis it has been shown that the scratch can close, which indicates the increased cell death of S. epidermidis compared to HaCaT keratinocytes [21]. The biological changes induced in human keratinocytes by direct and indirect treatment with different plasma sources have been evaluated and discussed in details in Refs. [22-24]. In vivo and in vitro (scratch) assay studies indicated that keratinocyte proliferation, migration and apoptotic mechanisms were not affected by the treatment with the cold atmospheric plasma generated with the MicroPlaSter $\beta$ plasma torch system [25]. It has been concluded, that a 2 min treatment with this plasma induces gene expression of key regulators important for inflammation and wound healing without causing proliferation, migration or cell death in keratinocytes [25]. With our studies we aim to verify the effect of the plasma needle-which insures the sample to be in direct contact with the active discharge plasma, in contrast with the atmospheric plasma jets where only afterglow species reach the sampleon the proliferation and migration of HPV-immortalized human keratinocytes.

The plasma needle is a plasma source with a non-thermal atmospheric glow discharge ignited at the tip of a needle. From its initial application [26] the plasma needle went through a series of transformations, which made it more and more suitable for biomedical applications [27-30]. Several studies have been conducted, which aimed to investigate the effect of the plasma needle on biological samples, such as, reattachement and apoptosis of 3T3 mouse fibroblast after plasma treatment [31], the proliferation and differentiation of mesenchymal stem cells [30], as well as its bactericidal effect [29, 33].

The needle configuration chosen for our investigations and the experimental set-up used to treat the biological samples are presented in section 2 . The studied cell cultures and the analysing methods are described in section 3. Section 4 discusses the choice of the treatment conditions through the viability of cells. The effects of the plasma needle treatment on the cell culture are presented in section 5 .

\section{Experimental setup}

\subsection{Plasma needle: overview for the choice of the needle configuration}

The basic plasma needle configuration used in our studies is similar to the last generation of plasma needles applied [30, 34]. In the present case the needle consists of a $0.3 \mathrm{~mm}$ diameter central electrode made of wolfram. The needle is covered by a slightly larger ceramic tube-except for a $2 \mathrm{~mm}$ segment at the tip-and placed in a glass tube of $4 \mathrm{~mm}$ inner and $6 \mathrm{~mm}$ outer diameter. The needle body is made of Teflon. Helium is flowing between the ceramic and the glass tube, the flow rates used are in the $1-1.45 \mathrm{slm}$ (standard liters per minute) range. The central electrode is powered by a $13.56 \mathrm{MHz}$ power generator (KJLC R601) through a matching network (EJAT3). Plasma is ignited between the needle and a grounded electrode. Figure 1 shows different configurations - concerning the position of the tip of the needle relative to the end of the glass tube and the nature and position of the grounded electrode-, which we have been tested in order to choose the most suitable configuration for the present application. In case of configurations (a), (b) and (e) the grounded electrode is served by the support of the plates, which contain the liquid protected cell culture. The overall aim is to sustain stable glow discharge in contact with the liquid surface.

In order to insure a safe distance between the treated sample and the needle, which can secure a stable glow operation without arcing, the needle is pulled inside the glass tube with $d=2-3 \mathrm{~mm}$, see configuration (b) in figure 1 . We have found that keeping the needle at a 'safe' position the arcing can be easily avoided, however in this case the plasma tends to be confined within the glass tube and mostly the afterglow species get in contact with the liquid surface. The biological tests have shown that this plasma has no considerable effect on the cells. Configuration (c) has been designed for the sake of ground stability, as it can assure at any type of treatment the same inter-electrode distance. The grounded ring has been placed close to the end of the glass tube and different positions have been tested. At reasonable gas flow rates we could not observe any glow (discharge or afterglow) beyond the grounded ring, which indicates that the density of plasma species reaching the liquid surface is very low. Nevertheless, with this configuration we could prove that plasma radiation 

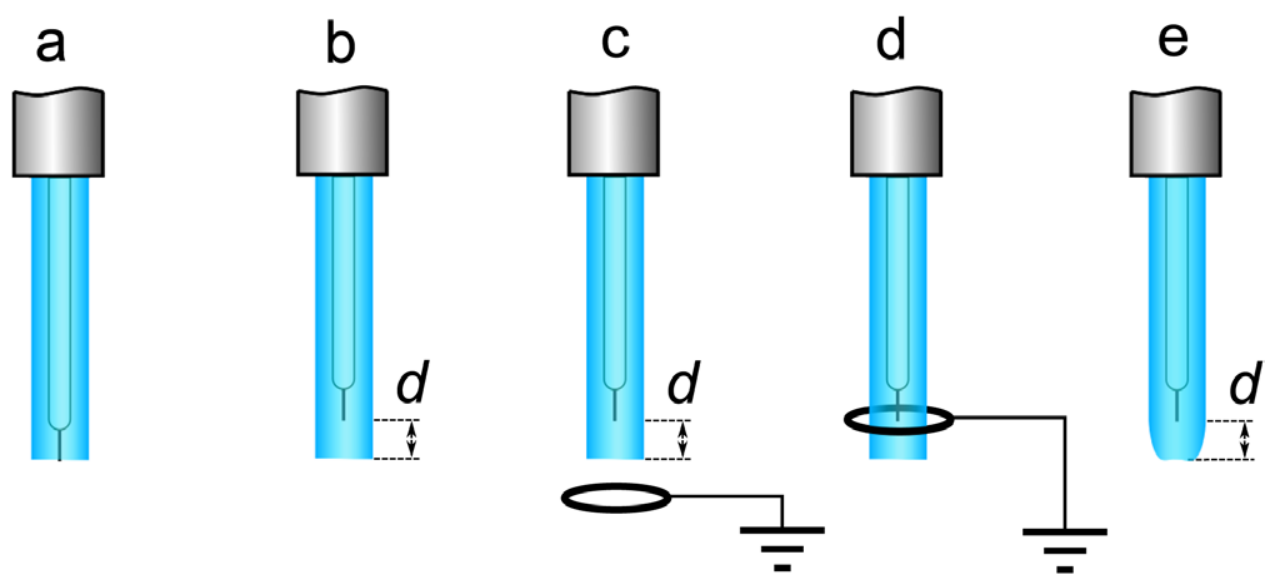

Figure 1. Different plasma needle configurations. The glow discharge is ignited between the tip of the powered needle and a grounded electrode, that can be the sample holder in the (a), (b) and (e) cases, or the grounded ring positioned close to the glass tube (c) and around the glass tube (d), respectively.

has no effect on the cell proliferation. To improve the flow of species towards the liquid surface a jet configuration has been designed, as shown by configuration (d), and the gas flow rate have been increased. This configuration resulted much higher gas temperature than the other configurations, and it was found not to be very safe for cell treatments as additionally a secondary spark like discharge develops to the grounded sample. Finally, in order to insure a better access into the small diameter well, a glass tube with a conical end has been chosen, as shown on configuration (e). In this case the same effect has been observed as in case of configuration (d), namely, the density of species reaching the sample is very low.

In view of these we have chosen the needle configuration (a), where the tip of the needle is in line with the edge of the glass tube. In order to make sure that the needle is kept always at the safe distance from the sample during treatments, the plasma needle has been mounted onto a holder. This distance has been set to $1.5 \mathrm{~mm}$, which assures a stable glow discharge operation (as illustrated in figure 2) without considerably increasing the temperature of PBS during the treatment time. The discharge is operated in the $15-30 \mathrm{~W}$ input power range and the dissipated plasma power is estimated using the subtraction method [35]. According to this method the plasma power is given by the difference in nominal power $\left(P_{\text {forwarded }}-P_{\text {reflected }}\right)$ with and without plasma at the same voltage. The plasma power has been found to be less than $500 \mathrm{~mW}$ also for the highest input power used, similar to the system of Kieft et al [31]. An accurate electrical characterization of a similar system can be found in the work of Puač et al [32].

\subsection{Plasma treatment}

We have conducted two types of cell treatment experiments: i.e. (i) wound-healing model and (ii) proliferation experiments, which required the use of two different types of cell plates. All the experiments have been conducted in a sterile biosafety cabinet.

In the first case, for the wound-healing assay treatment we used a 24-well plate (Corning, Sigma-Aldrich, USA), which

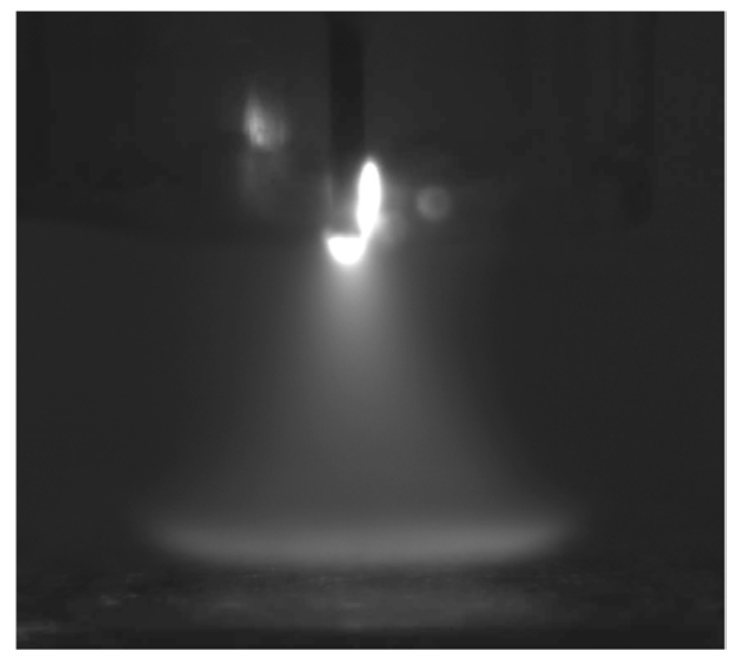

Figure 2. A typical image of the plasma needle glow as view from side.

has wells of $16 \mathrm{~mm}$ diameter and $20 \mathrm{~mm}$ height. Here the cells attached to the bottom of the well are covered with a PBS layer of $1.5 \mathrm{~mm}$ thickness, and the needle is approached to $1.5 \mathrm{~mm}$ distance to the PBS surface, as shown in figure 3 . The flow rate of helium is $1 \mathrm{slm}$. During treatments the visible plasma glow, shown in figure 2 , covers a $5 \mathrm{~mm}$ diameter circular area of the sample.

In order to limit the treatment environment to predominantly helium, the well is covered with a glass lid (see figure 3). Optical emission spectrum has been measured using an AvaSpec-3648 type spectrometer with $0.2 \mathrm{~nm}$ resolution and covering a spectral range of $250-800 \mathrm{~nm}$. According to the recorded spectra shown in figure 4, the emission is dominated by the $\mathrm{He}$ lines, accompanied by the $\mathrm{O}$ atomic line, the $\mathrm{OH}$ and low intensity $\mathrm{N}_{2}$ and $\mathrm{N}_{2}^{+}$bands. The $306 \mathrm{~nm}$ emission of $\mathrm{OH}\left(\mathrm{A}^{2} \Sigma^{+}-\mathrm{X}^{2} \Pi\right)$ transition is found generally when water vapour is present, while the first negative system of $\mathrm{N}_{2}^{+}\left(\mathrm{B}^{2} \Sigma_{u}^{+}\right.$ $-\mathrm{X}^{2} \Sigma_{g}^{+}$) can be observed in the presence of excess helium [36]. The low intensity of the nitrogen bands indicates that the discharge is mainly based on helium with small air inflow. We 


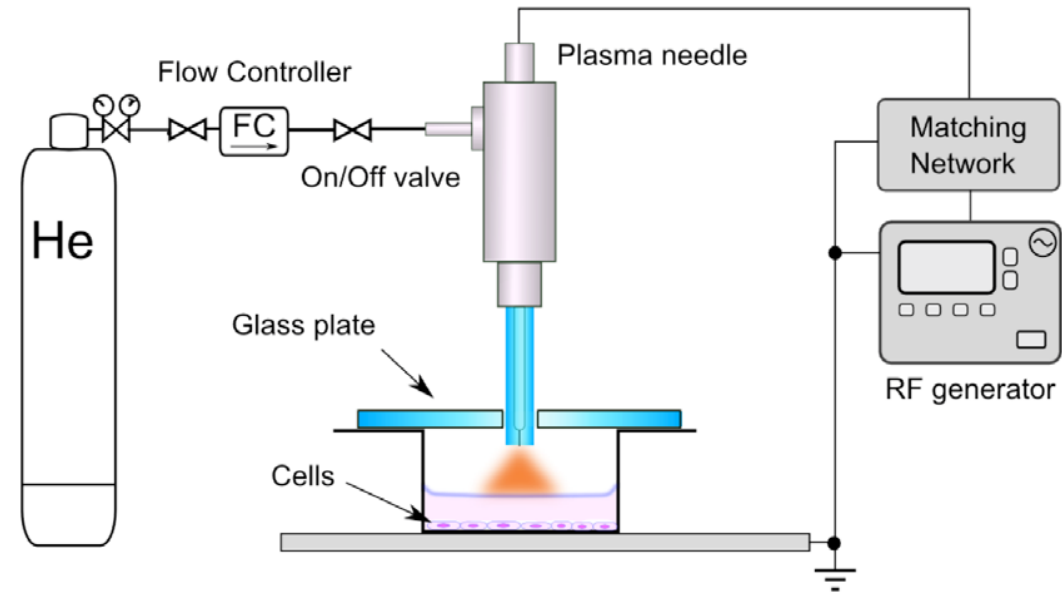

Figure 3. Schematic representation of the experimental set-up used in scratched cell assay experiments.

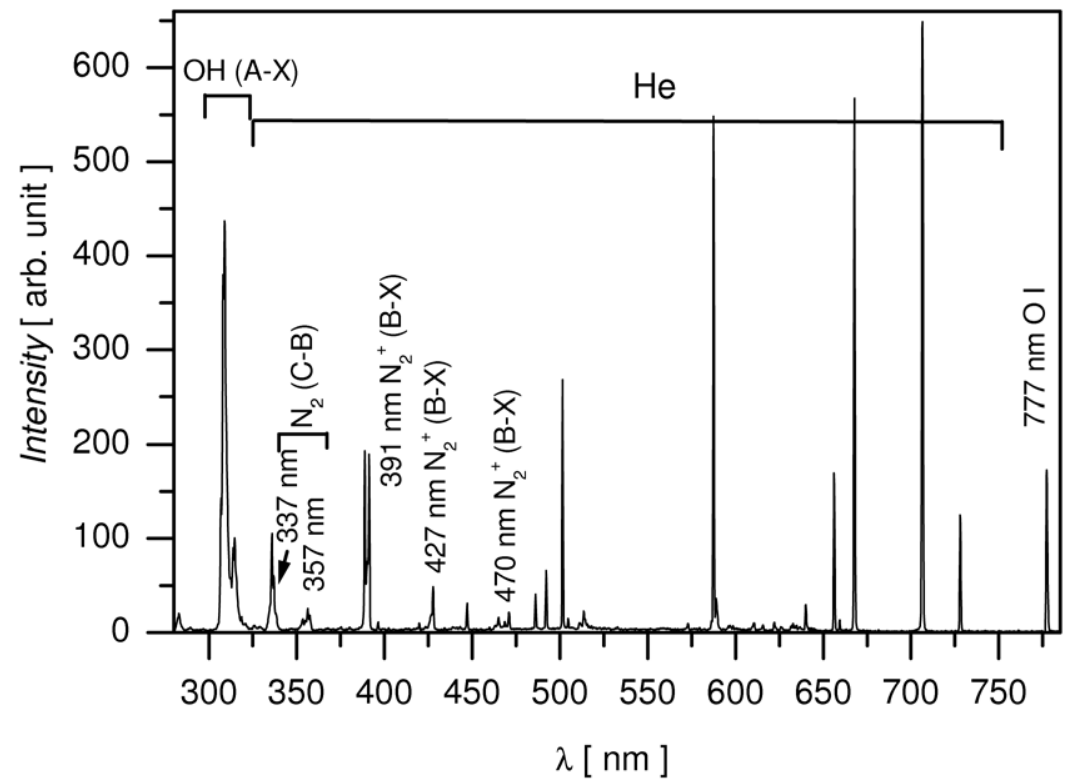

Figure 4. Spectra of the plasma needle ignited in the well covered with a glass lid, which assures predominantly helium environment.

note, that mass spectroscopical analysis of the plasma needle glow has been conducted by Malović et al [37] in open environment for a given set-up in order to identify the plasma species possibly reaching a treated surface. However, these data can serve only as a guideline for treatment studies conducted under different environmental conditions, as it is the present situation.

In the proliferation experiments a 96-well plate has been used, which belongs to the xCELLigence microelectronics biosensor system for cell-based assays, which provides dynamic, real-time, label-free cellular analysis. The wells are $6 \mathrm{~mm}$ in diameter and $10 \mathrm{~mm}$ in height. In this case the PBS layer is $3.5 \mathrm{~mm}$ thick. In order to be able to reach the PBS surface the $2 \mathrm{~mm}$ segment of the needle that is not covered with ceramic is pushed out of the glass tube, as illustrated in figure 5. With this configuration the $1.5 \mathrm{~mm}$ distance between the tip of the needle and the PBS surface could be reached, similarly to the wound-healing model experiments. To guarantee the helium environment here higher helium flow rate is used, i.e. $1.45 \mathrm{slm}$.

\section{Biological samples and analysing methods}

\subsection{Cell culture}

HPV-immortalized human keratinocytes (HPV-KER clone II/15) are seeded, according to the procedure described in $[38,39]$, in $500 \mu \mathrm{l}$ serum-free keratinocyte basal medium (KER-SFM, Gibco, Thermo Fisher Scientific Inc, Waltham, MA USA) supplemented with $1 \%$ L-glutamine and antibiotic/ antimycotic solution containing penicillin, streptomycin and amphotericin B (Sigma-Aldrich, USA). Keratinocytes were grown at $37{ }^{\circ} \mathrm{C}$ in a $5 \% \mathrm{CO} 2$ atmosphere.

For the proliferation experiments $5 \times 10^{3}$ cells per well are seeded into the 96-well xCELLigence plates $48 \mathrm{~h}$ before performing the plasma treatment.

3.1.1. Scratch assay for wound-healing model. In the case of the wound-healing model experiments $1 \times 10^{5}$ cells per well are seeded into 24-well plates. Before treatment a scratch wounding is performed with a cell scraper of $4 \mathrm{~mm}$ width, 


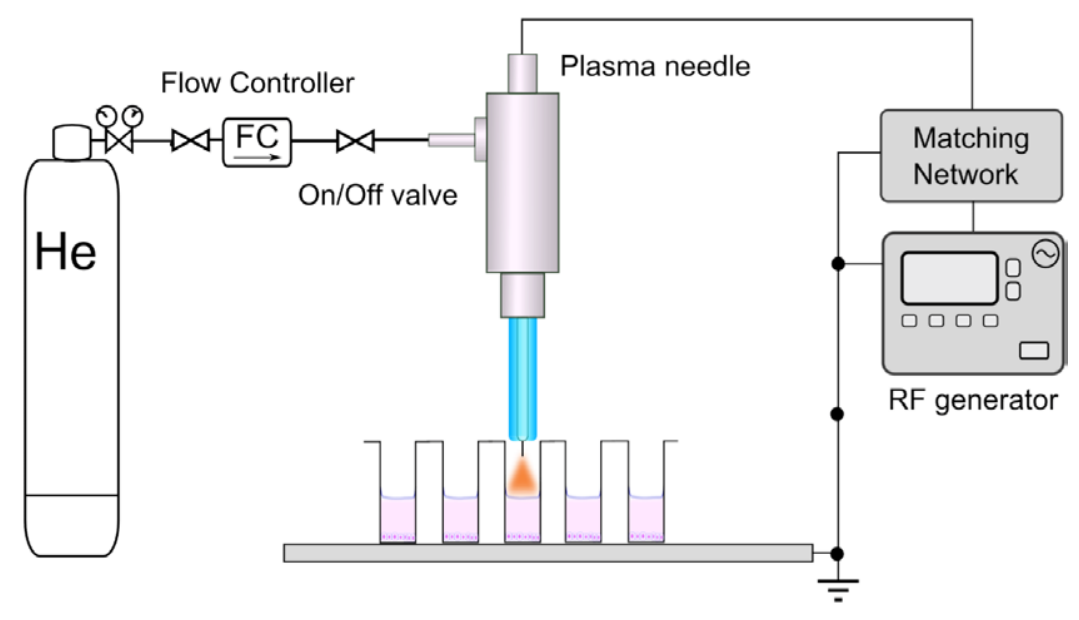

Figure 5. Schematic representation of the experimental set-up used in proliferation experiments with cells treated in 96-well plates.

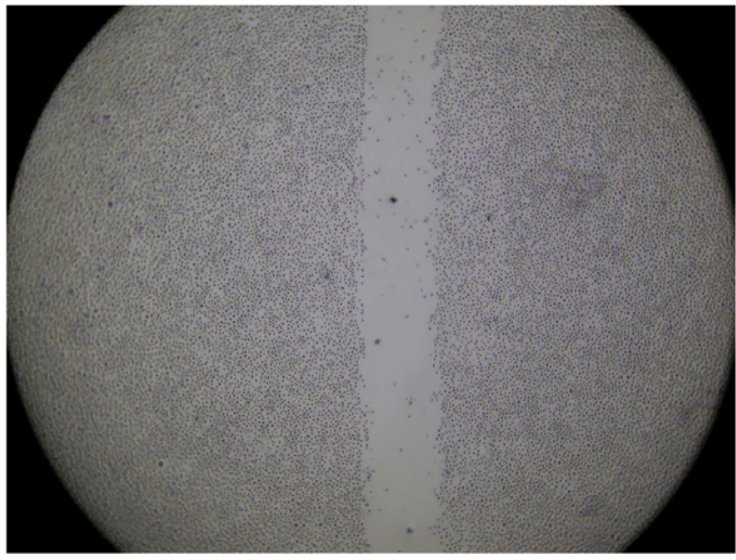

Figure 6. Image of the scratched cell culture. For a better contrast the assay was painted with Trypan Blue.

according to a well-established in vitro wound-healing assay [40], as shown in figure 6. For plasma treatment the medium covering the keratinocytes are replaced with PBS. The evolution of the scratch in time is observed and recorded using a Nikon Eclipse TS100 inverted routine microscope (Nikon Incorporation, Melville, USA) fitted with a Nikon Coolpix 4500 camera (Nikon Incorporation, Melville, USA). The width of the scratch is measured using the Gimp2 software. The scratch width reduction is calculated by subtraction of scratch width at $t=n \mathrm{~h}$ from scratch width at $t=0 \mathrm{~h}$.

\subsubsection{Cocultivation of Propionibacterium acnes and Kerati-} nocytes. P. acnes (ATCC 11828) are cultivated in KER-SFM medium with supplements (see section 3.1 ) during $24 \mathrm{~h}$. In order to determine the concentration of P.acnes in suspension its optical density at $600 \mathrm{~nm}$ is measured by spectrophotometry. The bacterial suspension is diluted with PBS to $1 \times 10^{9}$ cfu $\mathrm{ml}^{-1}$ cell density. This suspension is transferred into the medium covering the keratinocytes, achieving the multiplicity of infection (MOI-the ratio of bacteria per cell) 50 microorganisms. The scratch on the cell culture is performed before the transfer of suspension, the size of it and the general cell performance are observed during $24 \mathrm{~h}$. One day after plasma treatment, keratinocytes are stained with Trypan Blue solution
0.4\% (Sigma Aldrich, St. Louis, MO, USA) to distinguish the dead cells from living ones.

\subsection{Fluorescent staining}

Forty-eight hours after plasma treatment, keratinocytes are stained with propidium iodide (PI, BD Pharmingen, Heidelberg, Germany) to distinguish dead cells from living ones. After washing with calcium- and magnesium-free Phosphate-buffered saline (PBS), the cells are incubated with PI (final concentration: $1 \mathrm{ug} \mathrm{ml}^{-1}$ ) for $30 \mathrm{~min}$ in the darkness. The cells are observed afterwards by confocal laser scanning microscopy using an Olympus Fluoview FV1000 confocal laser scanning microscope (Olympus Life Science Europa $\mathrm{GmbH}$, Hamburg, Germany). The microscope configuration is the following: the objective is UPlanSApo $10 \times($ dry, numerical aperture: 0.4), the excitation source is a $543 \mathrm{~nm}$ HeNe laser, the laser transmissivity is $50 \%$; and the PI (propidium iodide) filter settings of the Olympus Fluoview software are used for detection.

\section{Cell viability: setting the plasma treatment conditions}

In order to set for the wound-healing model experiments the safe treatment conditions, which do not lead to cell death, viability experiments are performed. For this purpose 24-well plates are used with $1 \times 10^{5}$ cells per well. The treatment parameters that can influence the cell survival are: (i) input rf power, (ii) the thickness of PBS layer protecting the cells from desiccation, (iii) treatment time and (iv) the distance between the tip of the needle and PBS layer, which are set to $1.5 \mathrm{~mm}$, as described in section 2. Cells are treated under different conditions by varying the input power, PBS layer thickness and treatment time. The viability of cells at different conditions are analysed with staining methods using trypan blue and propidium iodide (see section 3.2).

Cells are stained with trypan blue immediately after plasma treatment to visualize the effect of the plasma's structure on the cell culture (dead cells take up trypan blue). Figure 7(a) shows the image of the cell culture treated in $200 \mu \mathrm{l}$ PBS 

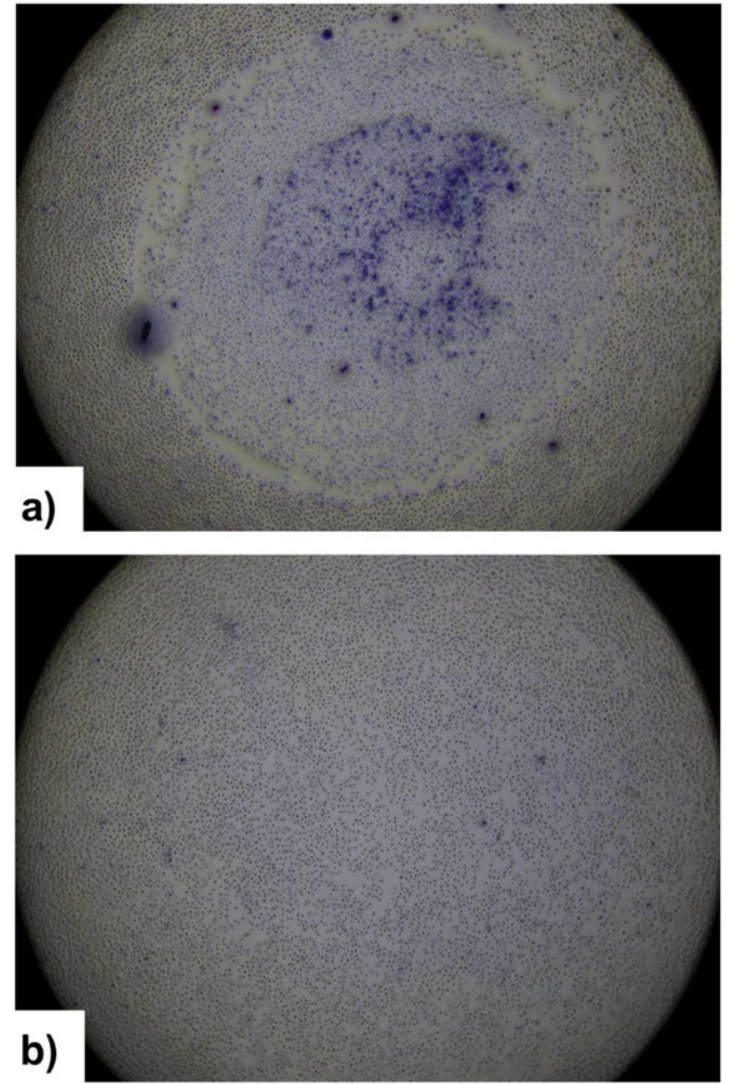

Figure 7. (a) The pattern of dead cells caused by plasma treatment on cell culture protected with $200 \mu \mathrm{l}$ PBS, equivalent to $1 \mathrm{~mm}$ thick layer, when treated for $7 \mathrm{~s}$ at $30 \mathrm{~W}$ input power. (b) The image of cell culture treated in $300 \mu \mathrm{l}$ PBS for $7 \mathrm{~s}$ at $30 \mathrm{~W}$ input power. The cells are stained with trypan blue, which is taken up by the dead cells.

— corresponding to a $1 \mathrm{~mm}$ thick PBS layer-for $7 \mathrm{~s}$ at $30 \mathrm{~W}$ input power. Here we see a pattern of dead cells in the area covered by the plasma glow. More precisely, most of the cells died in the treated region, while the cells in contact with the edge of the glow detached and diffused towards the central region. On the other hand when $300 \mu \mathrm{PBS}$ is used instead of $200 \mu \mathrm{l}$ PBS most of the cells remained viable.

A more systematic analysis are carried out with the propidium iodide staining method. The treated cells are stained $48 \mathrm{~h}$ after plasma treatment. The recorded images of the cells, which show the viability of cells - the dead cells stained with propidium iodide appear as red-are presented in figure 8 . We find that the cells covered with $200 \mu$ l PBS can survive only very short treatments, such as $5 \mathrm{~s}$ at an input power of maximum $20 \mathrm{~W}$. The increase of the treatment time or the input power, both lead to the death of cells. By increasing the PBS to $250 \mu$ thecells can survivelongertreatmentsat $20 \mathrm{~W}$ inputpower, however higher powers are still lethal. When using $300 \mu \mathrm{l}$ PBS the cells can survive treatments as long as $20 \mathrm{~s}$, even at powers as high as $35 \mathrm{~W}$.

Viability experiments have also been carried out in 6-well plates, with wells of $35 \mathrm{~mm}$ diameter. The volume of the PBS has been scaled up in order to obtain the same PBS layer thickness as in the case of the 24-well plate experiments. While in the 24-well plate the $1 \mathrm{~mm}$ PBS layer corresponds to $200 \mu \mathrm{l}$,

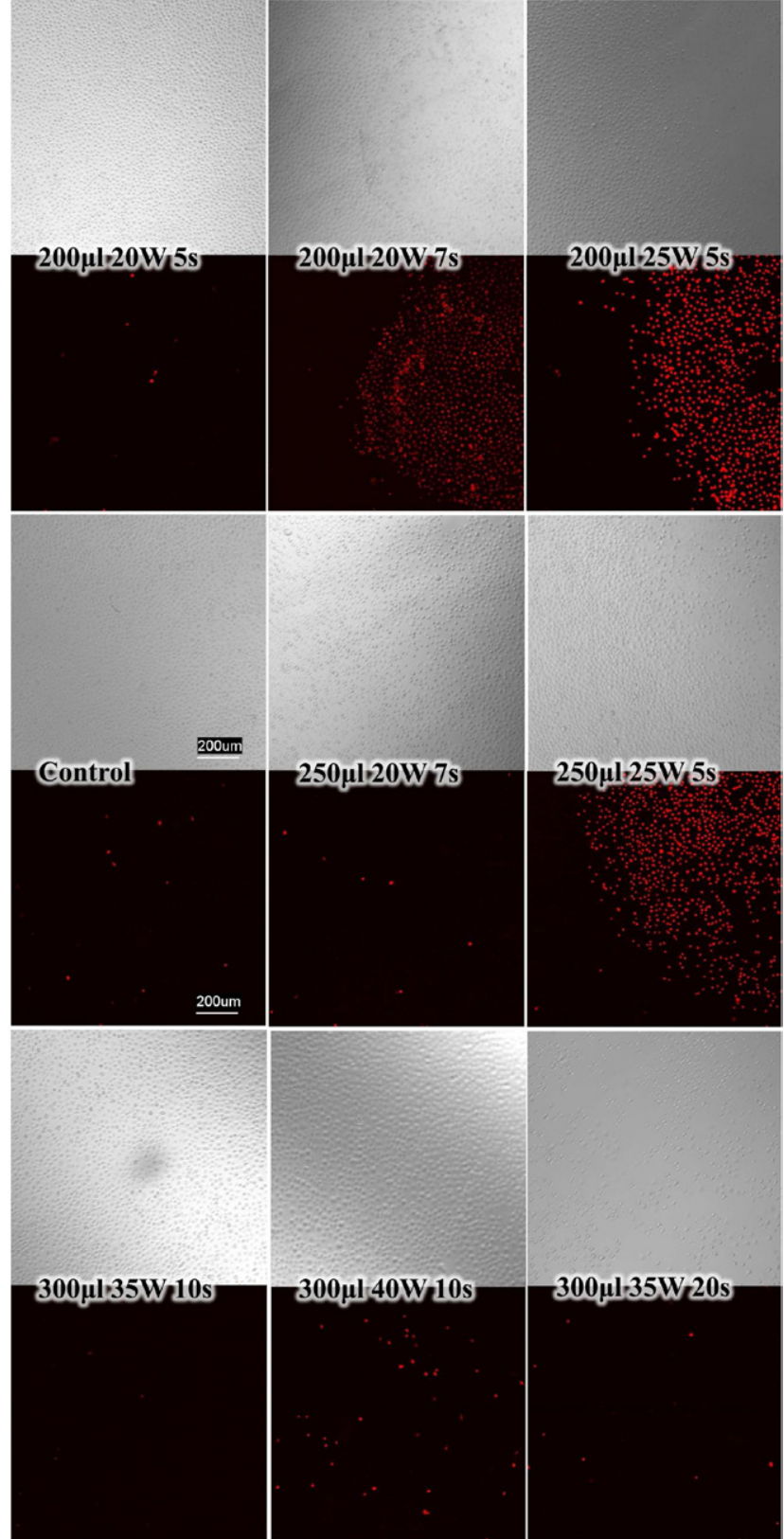

Figure 8. Keratinocytes $48 \mathrm{~h}$ after plasma treatment. Image of cells recorded by phase-contrast light microscopy (1st, 3rd and 5th rows), and confocal laser scanning microscopy image of dead cells stained with propidium iodide (2nd, 4th and 6th rows). The treatment conditions: PBS layer thickness, input power and treatment time, are marked on the images.

in the 6-well plate $962 \mu \mathrm{l}$ needs to be added to obtain the same layer thickness. Treating the cells in the 6-well plate at conditions, which lead to cell death in the 24-well plate-such as $5 \mathrm{~s}$ treatment at $25 \mathrm{~W}$ (shown in figure 8 first row last column) most of the cells stayed viable. This result indicates that it is not only the PBS layer thickness, but also the liquid surface and volume, which influences the density of active species reaching the cells. One important parameter can also be the heat transport, the heat dissipation increases with the volume of the liquid.

In the view of the viability results, in the wound-healing experiments, where the 24 -well plates are used, the treatment 
conditions are set as follows: (i) cells are covered with $300 \mu \mathrm{l}$ PBS; (ii) the input power is changed in the $18-30 \mathrm{~W}$ range and (iii) the treatment time is varied in the 5-30 s range.

\section{Results and discussion}

\subsection{Effect of plasma treatment on cell proliferation}

The effect of the plasma treatment on keratinocyte proliferation are followed with the xCELLigence microelectronics biosensor. Each well of the plate belonging to the device contains integral sensor electrode arrays allowing the monitoring of cells. The presence of the cells on top of the electrodes (i.e. attached to the bottom of the well) affects the local ionic environment at the electrode/solution interface, leading to an increase in electrode impedance. The more cells are attached on the electrodes, the larger is the increase of the electrode impedance. The impedance depends also on the quality of cell-electrode interaction; for example, increased cell adhesion or spreading will result larger electrode impedance. Thus, the electrode impedance displayed as Cell Index values reflects not only cell viability and number, but also morphology and adhesion degree, although their deconvolution is not straightforward.

The cells, as described in section 2.2, are treated in 96-well plates, protected by $100 \mu \mathrm{l} \mathrm{PBS}$, using input powers in the range of $18-30 \mathrm{~W}$ and treatment times in the 5-20 s range. The 96-well plates are placed back into the xCELLigence biosensor after all the wells have been treated and the PBS have been changed back to cell medium. For comparison reasons and to verify if the liquid composition influences the effect of the treatment, cells are also treated in the cell medium (given in section 3.1).

Figure 9 shows the proliferation of keratinocytes treated under different conditions in PBS (first column) and cell medium (second column). The error bars has been omitted from the figures for better visibility. The maximum error is about $12 \%$. We find that treatment of keratinocytes at $18 \mathrm{~W}$ and $20 \mathrm{~W}$ can positively influence the cell proliferation (see figures 9(a), (c) and (d)). A more significant increase of proliferation can be observed for the PBS covered cells in the case of the $10 \mathrm{~s}$ and $15 \mathrm{~s}$ long treatments at $20 \mathrm{~W}$ (figure 9(c)). However, after $60 \mathrm{~h}$ the proliferation in the case of treated cells falls below the control ones. This behaviour suggests that periodical treatments can keep the cell proliferation above the normal level. At the same time the increase of the treatment time above $15 \mathrm{~s}$, as well as the input power (figures 9(e)-(f)) cause the diminishing of the proliferation.

In the case of keratinocytes treated in cell medium we can observe a slightly different behaviour, i.e. the cell proliferation enhances at a much higher elapsed time after plasma treatment. At $20 \mathrm{~W}$ this occurs at $100 \mathrm{~h}$ after the treatment, except for the longest $20 \mathrm{~s}$ treatment. This different behaviour shows that due to plasma treatment the liquid chemistry-i.e. the created active species, which interact with the cells-in the two liquid mediums are different.

We note that the results shown here should not be used for quantitative comparison of the different conditions. All the treatments have been performed in a single 96-well plate, i.e. the cells being treated under different conditions in a row. The treatments were done in the following order: (1.) $P=18 \mathrm{~W}$ from $5 \mathrm{~s}$ to $20 \mathrm{~s}$, (2.) $P=20 \mathrm{~W}$ from $5 \mathrm{~s}$ to $20 \mathrm{~s}$, (3.) $P=25 \mathrm{~W}$ from $5 \mathrm{~s}$ to $20 \mathrm{~s}$, and (4.) $P=30 \mathrm{~W}$ from $5 \mathrm{~s}$ to $20 \mathrm{~s}$. As a result, the cells interact with the treated liquid for different periods of time, which influences the cell's response to the treatment, as also shown in the next section.

\subsection{Effect of plasma treatment on wound-healing}

For the wound-healing experiments keratinocytes are plated into 24-well plates, and the assay is prepared as described in section 3.1.1. The cells have been treated as described in section 2.2. In a 24-well plate 4 different treatment conditions are realized by using 6 samples for each case. Taking into account the viability of cells protected by PBS under laboratory conditions, the plates are treated two by two, meaning that the cell medium is replaced with PBS in two plates at a time, and changed back to medium after both plates have been treated. At each input power two plates are treated consecutively as follows: in the 1st plate the $5 \mathrm{~s}, 7 \mathrm{~s}, 20 \mathrm{~s}$ and $25 \mathrm{~s}$ treatment times are used, while in the 2nd plate the $10 \mathrm{~s}, 15 \mathrm{~s}$ and $30 \mathrm{~s}$ ones. In the 2 nd plate the forth row is occupied by the control samples.

Figure 10 shows the evolution of the scratch on the cell culture as a function of input power at different elapsed times after the plasma treatment. At several treatment conditions-particularly at low treatment times and low powersthe scratch width reduction is higher than in the case of the untreated control, i.e. the closing of the scratch is faster. As time elapses, at certain conditions the closing of the scratch slows down comparing to the control case, more pronouncedly when $25 \mathrm{~W}$ and $30 \mathrm{~W}$ powers are used. In these cases, at the $48 \mathrm{~h}$ elapsed time the scratch width reduction, independently of the treatment time used, falls below the control one (figure $10(\mathrm{~d}))$. In the case of the lower powers- $18 \mathrm{~W}$ and $20 \mathrm{~W}-$, the conditions of low treatment times become dominant as time elapses. This indicates that in order to stimulate the cells, a short and low power treatment, which induces stress to the cells may be adequate.

Figure 11 presents the closing of the scratch after the low power- $18 \mathrm{~W}$ and $20 \mathrm{~W}$ - treatments as a function of treatment time. In both cases the scratch width reduction shows similar behaviour, that is a non-monotonous one. With $48 \mathrm{~h}$ after treatment, the highest scratch width reduction occurs in the case of the lowest treatment time $5 \mathrm{~s}$, while the lowest is observed in the case of the $15 \mathrm{~s}$ treatment. Furthermore, in the case of the $25 \mathrm{~s}$ treatment a strong increase of the scratch closing can be observed. It is suspected, that this non-monotonous behaviour - with a sharp minimum and maximum — can be the result of the treatment protocol used. As described in the first paragraph of this section, two plates are treated consecutively ('two-by-two' protocol), due to which the cells at each condition stayed in the treated PBS for different periods of time, as presented in table 1 . According to this, the minimum scratch width reduction can be observed at the conditions, where the cells are kept in the treated medium for the shortest 

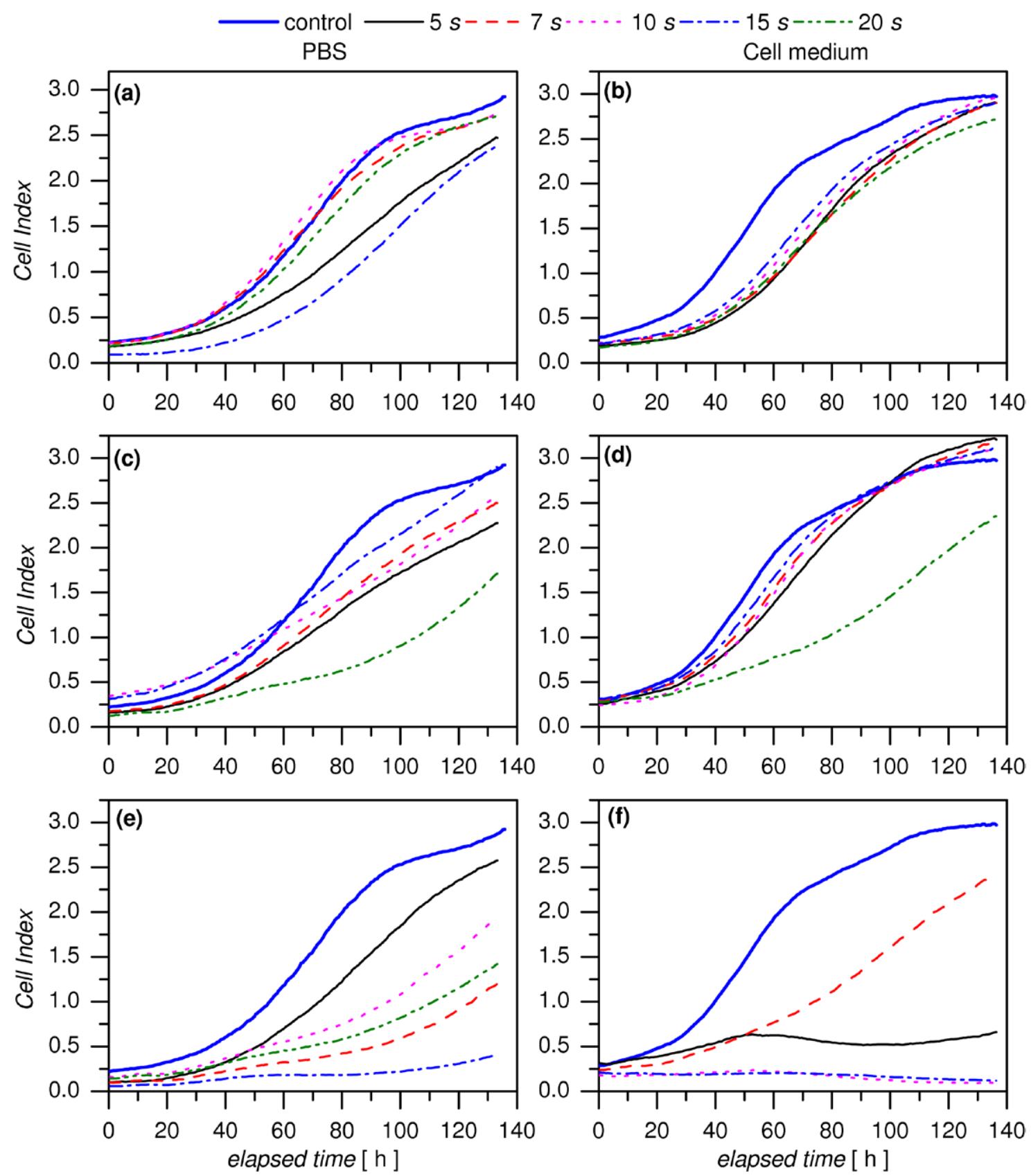

Figure 9. Cell Index, showing the cell proliferation, as given by the xCELLigence microelectronics biosensor for initial $5 \times 10^{3}$ cells treated in PBS (first column) and cell medium (second column) for conditions of different treatment times in the 5-20 s range at input powers of $18 \mathrm{~W}$ (a)-(b), $20 \mathrm{~W}$ (c)-(d) and $25 \mathrm{~W}$ (e)-(f), respectively. $t=0$ marks the time moment when the cells have been recovered after the plasma treatment.

period of time. In order to verify this effect and to find out if the behaviour depicted in figure 11 should be monotonous, a new protocol is chosen, where the plates are treated one by one ('plate-by-plate' protocol) and in each plate the PBS is replaced with the cell medium 10 min after the last treatment in the plate. Although in this way we can not equalize the interaction times of treated cells and PBS for all conditions, but by keeping most of the parameters the same the large differences can be diminished as presented in table 2. More precisely, in the case of the $10 \mathrm{~s}$ and $15 \mathrm{~s}$ treatments, where previously the minimum in the scratch width reduction has been observed, the treated cell-PBS interaction time has been increased to the level of the $5 \mathrm{~s}$ treatment condition, where previously the highest scratch width reduction has been obtained.

Figure 12 shows the evolution of the scratch after the new protocol treatments at $18 \mathrm{~W}$ input power. According to the results, the previously observed sharp minimum and maximum of the scratch width reduction as a function of treatment time disappears. In the case of the $10 \mathrm{~s}$ and $15 \mathrm{~s}$ treatments the scratch width reduction increases considerably, comparing to the previous results shown in figure 11, and as a result a faster closing is obtained than in the case of the control sample. This result indicates the importance of the treated cell-PBS interaction time. However, in the case of the longest treatment here 


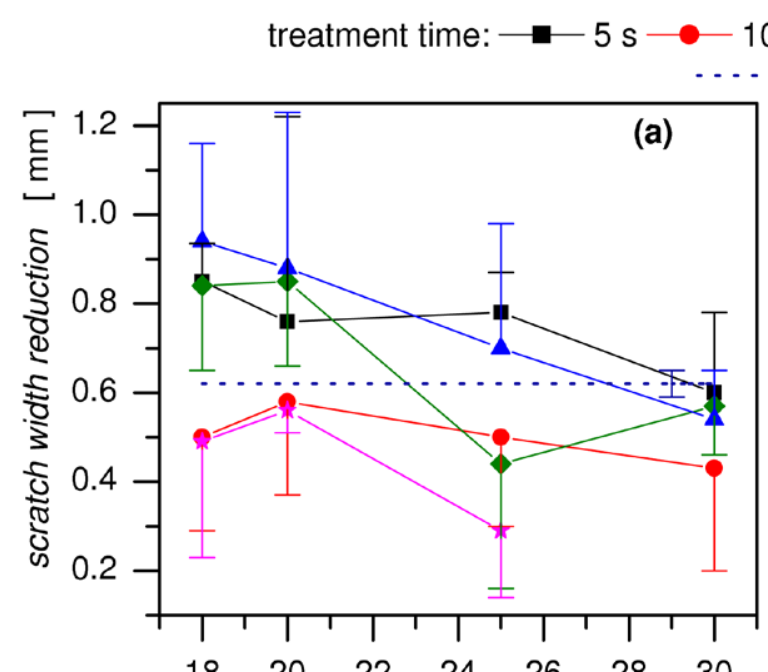

$10 \mathrm{~s} \longrightarrow 20 \mathrm{~s} \longrightarrow-25 \mathrm{~s} \rightarrow-30 \mathrm{~s}$

- control
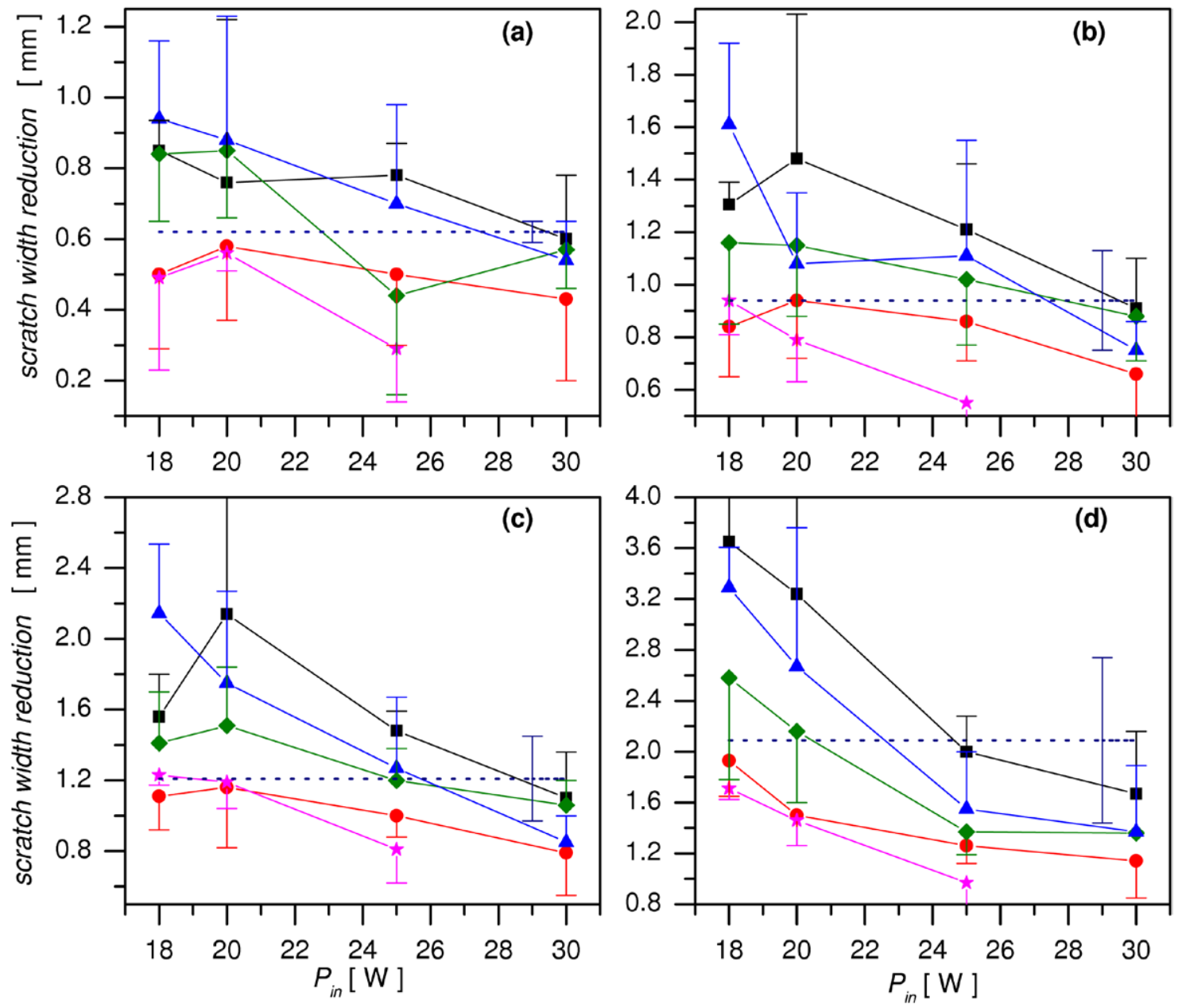

Figure 10. The scratch closure with (a) $15 \mathrm{~h}$, (b) $24 \mathrm{~h}$, (c) $38 \mathrm{~h}$ and (d) $48 \mathrm{~h}$ after the plasma treatment as a function of the input power. Different symbols mark the different treatment times.
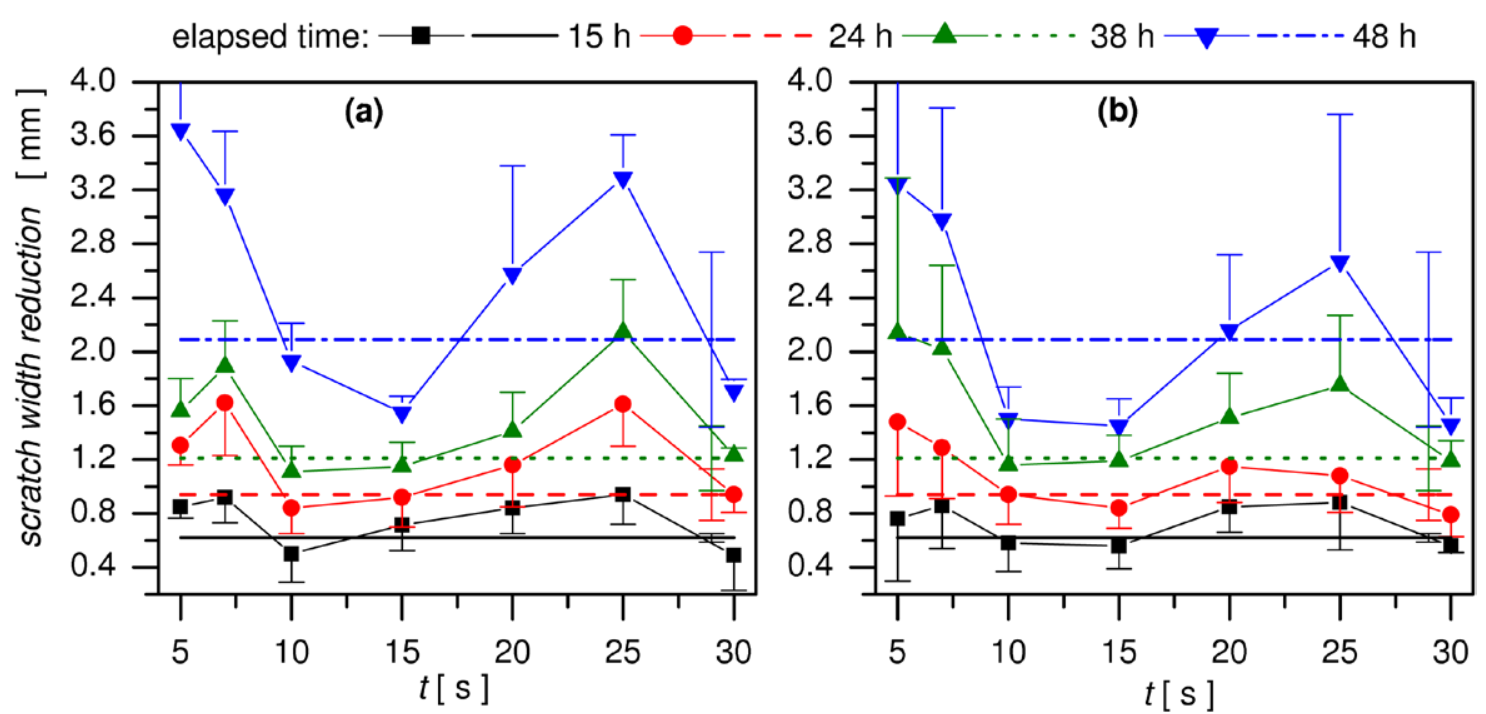

Figure 11. The scratch closure as a function of the treatment time for different elapsed times after treatment at (a) $18 \mathrm{~W}$ and (b) $20 \mathrm{~W}$.

investigated-the $30 \mathrm{~s}$ treatment- the increase of the treated cell-PBS interaction time has no positive effect on the scratch closing. Finally, we can still observe a small peak in the scratch width reduction as a function of treatment time at $25 \mathrm{~s}$. These results indicate that there is a complex relation between the cell activation, treatment time and treated cell-PBS interaction 
Table 1. The estimated time while the cells have been covered with the treated PBS after the direct plasma treatment of the PBS protected cells.

\begin{tabular}{lcc}
\hline $\begin{array}{l}\text { Treatment } \\
\text { order }\end{array}$ & $\begin{array}{l}\text { Treatment } \\
\text { time (s) }\end{array}$ & $\begin{array}{l}\text { Estimated elapsed } \\
\text { time in treated PBS (s) }\end{array}$ \\
\hline 1 & 5 & 1100 \\
2 & 7 & 1000 \\
5 & 10 & 480 \\
6 & 15 & 330 \\
3 & 20 & 820 \\
4 & 25 & 600 \\
7 & 30 & 90 \\
\hline
\end{tabular}

Note: The seven different length of treatments have been realized in two consecutively treated 24-well plates. The PBS is removed after both plates are fully treated. The different elapsed times occur from the treatment order of the PBS covered cells.

Table 2. The estimated time while the cells have been covered with the treated PBS after the direct plasma treatment of the PBS protected cells, when the plates are treated one by one and PBS is removed with $10 \mathrm{~min}$ after the plate has been fully treated.

\begin{tabular}{llcl}
\hline $\begin{array}{l}\text { Treatment } \\
\text { order }\end{array}$ & $\begin{array}{l}\text { Plate } \\
\text { ID }\end{array}$ & $\begin{array}{l}\text { Treatment } \\
\text { time (s) }\end{array}$ & $\begin{array}{l}\text { Estimated elapsed } \\
\text { time in treated PBS (s) }\end{array}$ \\
\hline 1 & 1 & 5 & 1100 \\
2 & 1 & 7 & 1000 \\
1 & 2 & 10 & 1100 \\
2 & 2 & 15 & 950 \\
3 & 1 & 20 & 820 \\
4 & 1 & 25 & 600 \\
3 & 2 & 30 & 690 \\
\hline
\end{tabular}

time. The cell activation is influenced both by the direct interaction of cells with the plasma and with the species resulted from the plasma induced liquid chemistry. The effect of the treated cell-medium interaction time on the cells viability has been also observed by Strassenburg et al [23].

When treating the PBS protected cell culture directly with the plasma needle, the bottom of the well with the attached cells serves as the grounded electrode of the rf discharge. According to the calculations of Sakiyama et al [41], at a sample positioned at $1 \mathrm{~mm}$ from the needle the electric field is in the range of $2.5 \times 10^{5} \mathrm{~V} \mathrm{~m}^{-1}$ in the needle axis, and decreases radially to about $0.5 \times 10^{5} \mathrm{~V} \mathrm{~m}^{-1}$ in $2 \mathrm{~mm}$.

When treating scratched assays, the keratinocytes are in direct contact with the edge of the plasma spot, that is beyond $2 \mathrm{~mm}$, where the electric field is below $0.5 \times 10^{5} \mathrm{~V} \mathrm{~m}^{-1}$. These electric fields, according to biological studies, can cause cell poration and cell fusion. The threshold field for electro-poration has been found to be at about $0.3 \mathrm{kV} \mathrm{cm}^{-1}[43,44]$. Fields as high as $2 \mathrm{kV} \mathrm{cm}^{-1}$ can lead to high cell permeabilization with still high viability of cells [42]. However, the cell electroporation, which allows different species to cross the cell membrane is cell specific and depends not only on the field strength but also on the field frequency and pulse duration [1, 42]. The quantum calculations, which predict the experimentally observed 'window effect'-namely, that small electric fields do have an influence but large fields do not have-, suggest the increase of dermal fibroblasts proliferation for fields in the $10-1000 \mathrm{mV} \mathrm{m}^{-1}$ range, depending on the frequency [45].

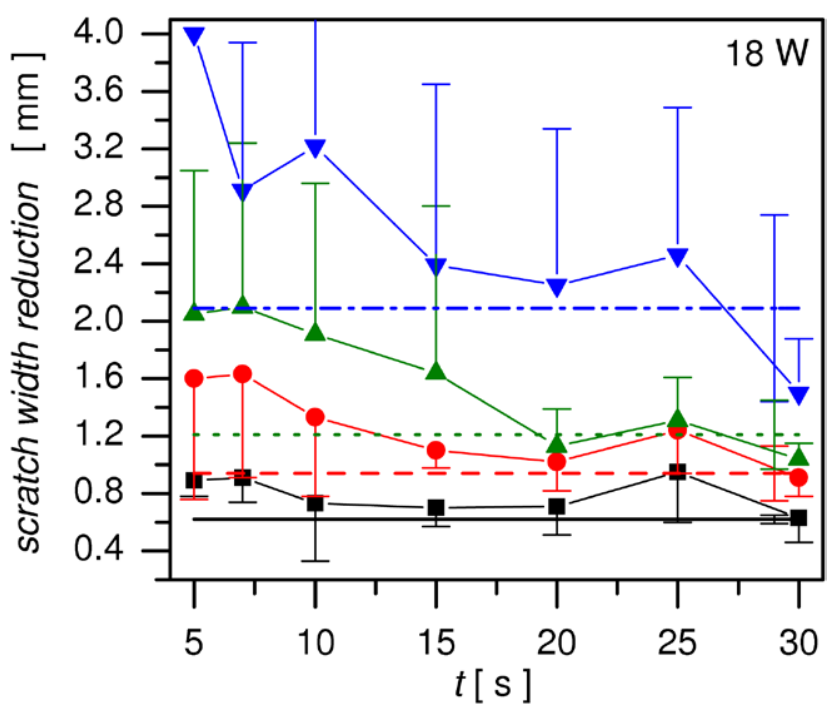

Figure 12. The scratch closure as a function of the treatment time for different elapsed times (marked with the same symbols as in figure 11) after the plasma treatment at $18 \mathrm{~W}$ using the "plate-byplate' treatment protocol described in the text.

On the other hand, in the case of the proliferation experiments conducted in the 96-well plates, as described in section 5.1, the cells are in contact with the full plasma spot, the cell culture being exposed to the whole radial field distribution of the plasma. Therefore, the differences in the two types of experiments may be attributed to the field effect.

In what concerns the chemical change of the treated PBS, we did not observe any change in the PH level.

\subsection{Cell selectivity of the plasma treatment}

In order to mimic an infected wound the keratinocytes have been cocultivated with P.acnes Gram-positive bacterium as described in section 3.1.2. The cocultivated assay is plasma treated as described in section 2.2.

Figure 13 shows the evolution of the scratch in the case of the untreated non-infected and P.acnes cocultivated assays, respectively, and the plasma treated P.acnes cocultivated assay. After $24 \mathrm{~h}$ the assay has been stained with trypan blue in order to distinguish the dead cells. We see that while in the case of the untreated non-infected and the plasma treated P.acnes cocultivated assays the scratch closes, in the case of the untreated P.acnes cocultivated assay the scratch width does not decrease at all and the keratinocytes all die. On the other hand, in the case of the plasma treated sample the keratinocytes do not die. This gives evidence that the plasma needle acts selectively regarding the keratinocytes and the Gram-positive bacteria. Similar effect has been observed in case of treatment of Staphylococcus epidermidis infected HaCaT cells with an argon high-frequency driven atmospheric-pressure plasma jet treatment [21].

\section{Conclusions}

The effect of the plasma needle on the wound healing process was investigated using HPV-immortalized human 


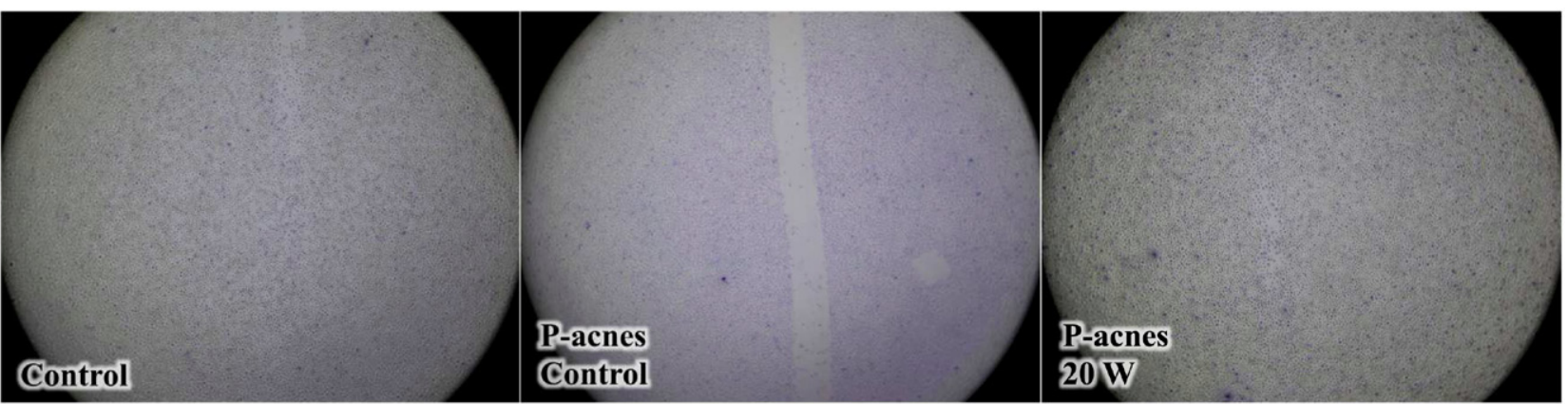

Figure 13. The evolution of the scratch in the case of the untreated non-infected and P.acnes cocultivated assays, respectively and the plasma treated P.acnes cocultivated assay.

keratinocytes. The wound was modeled with a $4 \mathrm{~mm}$ scratch made on the cell culture. The cells protected by a layer of phosphate buffered saline (PBS) solution were directly treated with the plasma generated in flowing helium by a plasma needle. We conducted two types of experiments: (i) cell proliferation and (ii) wound-healing model experiments. The plasma needle configuration, the plasma treatment conditions and the thickness of the protecting PBS layer were set based on viability experiments. We found that the minimum PBS layer necessary to protect the cells during treatment depended on the wells' dimensions, namely, in larger wells thinner layer appeared to be enough to protect the cells. This shows the difficulty of scaling the treatment conditions.

The proliferation studies showed that short, 5-10 s, and low power treatments, such as $18 \mathrm{~W}$ and $20 \mathrm{~W}$ input power, could positively influence the cell proliferation when keratinocytes were protected by PBS. We also found, that the cells treated in cell medium were more affected than those treated in PBS (i.e. cell proliferation decreased), which shows that the plasma induced liquid chemistry-i.e. the created active species, which interact with the cells-in the two liquid mediums were different. Therefore, the choice of the interaction medium is very important when setting the treatment conditions.

Monitoring the reduction of the scratch width after plasma treatment for $48 \mathrm{~h}$, we found that there was a maximum in the wound reduction as a function of the input power and treatment time, namely, at $18 \mathrm{~W}$ and $5 \mathrm{~s}$. Nevertheless, favourable conditions were also found in the case of $18 \mathrm{~W}$ and $20 \mathrm{~W}$ input powers and 5-25 s long treatments. We also found, that the wound reduction strongly depended on the treated cell—PBS interaction time.

To mimic an infected wound, the scratch assay was covered with a $1 \times 10^{9} \mathrm{cfu} \mathrm{ml}^{-1}$ Propionibacterium acnes suspension. The plasma treatment of this infected assay resulted in closing of the scratch, while in the non-treated assay the wound did not close at all.

The results suggest, that for activation of the healing process small stress induced to the keratinocytes is enough, and the treatment medium should be carefully chosen.

\section{Acknowledgments}

The work has been supported by Hungarian Science Foundation OTKA through K-104531. The authors acknowl-

\section{References}

[1] Kong M G, Kroesen G, Morfill G, Nosenko T, Shimizu T, van Dijk J and Zimmermann J L 2009 New J. Phys. 11115012

[2] Weltmann K D, Kindel E, von Woedtke M H, Stieber M and Brandenburg R 2010 Pure Appl. Chem. 821223

[3] Yonson S, Coulombe S, Léveillé V and Leask R L 2006 J. Phys. D: Appl. Phys. 393508

[4] Fridman G, Peddinghaus M, Ayan H, Fridman A, Balasubramanian M, Gutsol A, Brooks A and Friedman G 2006 Plasma Chem. Plasma Process. 26425

[5] Stoffels E 2007 Contrib. Plasma Phys. 4740

[6] Lademann J, Ulrich C, Patzelt A, Richter H, Kluschke F, Klebes M, Lademann O, Kramer A, Weltmann K D and Lange-Asschenfeldt B 2013 Clin. Plasma Med. 15

[7] Li Y-F et al 2013 Clin. Plasma Med. 135

[8] Boekema B K H L, Hofmann S, van Ham B J T, Bruggeman P J and Middelkoop E 2013 J. Phys. D: Appl. Phys. 46422001

[9] Dobrynin D, Fridman G, Friedman G and Fridman A 2012 Plasma Med. 271

[10] Orazov M, Sakiyama Y and Graves D B 2012 J. Phys. D: Appl. Phys. $\mathbf{4 5} 445201$

[11] Babaeva N Y and Kushner M J 2013 J. Phys. D: Appl. Phys. 46025401

[12] Stoffels E, Sakiyama Y and Graves D B 2008 IEEE Trans. Plasma Sci. 361441

[13] Dobrynin D, Fridman G, Friedman G and Fridman A 2009 New J. Phys. 11115020

[14] Graves D B 2012 J. Phys. D: Appl. Phys. 45263001

[15] Graves D B 2014 Plasma Med. 238

[16] Arndt S et al 2013 PLoS One 8 e79325

[17] Park C H et al 2014 J. Phys. D: Appl. Phys. 47435402

[18] Nasruddin, Nakajima Y, Mukai K, Rahayu H S E, Nur M, Ishijima T, Enomoto H, Uesugi Y, Sugama J and Nakatani T 2014 Plasma Med. 238

[19] Nastuta A V, Topala I, Grigoras C, Pohoata V and Popa Gh 2011 J. Phys. D: Appl. Phys. 44105204

[20] Isbary G et al 2013 Clin. Plasma Med. 125

[21] Wende K, Landsberg K, Lindequist U, Weltmann K-D and von Woedtke T 2010 IEEE Trans. Plasma Sci. 382479

[22] Schmidt A, von Woedtke T, Weltmann K-D and Masur K 2013 Plasma Med. 315

[23] Strassenburg S, Greim U, Bussiahn R, Haertel B, Wende K, von Woedtke T and Lindequist U 2013 Plasma Med. 357

[24] Barton A, Wende K, Bundscherer L, Hasse S, Schmidt A, Bekeschus S, Weltmann K-D, Lindequist U and Masur K 2013 Plasma Med. 3125

[25] Arndt S, Landthaler M, Zimmermann J L, Unger P, Wacker E, Shimizu T, Li Y-F, Morfill G E, Bosserhoff A-K and Karrer S 2015 PLoS One 10 e0120041

[26] Stoffels E, Flikweert A J, Stoffels W W and Kroesen G M W 2002 Plasma Sources Sci. Technol. 11383 
[27] Stoffels E, Kieft I E and Sladek R E J 2003 J. Phys. D: Appl. Phys. 362908

[28] Kieft I E, van der Laan E P and Stoffels E 2004 New J. Phys. 6149

[29] Goree J, Liu B and Drake D 2006 J. Phys. D: Appl. Phys. 393479

[30] Miletić M, Mojsilović S, Dordević O I, Maletić D, Puač N, Lazović S, Malović G, Milenković P, Petrović Z Lj and Bugarski D 2013 J. Phys. D: Appl. Phys. 46345401

[31] Kieft I E, Kurdi M and Stoffels E 2006 IEEE Trans. Plasma Sci. 341331

[32] Puač N, Petrović Z Lj, Malović G, Dordević A, Živković S, Giba Z and Grubišić D 2006 J. Phys. D: Appl. Phys. 393514

[33] Goree J, Liu B, Drake D and Stoffels E 2006 IEEE Trans. Plasma Sci. 341317

[34] Stoffels E, Roks A J M and Deelman L E 2008 Plasma Process. Polym. 5599
[35] Horwitz C M 1983 J. Vac. Sci. Technol. A: Vac. Surf. Films 11795

[36] Pearse R W and Gaydon A G 1965 The Identification of Molecular Spectra (London: Chapman and Hall)

[37] Malović G, Puač N, Lazović S and Petrović Z Lj 2010 Plasma Sources Sci. Technol. 19034014

[38] Polyanka H et al 2011 J. Invest. Dermatol. 131 S70

[39] Fazekas B et al 2014 J. Photochem. Photobiol. B 140215

[40] Matsuura K, Kuratani T, Gondo T, Kamimura A and Inui M 2007 Eur. J. Pharmacol. 56383

[41] Sakiyama Y and Graves D B 2009 Plasma Sources Sci. Technol. 18025022

[42] Chang D C 1989 Biophys. J. 56641

[43] Teissié J and Rols M P 1993 Biophys. J. 65409

[44] Teissié J, Eynard N, Gabriel B and Rols M P 1999 Adv. Drug Deliv. Rev. 353

[45] Binho V N and Goldman R J 2000 Biochim. Biophys. Acta 1474147 